\title{
AVALIAÇÃO DO MÉTODO EDAFO-FITODEPURAÇÃO PARA TRATAMENTO PRELIMINAR DE AGUAS
}

\author{
EMEIDA SALATI MAMFRIMATD \\ ENGENHEIRA CIVIL
}

Drientiador: Prof. Dr NILSOM A. YLLA MOYA

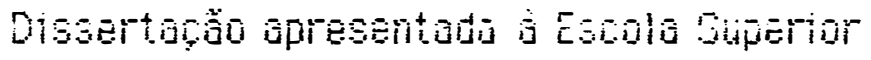
ue Aqricultura "Lit de Dueiro", ta

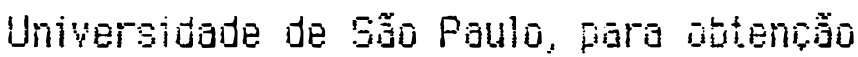
do titulo de mestre em agronomia, area de Concentração: Centro de Energia Nuclear na Ag̣ncultura.

PIRACICABA

Estado de São Paulo - Brasil

FEVEREIRD/ 1909. 
Manfrinato, Eneida Salati

M276a Avaliação do método edafo-fitodepuração para tratamento preliminar de águas. Piracicaba, 1989.

$98 \mathrm{p}$.

Diss.(Mestre) - ESALQ

Bibliografia.

1. Água fluvial - Tratamento - Método 2. Agua pe - Atividade depuradora 3. Arroz - Solo 4. Rio Piracicaba - Poluição - Controle I. Escola Superior de Agricultura Luiz de Queiroz, Piracicaba

CDD 628.39 


\title{
AVALIAÇÃO DO MÉTODO EDAFO-FITODEPURAÇÃO PARA TRATAMENTO PRELIMINAR DE AGUAS
}

\author{
ENEIDA SALATI MANFRINATO
}

aprovada em 04105:1989

Comissäo Julgacora:

Frof. Or. Reynaldo Luiz VIctoria

ESALQ/USP

Prof. Or. Nilson A Villa Nova

ESALQ/USP

Frof. Or. Marcos Vinicius Folegatt

ESALQ/USP

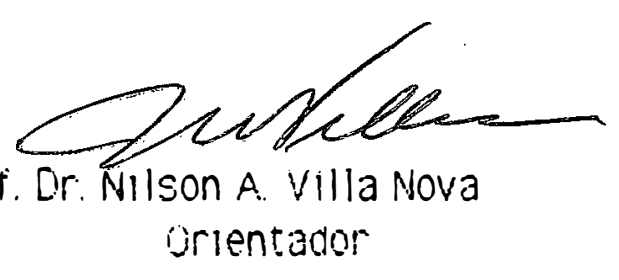


Aa meu camponheira, Morcas Aas meus filhas Toles $e$ Luizo Aa meu filha que irá noscer, que cam autras criancas. merecem um munda mois limpa:

DEDICO

is meu pai,

Ele. gue cam corinha e smar Nunce se consou de Ensinar a yijer e amor As caisos do Terro e da Cëu. Sempre serei grots

MINHA HOMENAGEM ESPEC/AL 


\section{AGRADECIMENTOS}

- ho Centro de Energia Nuclear na Agricultura (CENA/USP), pelas condições oferecidas;

- Ao meu Bu-orientador Prof. Dr. Ricardo B. Sgrillo, pelo apono dado desde a inicio dos meus estudos;

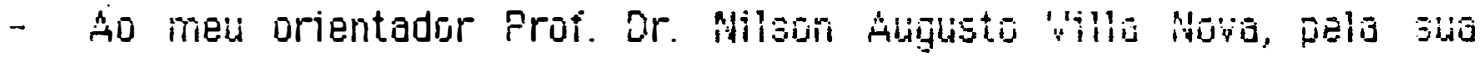

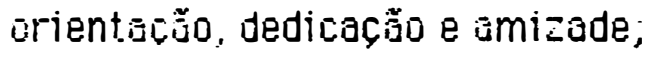

- A Prefeitura Municipal de Piracicaba, Jurante ja gestǘ do Sr. Prefeito Adilson Benedito Maluf, cujo apoio foi iundamentia jura o indomento desta pesquisa;

- Ao Serviço Municipal de Agua e Esgoto de Piracicaba (GeMAE), em especial ao Eng. Hugo Marcos Piffer Leme, pelas análises realizadas;

- `A seção de Isótopos Estáveis e Hidrologia/CENA, pelo apoio logístico e infra-estrutura para o desenvolvimento do meu trabalho;

- 'A seção de Ecologia/CENA, em especial aos técnicos Rosângela A. de Gaspari Rocha e Odair Bastos de Almeida, pela colaboração nas coletas Jas amostras e análises realizadas;

- ‘ seção de Radioquímica/CENA, em especial ao Prot. Dr. Francisoo d. Krug̣, pelas análises realizadas;

- Aos amigos Miguel Luiz Baldessin, e Adriana C. Biagioni Lopes, pelo jpoio 
no manuseio dos computadores;

- 'As bibliotecárias Silvia Maria Zinsly e Liamar Conizete Antoneli, pelo apoio na revisẫo da citaçẵo de literatura;

- Aos colegas Luiz Antonio Martinelli, Ana Elisa de Yives Cameiro e Robinson Luis Tuon, pela amizade e companheiriemo;

- A000o00 todas as pessoas aqui não citadas, mos que contribuiam para a reglizoç̃o deste trabalho 


\section{INDICE}

Página

LISTA DAS FIGURAS

LISTA DAS TABELAS ........................................................................................ vi

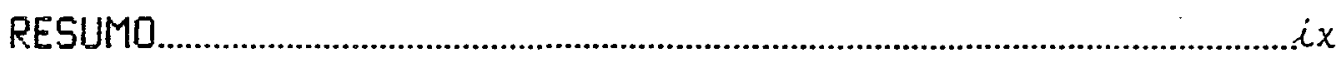

SUMMARY

1.INTRODUCAO

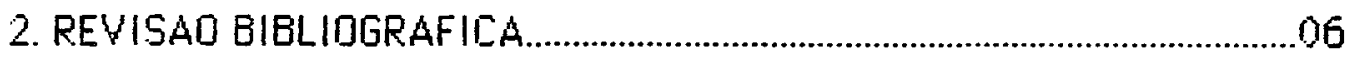

2.1. 0 AGUAPE

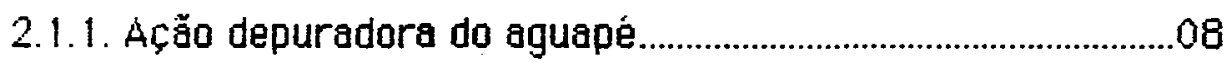

2.1.2. Alguns projetos de dispoluição hídrica que utilizam o aguapé

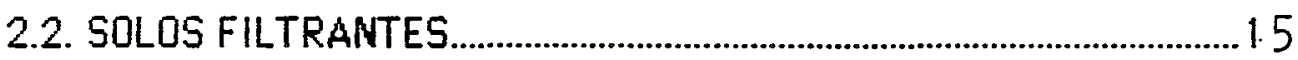

3. MATERIAL E METDOD

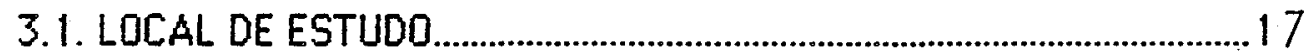

3.2. DESCRIÇAO DO SISTEMA DE DESPOLUICAAO....................................... 17

3.2.1. Sistema 1: Canais cultivados com plantas aquáticas e solos filtrantes...................................................................... 18

3.2.2. Sistema 11: Solos filtrantes consecutivos..........................21

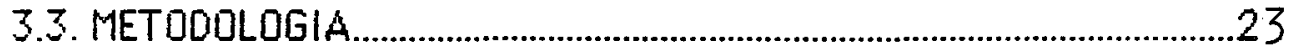

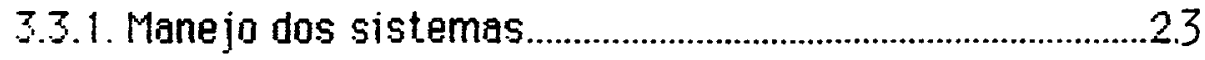


3.3.1.1.Sistema I : canal de aguape-solosfiltrantes...23

3.3.1.2. Sistema II: Solos filtrantes cansecutivos........23

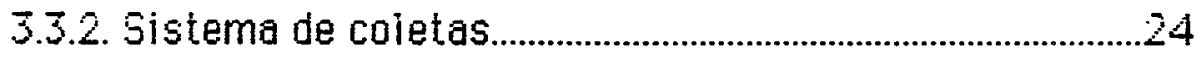

3.3.3. Parâmetros anaiisados..........................................................26

3.3.4. Colibracão das Calhas "PARSHALL" de " " e 9"...............27

4. RESULTADOS

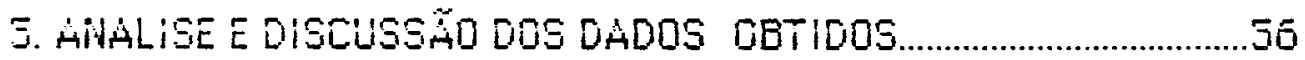

5.1. EFICIENCIA DOS PROCESSOS ESTUUADUS ...........................56

5.1.1 Sistema I: Canal com aguapé e solos filtrantes........... 56

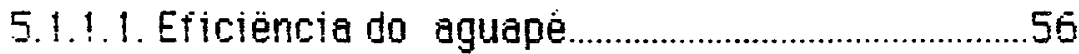

5.1.1.2. Eficiencia do solo filtrante.....................................58

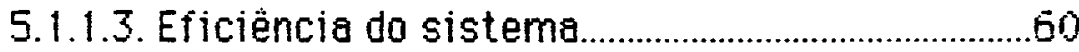

5.1.2. Sistema II: Solos filtrantes consecutivos........................62

5.2. MUDAPIÇA DA CLASSIFICAÇAO DA AGUA PARA

ABASTECIMENTO

5.2.1. Sistema I: Canal de aguapé e solo filtrante..................65

5.2.1.1. Agua de entrada do sistema (água da

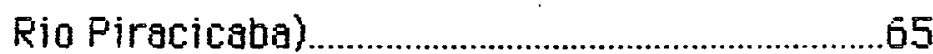

5.2.1.2. Canal com aguapé ..................................................

52.1.3. Saida do sistema.............................................................

5.2.2. Sistema II: Solos filtrantes cansecutivos …..................67

5.2.2.1. Agua de entrada do sistema (égue do

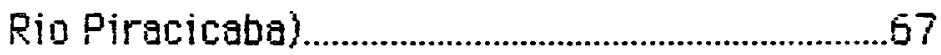


Página

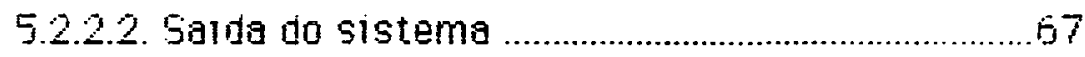

6. CONCLUSOัES

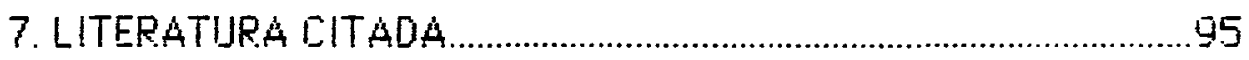


1 Efluentes Domesticos e Industriais- Evoluçän das vazổes totials 04

2 Efluentes Dométicose Industriais - Evoluçoo nas cargas polunaras. 05

3 Sistema de desnoinnogo nudrica luthlzanno cana! ne olantas anuatuas e solos filtrantes

4 Detaine no sistema de arenagem dos solos initrantes...........

5 Sistema de despoluição hidrica, utulizando solos filtrantes consecutivos 22

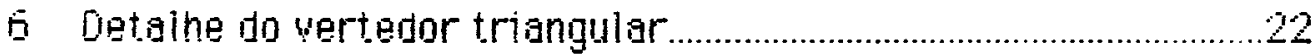

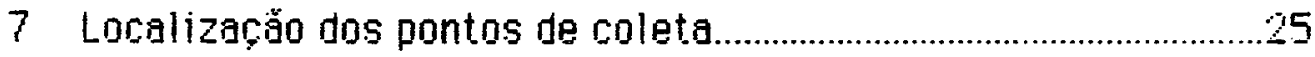

9 Curva teórica e curva observada na calibraçăo da calha "PARSHALL", DE G" 29

9 Curva teorica e curva observada na calibração da calna "PARSHALL" de g" 
viii

\section{LISTA DAS TABELAS}

TÄBELA

Pogna

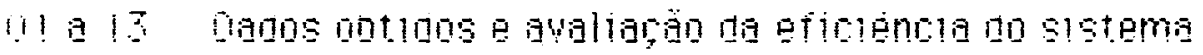
aguape-solo filtrante.

14 a 24 bagos obtidos e avaliação da eficiencia do sistema solos filtrantes consecutivos 45

25 a 37 Qesvio relativo do sistema aguapé-solo filtrante, em relaçẵo aos padrỗes utilizados pela CETESB 69

38 a 48 Desulo relativo do sistema solos filtrantes consecutivos, em relaçằ ans padrões utilizados pela CETESG 82 


\title{
AVALIAÇOOO DO METODO EDAFD-FITODEPURAC PAD PARA TRATAMENTO PRELIMINAR DE AGUAS
}

\author{
AUTORA EMEICA SALAT: MANFRIMATO

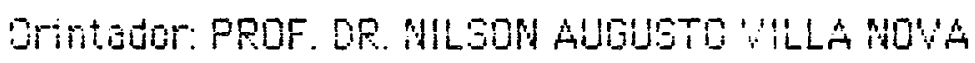

\section{RESUMO}

Foram analisados os parametros mais relevarites ( Demandi Bioqumica de Dxigènio, Coliformes Fecais e Totạis, Turbides, Cor, e

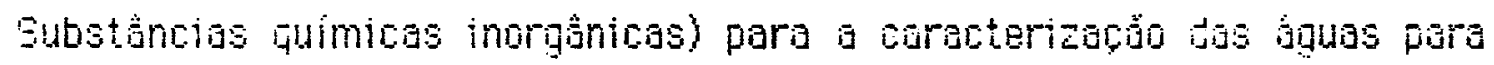
sbastecimento publico no Rio Piracicaba, durante o periodo de junho/ 1968 a

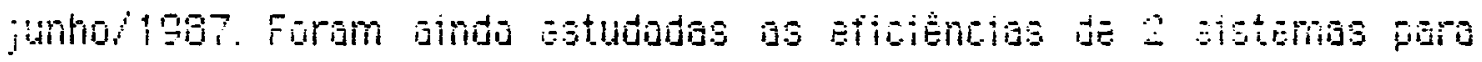
descontimingono de tquas.

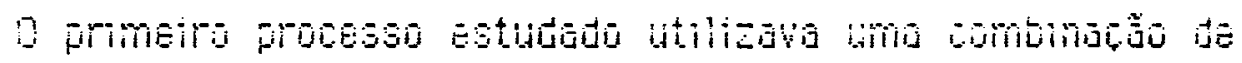
plantas aquatices ilutuantes (pricipalmente a Eichomis arasipes) e sohos

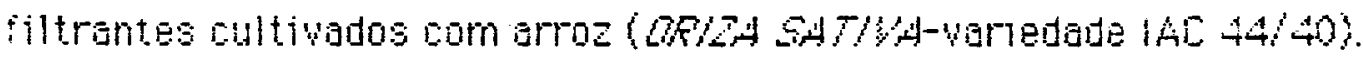




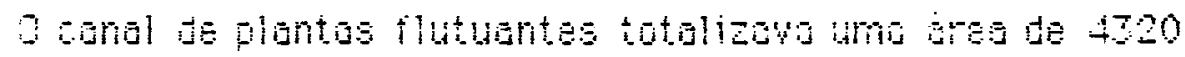

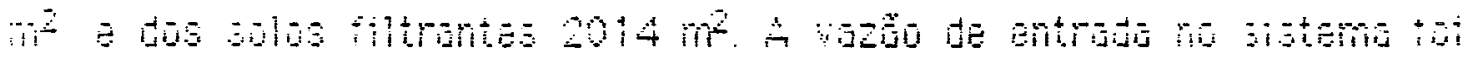

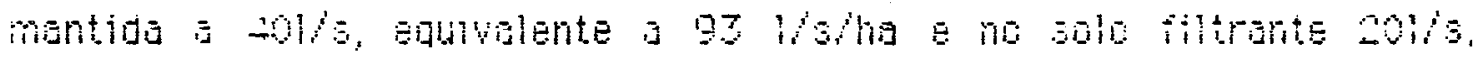
aquivilente o 99 lisho.

a segundo processo estudado toi uma sequencio de dots solos

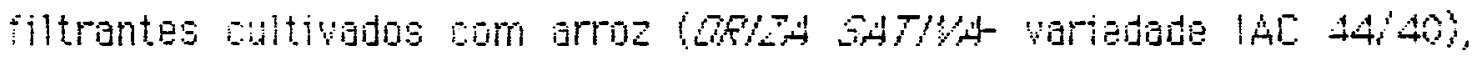

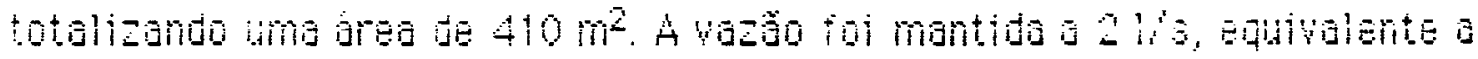
49 1/ iha.

Ts dados ottidos indicaram que a utilizaço deses sistemes permite uma descontaminaço da agua, especialmente no que diz respeito i

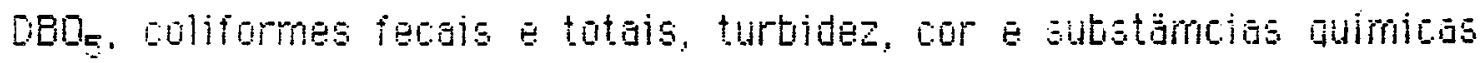
Inorgantcas. 


\title{
EYALUATION OF THE METHOD EDAPHIC-PHYTODEPURATION FOR PRELIMINARY TREATMEHT OF HATERS
}

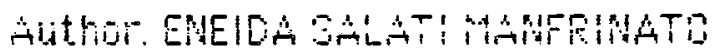 \\ AdVISER: PROF. OR NILODN AUGUSTO ULLA NOYA
}

\section{SUMMARY}

The most important parameters ( $800_{5}$, Tutal and Fecal Coliformes, turbidity, color and inorganic compounds) for charactenzation of drinking water were analysed during the pernod of zune/1986 to June 1967 . The efficlency of two systems ior water decrontammation wäro studed durng the pernod.

The firet syetem stumed was a rombinaton or ringng anuatro plants and soli beds cultivated with roce The area of the sysern with aquatic plants was $4,320 \mathrm{~m}^{2}$ and the area of the soll beds was $2114 \mathrm{~m}^{2}$. 
The flow in the system with aquatic plants was constant during the whole experiment time and equil to $401 / 3$, corresoming to is fow equwalent to $93 \mathrm{~V} / \mathrm{s}$ ha. In the soil bed the flow was $20 \mathrm{l} / \mathrm{s}$, aquivient to 99 lisha.

The second system studied was a sequence of tho soll beds cultivated with rice, with a total area of $410 \mathrm{~m}^{2}$. The thit was also constant and equal to $2 \mathrm{l} / \mathrm{s}$, equivient to $49 \mathrm{~V} / \mathrm{ha}$.

The data ottaned durng one year of the enperment showed that both systems can reduce significantly the most important parameters of the water, such as total and fecal coliformes, 800 , turtidity. color anu inorganic compounds. 


\section{INTRODUÇĀO}

0 abastecimento de água das cidades do Brasil em arande parte e feito com aguas superficiais, provenientes de rios ou lagos artificiais abastecidos por corregos ou rios.

Muitas das estaçǒes de tratamento de jguas existentes, foram profetadas e construidas há algumas dezenas de anos, quarido as agüus dos rlos e represas estavam dentro dos limites de qualidade exigidos pelas leis para abastecimento.

Nestas últimas décadas, quer pelo crescimento dos parques industriais, quer pelo aumento da população nos centros urbanos, os córregos, vários rios e represas apresentam-se altamente contaminados e estăo na maior parte do ano com suas aguas fora dos limites para potabilidade.

Em particular, a bacia do Piracicaba, a qual abrange 44 Municipios sendo 40 do Estado de São Paulo e 4 do Estado de Mirias Gerais, numa area de aproximadamente $12.000 \mathrm{~km}^{2}$, è uma das mais poluidas do pais. As cidades em sua maioria foram crescendo sem a preocupaçăo úásica de implantar sistemas para tratamento de seus esgotos domésticos, de tal forma que de um total de 2.500 .000 (dois milhões e quinhentos mil) de habitantes, apenas 5\% das cargas orgânicas de origem urbana são removidas por estações de tratamento, e a parte restante 76 toneladas de 
DBO/dia ainda é lançada diretamente aos rios. Quanto 'a carga orgânica de origem industrial, observa-se que o potencial poluidor é da ordêiii de 1.440 toneladas de DBO/dia, cerca de 18 vêzes a carga uroana, mas aproximadamente $95 \%$ desse valor é removido remanescendo 77 toneladas de $\mathrm{DBO}$ dia. Apesar do elevado indice de remoçăo nesse caso, verifica-se que os 5\% remanescentes ainda são da mesma magnitude das cargas urbanas lançadas. As unidades de tratamento existentes, na sua maloria estao instaladas em pequenos municiplos e as grandes cidades como Piracicaba, Rio Claro, Limeira, Americana, Santa Bárbara D'oeste, etc., năo possuem um sistema adequado para tratamento de seus ef luentes líquidos.

Estudos realizados pelo DAEE (Departamento de Agua e Energia Elétrica) - 1984, comprovam a necessidade de se implantar urgentemente sistemas de tratamento de águas de esgotos urbanos e industriais ao longo da bacia do Piracicaba. A situação atual e projeçôes futuras das vazões e cargas poluidoras dos efluentes domésticos e industriais para o caso especifico da Bacia do Piracicaba, encontram-se nas figuras i e 2.

Duas alternativas podem ser utilizadas para resolver os problemas:

- alterar as caracteristicas das estações de tratamento.

- buscar água em córregos ou rio menos poluidos.

Estas duas alternativas săo caras e nem sempre podem ser exequiveis.

Buscando solução para o problema, foram desenvolvidos diversos trabalho para purificar as aguas dos rios. Uma estação piloto de tratamento utflizando plantas aquáticas e solos filtrantes, fol implantada num trabalho em conjunto da Prefeitura Municipal de Piracicaba e do Centro 
de Energia Nuclear na Agricultura (CENA/USP). Os detalhes básicos dos processos despoluidores desta estaçăo estão discutidos por SALATI \& RODRIGUES (1982) e Dor SALATI (1987).

A finalidade deste trabalno fol estudar a eficlêncla de tratamento do sistema plloto (Edafo-Fitodepuração): solo filtrante mais plantas aquaticas, preconizado por SALATI \& RODRIGUES (1982) e SALATI (1987), na recuperação da água do Rio Piracicaba. 
- TOTAL

... PIRACICABa

-.- JAgUaRí

-.- Corumbatai

ATIBAía

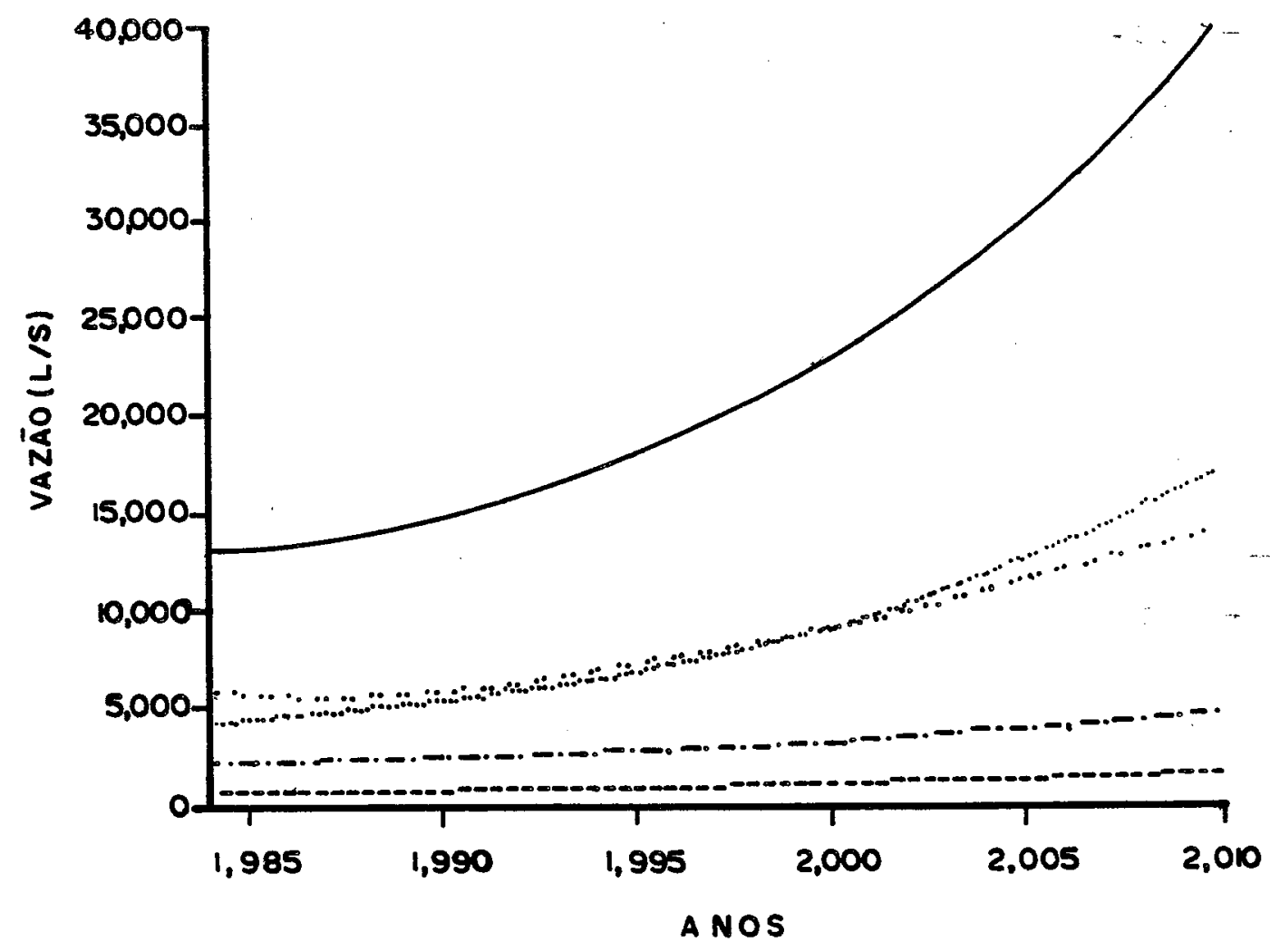

Figura 1: Efluentes Domésticos e IndustriaisEvolução das vazões totais. 
- TOTAL
$\ldots$-. PIRACICABA
-- JAGUARI
-- CORUMBATAi
-..- ATIBÁlA

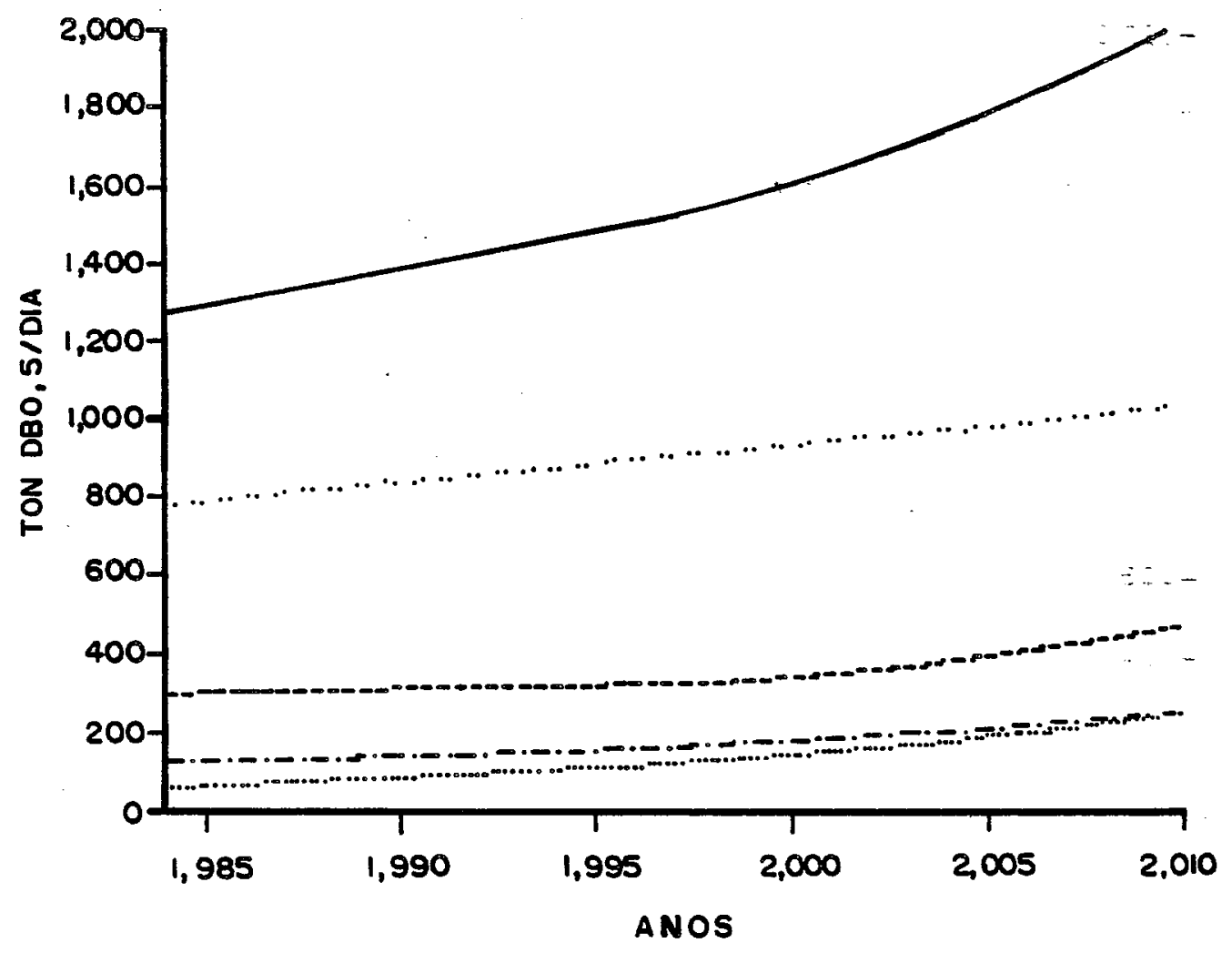

Figura 2: Efluentes domésticos e industriais- Evolução das cargas poluidoras. 


\section{REVISÃO BIBLIOGRAFICA}

o poder depurador de diversas plantas aquaticas flutuantes. como o aguapé, salvinia, pistia e outras, foi estudado em diferentes regiỏes e com diferentes efluentes. 0 aguape, sempre apresentou melhores resultados, sendo mais resistente ao nosso clima e de rapida adaptaçao quando em contato com os mais diversos tipos de efluentes. Assim, a planta aquatica utilizada para realizar a depuração da água neste trabalho, foi 0 aguapé .

\subsection{0 aguapé}

o aguapé, Eichornia crassipes (Mart.) Solms, è uma monocotiledônea, pertencente à familia das Pontedericeâe. E uma planta suculenta, constituida em cerca de $95 \%$ da agua, corisistindo de raizes, rizomas, estolões, peciolos, folhas e infilorescéncia. Varia em altura desde alquns centimetros até cerca de um metro. As raizes são fibrosas, sem ramificaçoes, com uma coifa conspicua e podem atingir ate quase um metro de comprimento, suspensas livremente na água ou fixas ao fundo em aguas razas, podendo ate enraizar em locals sêcos, neste caso seño a plantá 
reduzida em tamanho. Em plantas pequerias ou isoladas, a base do peciolo se dilata e as celulas do parânquima de enchimento proudueeni um ilutuador. Em plantas maiores, que geralmente ocorrem em agregados densos, a base dô peciolo rão tem bulbo tão distinto. Todas as partes da planta, com exceçăo da semente, tem densidade inferior a 1 , e, consequentemente, a planta $\hat{\epsilon}$ flutuante.

O talo vegetativo, ou rizoma, consiste de um eixo com curtos entrenos, e que produz, nos numerosos nós, todas as ralzes, folhas, ramos, $\hat{\epsilon}$ inf lorescencia da planta.

A reprodução ocorre primáriamente por processos vegetativos: riovas plantas são produzidas por estolöes e o crescimento lateral se taz a partir do rizoma. A medida que cada planta produz outras, forma-se uma enorme e espessa camada de plantas interligadas. O tempo medio para duplicacão da planta e de cerca de duas semanas, de modo que, suto condicòes ideals, dez plantas podem cobrir um acre em dez meses. 0 aquape tem aronde capacidade de regeneraçăo; se quebrado ou tritirado, o rizoma pode regenerar uma nova planta dependendo esta regeneraço do tamantio do fragmento (PENFOUND \& EARLE, 1948).

0 aguapé produz uma espiga com 2 a 38 flores. De acordo com Penfound \& Earle (1948) parece que ocorre autopolinizaçao devido ao dobramento e esperilamento, quando a flor murcha. Nesta ocasıão, a espiga afunda na água, para dispersar suas sementes. Embora a planta filoresça quase 0 ano todo, não há liberação das sementes até 0 inicio da estação fria. Quando a cánsula do fruto maduro se rompe, as sementes são espalhadas pela camada de plantas circundantes ou na agua, onde afundam. As sementes permacem viáveis por um minimo de sete anos sendo 
pré-requisitos para germinação a escarificação por meio fisico-químicos ou biológicos e a sua exposição ao ar [PERFOUND \& EARLE, (1948)].

- aguapé encotra-se espalhado por vários contimentes, principalmente em regiões tropicais e sub tropicais, podendo tambem ser encontrado em regiões temperadas. E bastante conhecido pela grande capacidade de sobrevivência em meios hidricos poluidos, pela excepciorial produçà de biomassa e tambem pela açäo depuraũora dos corpos d’água.

\section{1. I. Af̧ão depuiradora do aguapé}

Estudos cientificos iriclados pela NASA e posteriormente for outras entidades de pesquisa demostraram que, entre outras plantas aquáticas vasculares, o aguape (Eichornia crassioes), tem uma fantástica e polivalente utilidade de se transformar de praga em elemento de alto valor na defesa do meio ambiente, seja purificando os residuos poluentes, quer como fonte supridora de proteinas ou ainda como fonte produtora de gás combustivel.

A ação depuradora do aguapé é devida à:

a) Grande velocidade de desenvolvimento imultiolicacoes e crescimento) em aquas poluidas. BATANOUNY $\in$ EL $-F I K E$, (1975), trabalhando no Egito verificaram que uma planta com area basal de $450 \mathrm{~cm}^{2}$ apos 50 dias cobria uma área de $1084 \mathrm{~m}^{2}$. Apos 200 dias estendia-se por aproximadamente $150.000 \mathrm{~m}^{2}$. com cerca de 3.418 .000 plantas. Em condiçoes nutricionais adequadas (àqua poluida com esgoto domestico) pode produzir ate 262 tonelada/ha/ano de materia seca, SALES (1978).

b) Capacidade de absorver metais pesados: Oे aua a remove 
rapidamente metais pesados dissolvidos na agua. Numerosos desses metais constituem uma ameaca a saude humana. Dentre as mals perigosos destacam-se o caamio, o mercurio, o niquel, o chumbo e a prata.

WOL VERTON (1975a) investigou o papel do aguape há remocão de cadmio e niquel em sistemas estáticos com agua poluidas. Esta plantá demonstrou a capacidade de remover metais pesados de sistemas aquáticos por absorção pela raiz e concentração até $0,67 \mathrm{mg}$ Cd e 0,50 mg Ni por grama de materia seca quando exposta por um periodo de 24 horas a águas poluidas com concetraçoes desses metals variando de 0,578 a 2,00 ppm. Desta forma, um hectare de aguape tem o potencial de remover $300 \mathrm{~g}$ de cadmio ou niquel de 240.000 litros de água poluida por esses metais, num periodo de 24 horas.

BLAKE et alii (1986), compararam a incorporaçăo do cadmio em experimento em serie ou sistemas continuos, usando concentraçũes diferentes de cadmio $(0,25 ; 0,50 ; 1,00 ; 2,00 \mathrm{ppm})$, sendo que os efeitos toxicos são óbvios a concentraçăo de $1 \mathrm{ppm}$ em meio de cuitura, concluindo que as raizes acumularam a maior parte $(73-86 \%)$ do cádmio incorporado.

WOLVERTON \& MC DONALD (1975b), estudaram a remoção da prata, cobalto e estrôncio pelo aguape em sistemas estaticos com aquas poluidas, sendo que este demonstrou a capacidade de remover $0,439 \mathrm{mg} A \dot{A}$, $0,568 \mathrm{mg}$ Co e $0,544 \mathrm{mg} \mathrm{Sr}$, em forma ionizada, por grama de matéria vegetal seca num periodo de 24 hs. Portanto 1 ha de aguapé é potencialmente capaz de remover $263,3 \mathrm{~g}$ Ag, $340,8 \mathrm{~g}$ Co e $326,4 \mathrm{~g} \mathrm{sr}$ por dia.

ROQUETE PINTO et alii (1983), realizaram estudos para determinar a capacidade de absorção e concentração de prata da planta 
Eichornia crassipes, utilizando uma solução de $40 \mathrm{ppm}$ de prata onde 0 aguape permaneceu $24 \mathrm{hs}$, concluindo que a planta remove a media de $10 \mathrm{mg}$ de prata por grama de materia seca.

WOLVERTON \& MC DONALD (1975a.) demostraram que o aguape tem capacidade de remover $0,176 \mathrm{mg}$ de chumbo e $0,150 \mathrm{mg}$ de mercúrio por grama de matéria seca num periodo de 24 hs, em um sistema estatico utilizando agua poluida. Assim, um acre de aguapé e potencialmente capaz de remover $105,6 \mathrm{~g} P \mathrm{~Pb}$ e $90,0 \mathrm{~g} \mathrm{Hg}$ por dia. Esta taxa de remoçăo do metal è baseâda nâ remoção continua das plantas saturadas.

TORNISIELO et alii (1986) estudaram a absorçào de mercurio (Hg) por plantas de aguape, utilizando mercúrio marcado (203Hq), nas sequintes concentrações 25,50 e $100 \mathrm{ppb}$ de $\mathrm{Hg}+++$, en vasos de 0 litros de agua. Em cada vaso foram colocados 5 plantas de tamalnito medio, que ficaram em contato com uma solução de $\mathrm{Hg}$ por 25, 50, 100 e 200 houras. Para cada vaso de 8 litros usou-se $10 \mu \mathrm{ci}$ de $203 \mathrm{Hg}$ e após os respectivos tempos de contato, as plantas foram retiradas e dissecadas, separando-se folhas, bulbo, pseudo-caule e raizes para análise da concentração de $\mathrm{Hg} \mathrm{em}$ cintiliçăo sólida. Verificou-se que $93 \%$ do $\mathrm{Hg}$ absorvido pelas plantas ficou retido nas raizes e que o tempo de 50 hs de contacto apresentou malor taxa de absorçăo do metal. os dados obtidos indicam que o aquapé pode ser usado para retirada de $\mathrm{Hg}$ da água mesmo em baixas concentraçðes, com capacidade maxima de retirada de $154,5 \mathrm{~g}$ de $\mathrm{Hg} / \mathrm{ha} / \mathrm{dia}$.

OSTROWSKI et alii (1981), realizaram estudos sobre Fichornia crassipes, visando verificar sua capacidade de absorçäo do chumbo. Verificaram que a planta em 45 hs absorveu $40 \mathrm{ppm}$ de Pb + de uma sôluçăo de $\mathrm{Pb}++$ de 100 ppm e 25,5 ppm de uma soluçăo de 30 ppom e quie mais dê 
$10 \%$ do chumbo total retirado pela planta em 48 hs foi absorvido rias primeiras 6 his de permanëncia na soluçăo.

c) Grande eficiência na reducão da demanda bioquimica de oxigẻnio (DBO) das áquas poluidas. A redução da Demanda Bicquimica de oxigenio se deve principalmente a um mecanismó diolougico associado ao sistema radicular do aguapé. Esse mecanismo constitui una especie de simbiose entre a populaçăo bacteriana fixado nas raizes e ná pianita.

Dada a configuração dessas razes, extremamente ramificadas a pliosas (forma de cabeleira), as mesmas constitulem um otimo substrato para fixaçào de uma população de bacterias. As bacterias atraves de seu metabolismo, decompōem os solidos orgânicos suspensos e dissolvidos na água e os produtos dessa decomposiçăo săo parcialmente assimilados, como nutriente pela planta. Esse processo reduz tambem os maus odores da agua poluida. Alem disso, por um mecanismo físico essa configuração propicia uma filtragem mecànica dos sólidos decantávels, diminuindo a turbidez.

WOLVEROTN (1979), conseguiu obter atraves de resultados encontrados em experiencia de laboratorio, taxas quanto ao poder de depuraçăo do aguape em termos de reduçăo de D.B.O., utilizando áqua de esgoto bruto. 0 valor mèdio encontrado foi de $4,0 \mathrm{mg}$ de D.E.O/grama de aguape, iresco, para um tempo de residencia de 7 dias.

BRUNETTI et alii (1981), em experimento realizado com aquas residuarias de uma pequena cidade da Italia, utilizando uma lagoa de 300 m了 cultivada com aguapé, obtiveram uma reduçăo de $70 \%$ da $0 . E .0$ após o efluente passar por essa lagoa.

Estudo realizados pela CESP (1983), sobre a possibilidade do uso do aguape para despoluição do Rio Pinneiros na cidade de São Paulo, 
indicaram que o poder de reduçăo para D.B.O e da ordem de $170 \mathrm{~kg}$ de D.B.o/ha.dia.

d) Dutros aspectos de depuracäo hidrica pelo aquape A capacidade de remoção de nutrientes é resultado do crescimento rápido da planta, de reações físico-quimicas corganismos que crescem no ecossistema). Segundo WOLVERTON (1975b.), o aguapé de 0,40 ha (1 acre) tem o potencial de remover a produção diárla de cerca de 325 individuos. Dados semelhantes foram obtidos por ROGERS (1971), que calculou a remoção dos residuos anuais de nitrogennio e fósforo de cerca de 550 pessoas por um hectare de aguapé no periodo de 6 meses.

A remoçăo de Fenois de aguas poluidas, foi estudada entre outros por WOL VERTON (1975b.), em sistemas estaticos, verificando que 2,75 g de peso seco da planta, demostraram capaciuade de absurver $100 \mathrm{mg}$ de fenol em 72 horas; desta forma, um hectare de aguape potenicialmentê capaz de remover $160 \mathrm{~kg}$ de fenol em 72 horas, de aquas poluidas por esse produto.

MOUSSE et alif (1979) efetuaram estudo sobre o tratamento biologico de aguas residuais, verificando que o aguape pode efetuar uma reduçăo significativa de algas e coliformes (alem de nutrientes), por absorção em suas raizes, tornando os ef luentes limpidos e adequados para serem lançados sem comprometimento do corpo receptor.

SAITO et alii (1982), demostrou que a taxa de coliformes é também diminuida quando a água passa por tanques de aguapé, sendo a redução da ordem de $77 \%$. 


\section{1.2. Alguns projetos de despolviçäo hidrica que utilizamo aguapé.}

KAWAI e GRIECO (1983), (CETESB), atraves do projeto "UTILIZACAAOO DO AGUAPE PARA TRATAMENTO DE ESGOTOS DOMESTICOS ESTABELECIMENTO DE CRITERIOS DE DIMENSIONAMENTO DE LAGOAS E ABORDAGEM CE ALGUNS PROCESSOS OPERACIONAIS", coricluiram que uma lagoa de aquape, com um hiectares pode tratar os esgotos correspondentes a aproximadamente 2.500 habitantes.

SANTOS e LEÃO (1983), (CESP), desenvolverañ estudos nio Rió Pinheiros-SP, do uso do aguape quanto ao caracter cientifico e economico, concluindo que "o tratamento de esgotos por métodos aquaticos que utilizam plantas, pode ser alternativa interessante, principalmente do ponto de vista do custo de implantação para pequenas vilas e cidades.

SALATI e RODRIGUES (1982), desenvolveram sistemas de descontaminação de águas poluidas, uttilizando aguape e solos filtrantes plantados com arroz (Oriza sativa). O processo tem sido utilizado para tratamento secundário e terciário (as vezes primário) de residuos urbanos e industriais e como pre-tratamento de rios poluidos e esgotos para alimentação de estaçōes convencionais de tratamento de agua. No primeiro trabalho [SALATI e RODRIGUES (1982)], como primeiro passo, utilizaram-se de canais com aguape e subsequentemente solos filtrantes plantados com arroz. Neste processo há uma redução de $90 \%$ de D.B.O, quando a D.B.O do efluente varia de $150-200 \mathrm{mg} / 1$.

Em outros sistemas, (SALATI, 1987), a àgua poluida é filtrada uma vez, duas vezes, ou tres vezes pelos solos filtrantes plantados ou năo 
com arroz. Apos este tratamento o efluente passa por um canal de aguape para o tratamento final. Este sistema tem sido testado especialmente com aguas de lavagens de cana em Usina de Açucar e Alcool, como tratamento final em fábricas de celulose e papel e com industrias de laminados.

Alem desses projetos, outros foram apresentados no simposio "Pesquisas e Aplicações de Plantas Aquaticas para Tratamento de Agua e Recuperação de Recursos", realizado em orlando, Flórida (1986), sendo que os mais importantes são: Aquatic Plants Systems for Water Treatment: Enginering Considerations [Tchobanoglous, G. (1987)]; Water Hyacinth Systems for water Treatment [HAYES, T.D. et alii, (1987)]; Application of Water Hyacinths for Treatment of Domestic waste Water, Generation of Biogas and Organic Manure [JOGLEKAR, V.R. \& SONAR, V.G. (1987)]; Aquiatic Plants for Water Treatment in Florida: Prospects and Constaints [THABARAJ, G. J. (1987)].

Atualmente a maior estaçăo de tratamento utilizando aguape encontra-se na flórida na cidade de Orlando, rum local denomirado Iron Bridge Consta de um conjunto de lagoas com 12 ha e edestinada a fazer um tratamento terciário do ef luente da estação de tratamento convensional que existe neste local. Esta estação está em funcioriamento ja há 3 anos e, tem apresentado excelentes reduções, atingindo as especificações da legislação vigente naquele Estado. $O$ aguapé è utilizado para produção de biogás e bioferitilizantes. 


\subsection{Solos filtrantes}

Pode-se observar na natureza que as aguas apos passarem por solos sofrem um processo de purificação, sendo que a ação depuradora desses solos é devida à três fatores principais:

a) acăo de filtragem mecannica a qual depende fundamentalmente da estrutura granulometrica do solo e da sua composiçào quimica.

b) acüo fisico-qumica para retençüo de anons a cations Esta açăo esta intimamente ligada com a capacidade de troca cationica dos solos.

c) acão biológica que pode ser atwa atraves de quatro mecanismos principais:

c.1) acão dos microorganismos do solo que decompõe a materia orgànica;

c.2) acão de microoraanismos do solo que ativam os processos biogeoquimicos;

c.3) acão de microorganismos do solo sobre microorganismos que existem nas aguas poluidas;

c.4) acăo das plantas que crescem nos solos e retiram nutrientes ao mesmo tempo em que o sistema radicular melhora as conidições fisico-quimicas do solo.

Para atingir a finalidade de despoluir agua, o solo utilizauo devera ter entào as seguintes caracteristicas: possuir alta permeabilidade, ter alta capacidade de troca cationica e possuir uma alta capacidade microbiologica. As duas primeiras propriedades são geralmente 
antagônicas. Quando um solo possui alta permeabilidade normalmente tem baixa capacidade de troca catiônica.

Procurou-se contornar este problema quanto as caracteristicas do solo atraves da incorporaçăo de alguris prouduto. os melhores resultados foram obtidos utilizando-se vermicuitia expandida. Obteve-se assim um solo com boa permeabilidade e alta capacidade de troca catiónica.

Recentemente alem da Edafo-fitodepuraçăo descrito por SALATI (1987), outros sistemas tem sido desenvolvidos, utilizando solos e a atividade do sistema radicular das plantas, com sistemas despoluidores (BOON, 1987).

Alguns sistemas de grande porte ja foram instalados entre os quars destaca-se a "GSX Land Treatment Facility" instalado em Iberville Papish, Louisiana, U.S.A. Trata-se de uma estaçăo de tratamento de 388 hectares e com aplicações do efluente no solo a $30 \mathrm{~cm}$ de profundidade $E$ sistemas de drenagem. 


\section{MATERIAL E MÉTODO}

\subsection{Local de estudo}

Este estudo foi desenvolvido nas Terras do Engenho Central à margem direita do Rio Piracicaba, junto a área central da cidade de Piracicaba (latitude $22^{\circ} 42^{\prime} 30^{\circ} \mathrm{s}$; longitude $47^{\circ} 38^{\circ} 00^{\circ} \mathrm{W}$; altitude $540 \mathrm{~m}$ ).

\subsection{Descriçâo dos sistemas de despoluiçāo}

Foram implantados nesse local, dois sistemas de despoluição:

a) Um sistema que consta de canais cultivados com plantas aquáticas e um canteiro de solos filtrantes, o qual fora construido pela Prefeitura Municipal de Piracicaba e pelo Centro de Energia Nuclear na Agricultura (CENA), e que já se encontra em operação experimental desde 1984.

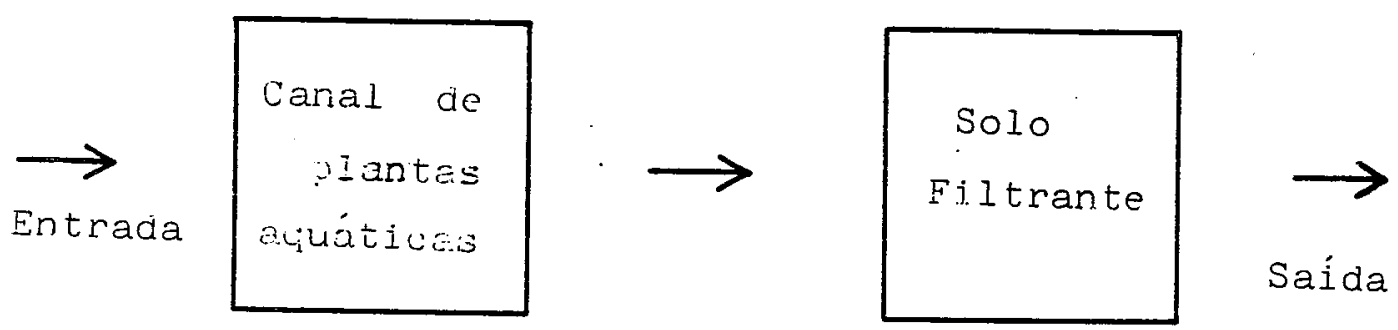


b) Um sistema formado por 2 módulos de solos filtrantes consecutivos.
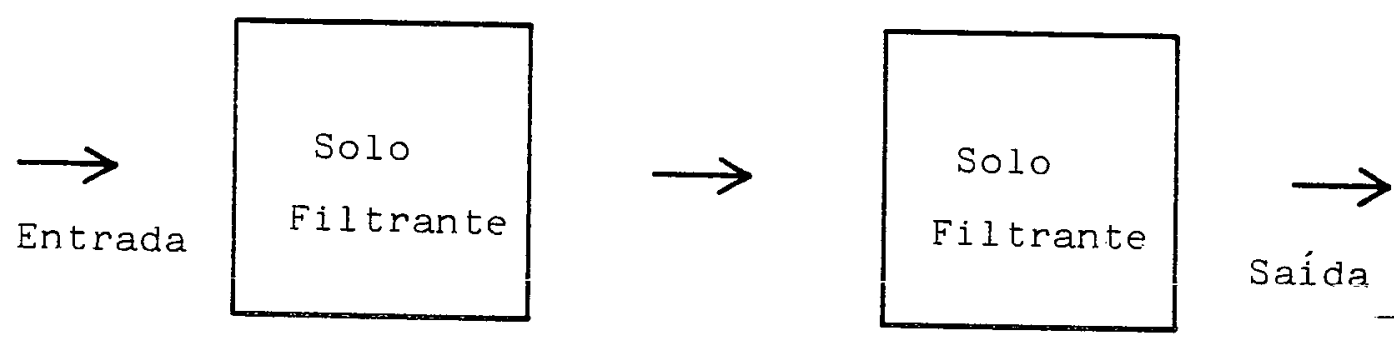

3.2. Sisteme $I$ - conais cultiyados cam plantas aquäticas e salas filtrontes.

- Canais de plantas aquáticas: os canais de plantas aquáticas foram cultivados com aguapé. Foram construidos 3 canais em paralelo, ligados em série por 2 lagoas de aeração, onde cultivou-se Elodea denso $a$ Yhisnerio gigonteo Cada canal têm as seguintes dimensōes: $0,7 \mathrm{~m}$ de profundidade, $15 \mathrm{~m}$ de largura e $96 \mathrm{~m}$ de comprimento, totalizando uma área de $4.320 \mathrm{~m}^{2}$. As lagoos de aeroção têm aproximodamente $250 \mathrm{~m}^{2}$ codo (Figura 3).

0 controle da vazăo de entrada neste sistema foi realizado através de uma comporta e a media da vazão foi feita através de uma calha "PARSHALL" de 9". Após a instalação desta calha "PARSHALL" foi feita a calibração da mesma. 
- Conteiro de solos filtrante: o canteiro de solo filtrante tem $53 \mathrm{~m}$ de comprimento e $38 \mathrm{~m}$ de largura, totalizando uma área de $2014 \mathrm{~m}^{2}$ (Figura 3). Este canteiro possui um sistema de drenagem constituido de: tubos de PVC perfurado de $100 \mathrm{~mm}$ de diamètro assentados de $2,00 \mathrm{~m} \mathrm{em}$ $2,00 \mathrm{~m}$ em valas de $40 \mathrm{~cm}$ de profundidade. Estas yalas sao preenchidas com brita 1. Sobre a superfície total existe uma camada de $15 \mathrm{~cm}$ de pedrisco e $20 \mathrm{~cm}$ de solo. (Fig. 4). Este solo foi composto de terra, a qual foi retirada de uma camada de $0-30 \mathrm{~cm}$ de Um LATOSOLO vermelho-amarelo da regiăo de Piracicaba, e vermiculita na proporçăo de $20 \%$ do yolume total da mistura.

0 controle da vazăo de entrada da água neste canteiro foi realizada através de uma caina "Parshall" de 6". Posteriormente calibrada. 


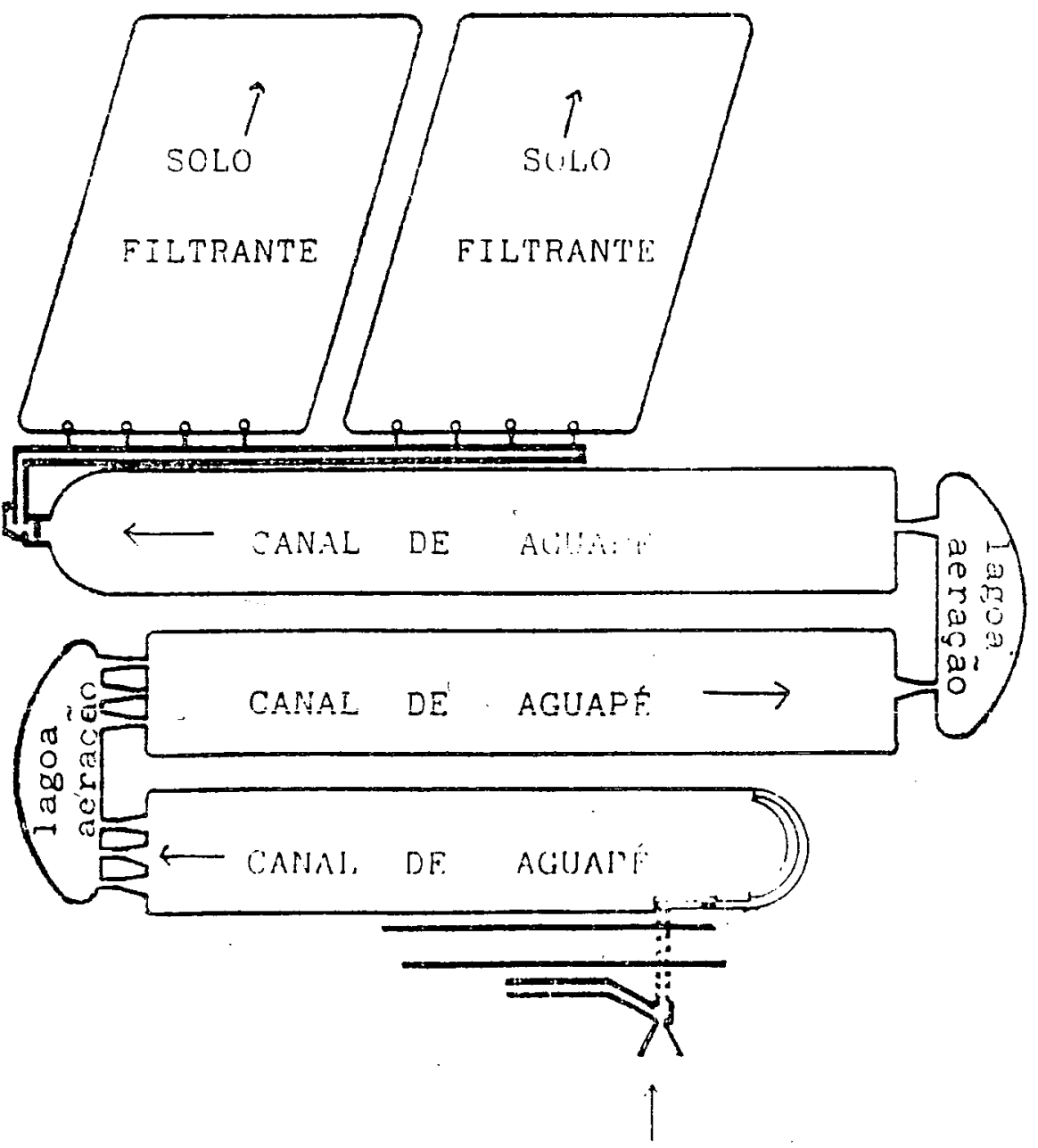

Figura 3: Sistema de despoluição hídrica, utilizando canal plantas aquáticas e solos filtrantes.

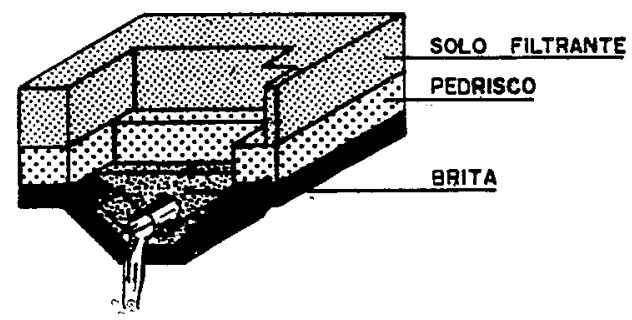

Figura 4: Detalhe do sistema de drenagem dos solos filtrantes. 
3.2.2. Sistema II -solos filtrantes consecutivos

Foram construidos 2 módulos com 2 canteiros de solos filtrantes cada um com uma área de $410 \mathrm{~m}^{2}$. (Fig. 5)

Seu sistema de drenagem e semelhante ao lá citado (Fiqura 2). $\hat{A}$ vazão de entrada foi controlada atraves da instalaçào de um vertedor triangular na entrada do sistema (Figura 6 ). 


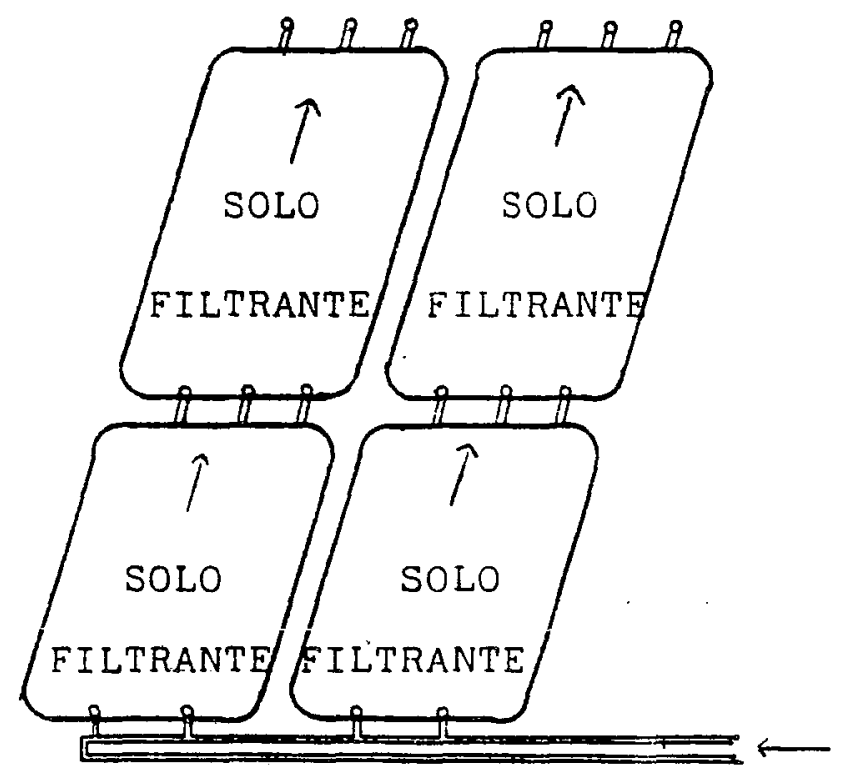

Figura 5: Sistema de despoluição hídrica utilizando solos filtrantes consecutivos.

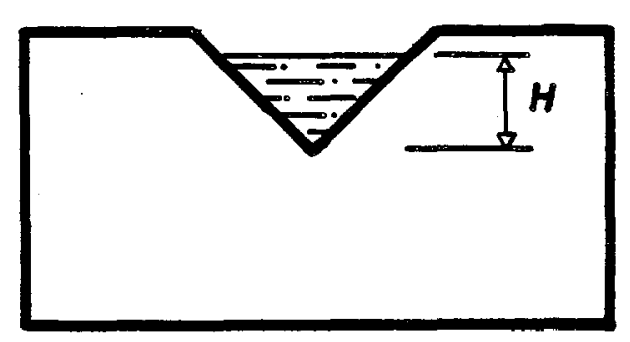

$Q=1,4 \mathrm{H}^{5 / 2}$

onde:

$Q=\operatorname{vaz} \tilde{a} o$

$H=$ altura d'água

medida no vertedor

Figura 6: Detalhe do vertedor triangular. 


\subsection{Metodologia}

\subsubsection{Manejo dos sistemas}

\section{?3.1.1 Sistema I - canal com aguape-solo ilitrante}

Durante todo experimento (Junho/86 a Junho/87), a vazào ûe entrada no canal de aguape fol mantida à $40 \mathrm{l} / \mathrm{s}$ (93 $\mathrm{l} / \mathrm{s} / \mathrm{ha}$ ), sendo que 0 tempo de residência da água no canal fol de 27.5 horas.

Em outubro/86, houve retirada de aguapé da ordem de $10 \%$ da massa total. Esse mane jo foi realizado manualmente. Parte da agua que sala do canal de aguape era desviada para o Rio Piracicaba, sendo que somente $20 \mathrm{l} / \mathrm{s}(99 \mathrm{l} / \mathrm{s} / \mathrm{ha}$ ) alimentava o canteiro de solo filtrante. Em oututuro/86, o fluxo de água no canteiro de solo filtrante fol interrompido por 21. dias para plantio do arroz. Escolneu-se a variedade IAC 44/40.

3.3.1.2. Sistema de solos filtrantes consecutivos

Os testes preliminares demostraram que seria possivel manter-se um fluxo equivalente a $50 \mathrm{l} / \mathrm{s} / \mathrm{ha}$ com uma carga hidraulica sobre o solo filtrante de $10 \mathrm{~cm}$. Em vista disso fol mantido um fluxo constante durante toda fase de desenvolvimento do arroz da ordem de 2 1/s/módulo (49 l/s/ha).

A manutenção da lâmina de água constante foi btida 
mantendo-se uma carga hidraúlica nos canos de saida, instalando-se canos na posição invertida na saida do sistema de arenagem.

\subsubsection{Sistema de coletas de água}

As coletas de água foram sistemáticas durante o periódo de 23 de junho/86 à 11 de junho/87. A metodologia utilizada foi a de uma amostragem simoles diaria, efetuada durante 5 dias consecutivos $e$ repetidas a cada is dias.

Os pontos de coleta foram 4 (Fiqura 7), serido quite em cada ponto foram coletadas 4 amostras de 1 litro de agua cada. Destes 4 litros d'áqua, 1,5 litros era enviado ao SEMAE unde foram analisados os parametros: cor, turbidez, coliformes totais e coliformes fecais, 1,5 litros era destinado a analise de D.B.O; e 1 litro a analise quimica completa. 


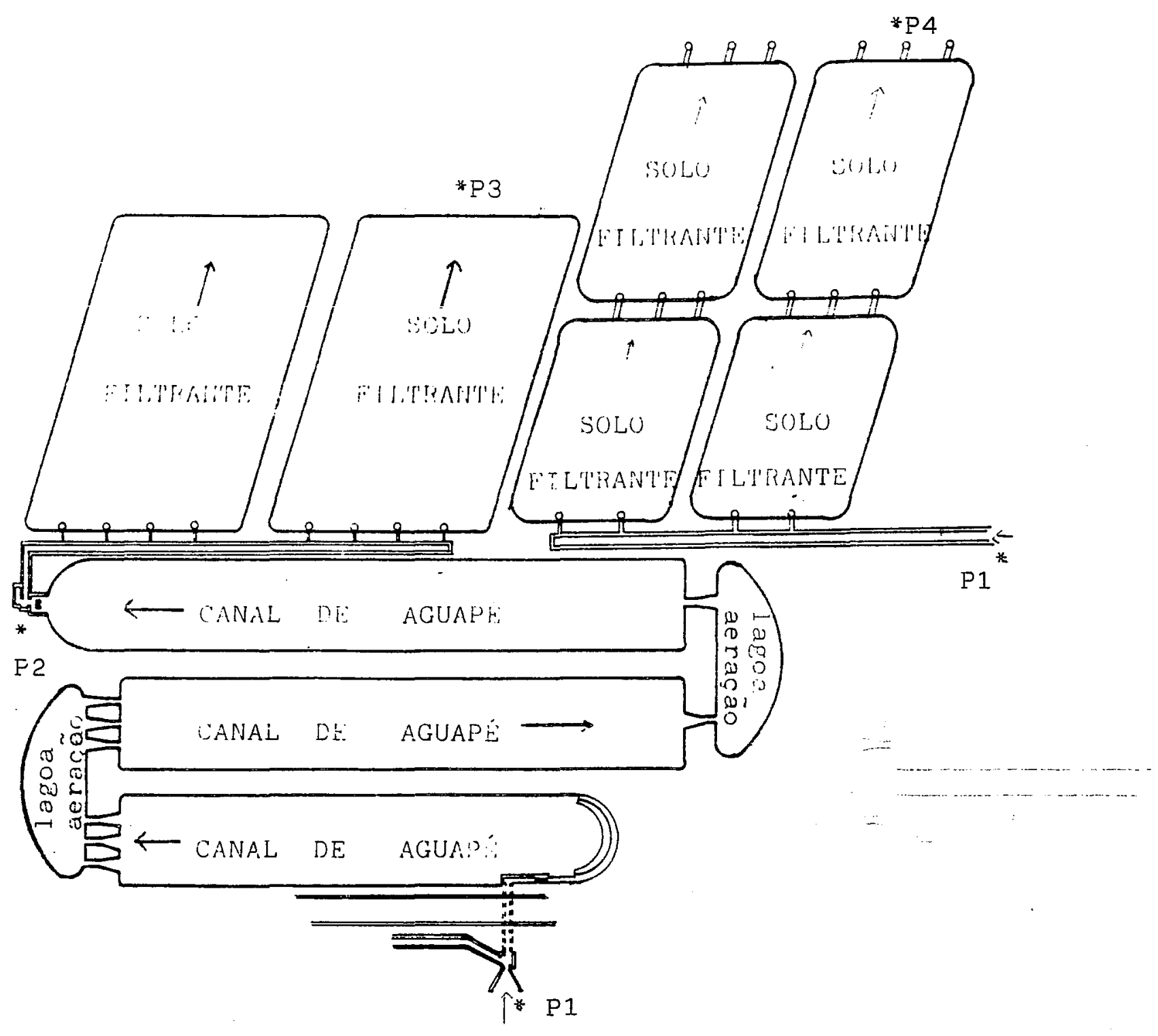

Figura 7: Localização dos pontos de coleta. 


\subsubsection{Pârametros analisados}

Demanda Bioquimica de Oxigènio (D.B.O.) : definido como a quantidade de oxigênto requerido pelas bactérias decompositoras para estabilizar a matérla orgânica disponivel na água, em condıções aeróbicas. Sua determinaçăo fol realizadapelo método da diluição e incubaçăo (20 'CC, 5 dias) ( CETESB-Normalização Técnica de Saneamento Ambiental -L5-120). Sua determinaça é feita através da diferença entre as concentrações, no inicio e no firial do periodo da incubaçăo ( para que ocorra a oxidaçăo da matéria orgânica) da amostra de cinco dias à $20{ }^{\circ} \mathrm{C}$, dado vêla seguinte expressão.

$$
\mathrm{DBO}_{5}=\frac{\text { ODI }- \text { ODF }}{V_{0} \text { amostre }} \times 100
$$

$$
\begin{aligned}
& \text { D.B.O }=(\mathrm{mg} / \mathrm{l}) \\
& \text { O.D.1. }=\text { Oxigênio Dissolvido Inicial (antes da incubação) } \\
& \text { O.D.F. = Oxigênio Dissolvido Final (apos } 5 \text { dias de incubaçăo) }
\end{aligned}
$$

Coliformes totais e fecais: A determinação do numero mais provavel de coliformes totais e fecais, foi feita pela tecnica dos tubos múltiplos (CETESB-Normalização Técnica de Saneamento Ambiental- 
Cor :0 metodo utilizado para a determinaçẩo da cor ioi o da comparaçăo visual, onde a amostra é comparada com soluçōes paúrǒes de cor (CETESB- Mormalizaçăo Técnica de Saneamento Ambiental-L5-117).

Turbidez: A determinaçẵo da turbidez na jgua foi realizada pelo método nefelamétrico (CETESB-Normalizaçăo Técnico de Saneamento Ambiental- $(5-156)$.

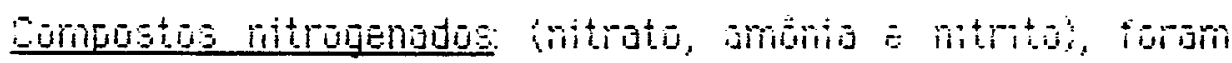
Leteminiadus por onisibe quimico em fluko continuo

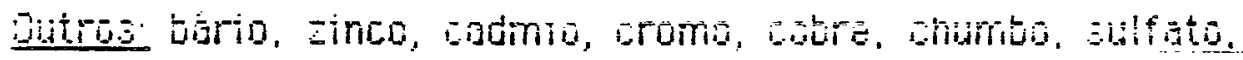

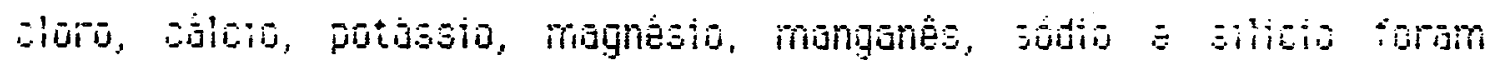
determinados em plasma de arĝ̣nió.

\subsubsection{Calibração das calhas "PARSHALL" de 6" e $9^{-}$}

O procedimento da colibraç̃o das calhas "PARSHALL" de $6 "$ " $7^{\prime \prime}$ foi o seguinte:

Mediu-se a largura da garganta da calha, unde é ieita a leitura do nivel da água, e dividiu-se esso largura em 3 secoñes. Yanou-se a altura da água, nesta garganta, de 6 a $20 \mathrm{~cm}$, e para cada altura da agho colculou-se a velucidade nas 3 seccões. A velocidade foi medida atraves de im molinete tipo "GURLEY" a da seguinte expressöo:

$\because=0.2 N+0.604$, onde $N$ é igual ao numero de rotacoses por mauto dado pelo molinete.

Através do produto da medida da seçño pelia velocidade larea da seccŏo $x$

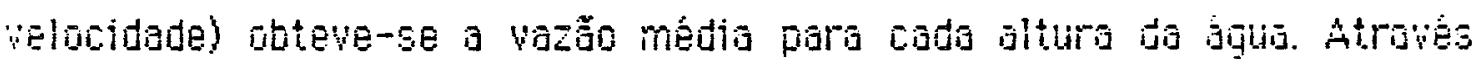
destes pares de dados (altura 8 vazốo), foi obtido uma curvo. 


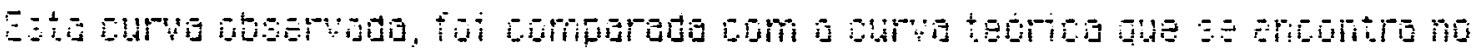

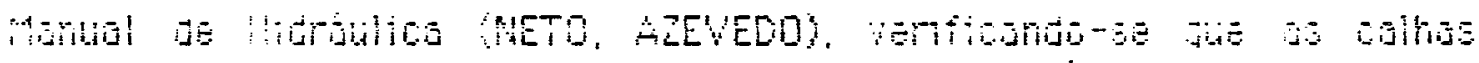

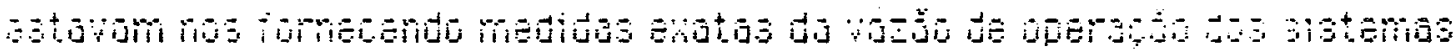

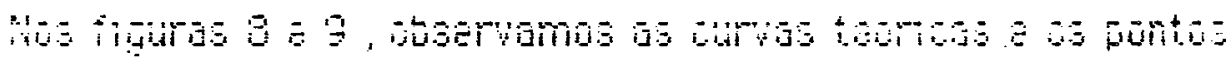

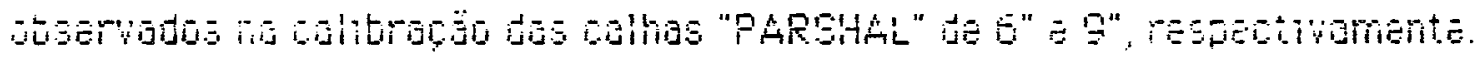




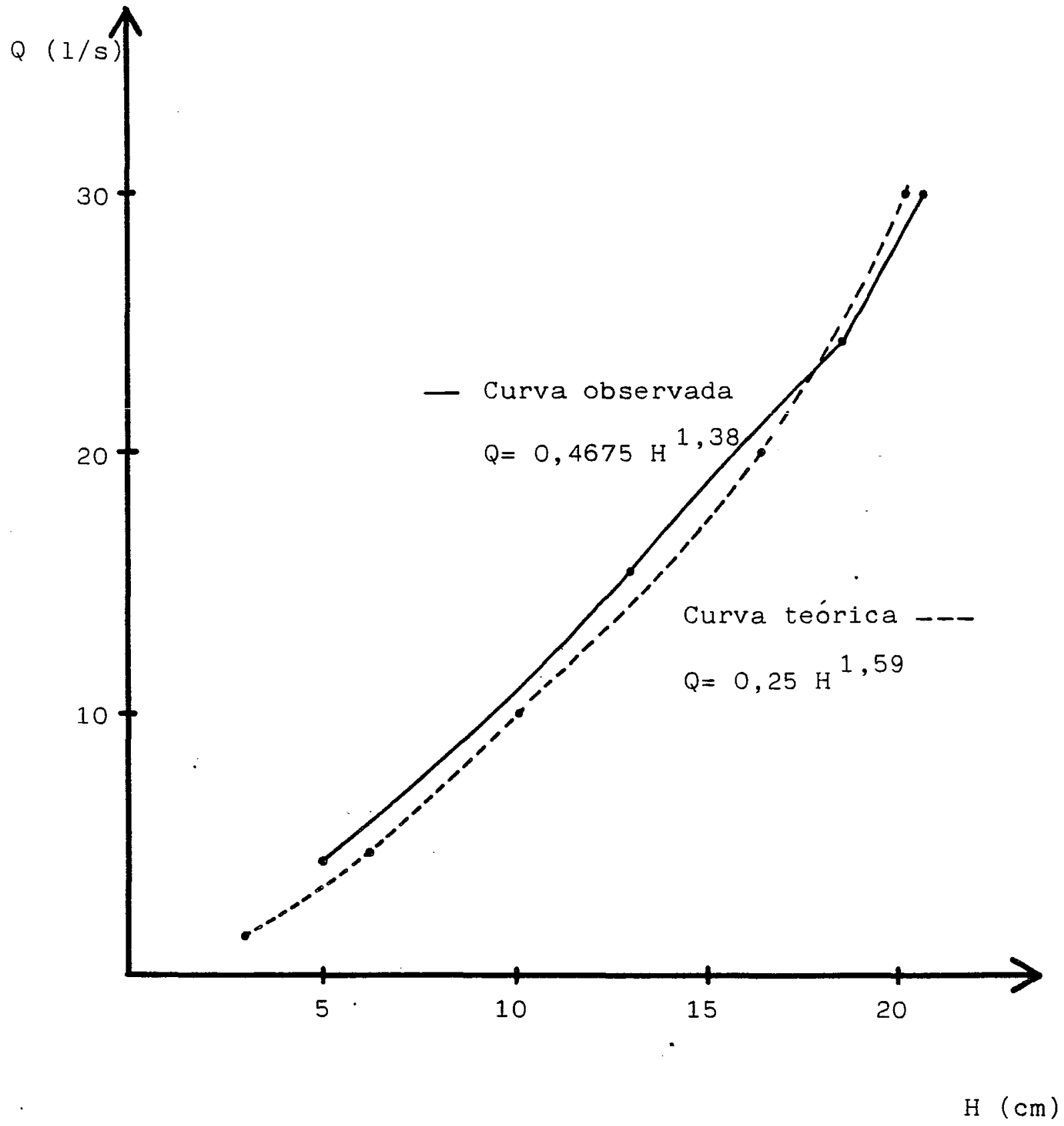

Figura 8: Curva teórica e curva observada na calibração da calha "PARSHALL" de 6". 


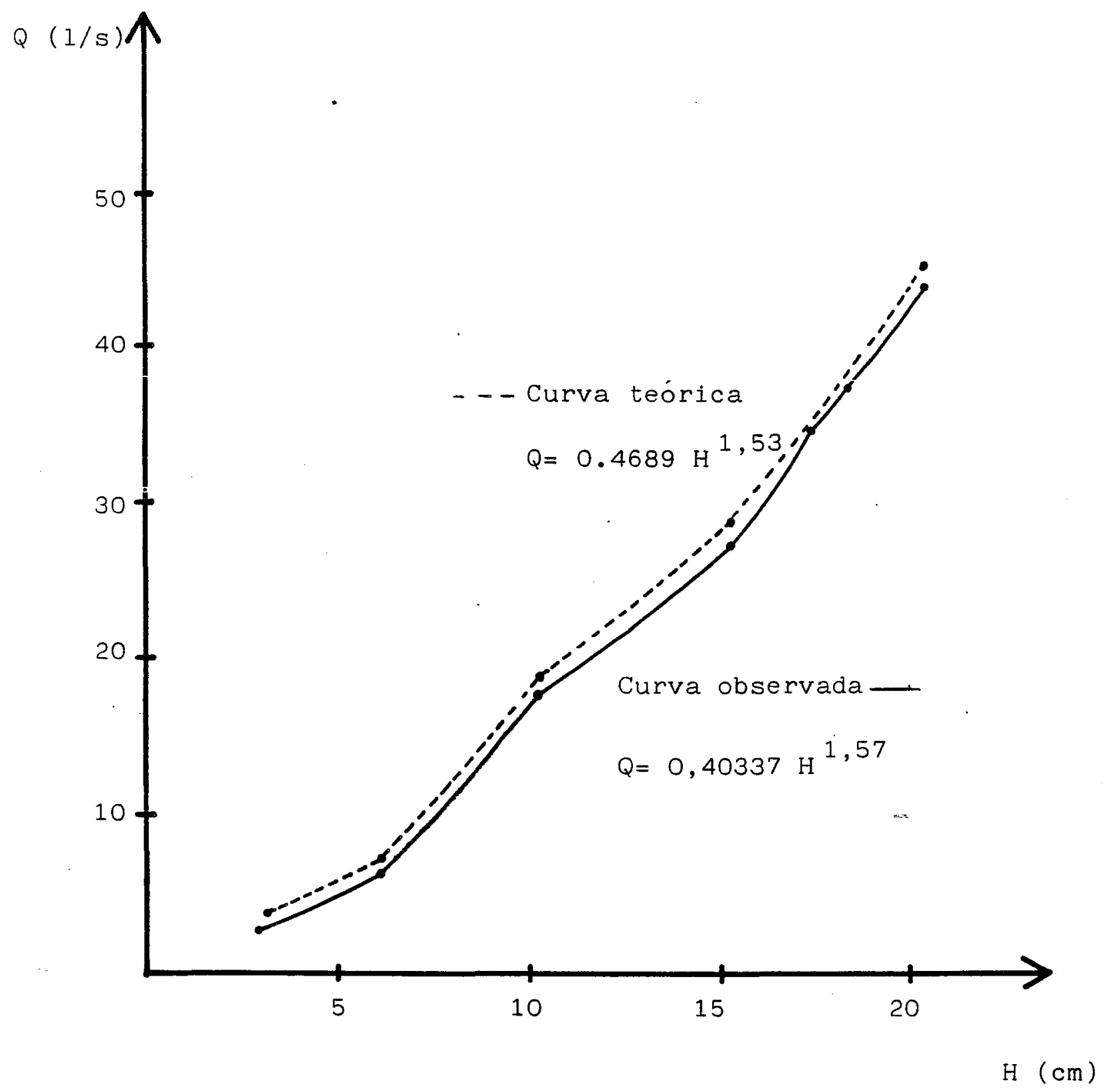

Figura 9: Curva teórica e curva observada na calibração da calha "PARSHALL" de 9 ". 


\section{RESULTADOS}

Os dados dos parämetros estudados nas diversas etapas de purificaçăo de água; encontram-se resumidos nas tabelas 1 a 24 , com exceção do niquel, prata, boro e nitrito, pois as concentraçōes desses parâmetros, em nenhuma amostragem, excederam os limites mínimos de detecção do método utilizado.

Esses limites minimos săo os seguintes:

- para o níquel : $<0.02 \mathrm{mg} / 1$

- para a prata : $<0.05 \mathrm{mg} / 1$

- para o boro : $<0.02 \mathrm{mg} / 1$

- para o nitrito $:<0.01 \mathrm{mg} / 1$ 
TABEL 1 .Dados obtidos a araliagĩo da eficiência do sistema aguapé-solo filtrante.

Período de amostragem: Junho/1986.

\begin{tabular}{|c|c|c|c|c|c|c|}
\hline FARAMETROS & $\begin{array}{l}\text { Aqua de } \\
\text { Eritrada } \\
\text { P1 }\end{array}$ & $\begin{array}{c}\text { Saida } \\
\text { Canal aguapé } \\
\text { P2 }\end{array}$ & $\begin{array}{l}\text { Eficiência }(\not{X}) \\
\text { Canal aguape }\end{array}$ & $\begin{array}{c}\text { Saida solo } \\
\text { filtrante } \\
\text { P3 }\end{array}$ & $\begin{array}{l}\text { Eficiëncia (\$) } \\
\text { Solo filtrante }\end{array}$ & $\begin{array}{l}\text { Eficência }\left(\Phi^{6}\right) \\
\text { do sistema } 6\end{array}$ \\
\hline O.B.O. $(\mathrm{mg} / \mathrm{h})$ & 5.54 & 0.92 & 83.4 & 0.69 & 25 & 87.5 \\
\hline Coli fecal (nmp) & 93000 & 1500 & 98.4 & 2300 & -53.3 & 97.5 \\
\hline Coli total (nmp) & 430000 & 23000 & 94.7 & 23000 & 0.00 & 94.7 \\
\hline Turbidez (FTU) & 16.4 & 4.2 & 74.4 & 2.7 & 35.71 & 83.5 \\
\hline Cor (ppm Ptco) & 56 & 33 & 41.1 & 16 & 51.52 & 71.4 \\
\hline Nitrato (mg/i) & 0.27 & 1.15 & -325.9 & 0.73 & 36.5 & -170.4 \\
\hline N-amoniacal (mg/l) & 1.59 & $<0.20$ & $>87.4$ & $<0.20$ & - & $>87.4$ \\
\hline Bisin $(\mathrm{mg} / \mathrm{l})$ & 0.28 & 0.35 & -25.0 & 0.30 & 14.3 & -7.1 \\
\hline Cadmio (mg/1) & 0.01 & 0.01 & - & 0.01 & - & - \\
\hline Chumbo (mg/1) & 60.10 & 40.10 & - & $<0.10$ & - & - \\
\hline Cobre $(\mathrm{mg} / \mathrm{l})$ & 0.02 & $<0.02$ & - & $<0.02$ & - & - \\
\hline Cromo (ing $/ 1)$ & 0.06 & 0.05 & 16.7 & 0.06 & -20.0 & 0.0 \\
\hline Zinco $(\mathrm{mg} / \mathrm{l})$ & 0.04 & 40.02 & $>50.0$ & $<0.02$ & - & $>50.0$ \\
\hline Sulfato (mg/l) & 29.73 & 30.37 & -2.2 & 32.02 & -5.43 & -7.7 \\
\hline Fósforo $(\mathrm{mg} / 1)$ & 0.19 & 0.11 & 42.1 & 0.12 & -9.09 & 36.8 \\
\hline Cloro (mg/l) & 23.27 & 22.65 & 2.7 & 22.9 & -1.10 & 1.6 \\
\hline Aluminio ( $\mathrm{mg} / \mathrm{l}$ ) & 0.48 & 0.28 & 41.7 & 0.26 & 7.14 & 45.8 \\
\hline Cólcio (mg/1) & 10.06 & 9.46 & 6.0 & 10.1 & -6.77 & -0.4 \\
\hline Ferro (mg/l) & 1.06 & 0.34 & 67.9 & 0.07 & 79.41 & 93.4 \\
\hline Potóssio (mg/l) & 4.19 & 3.94 & 6.0 & 4.17 & -5.84 & 0.5 \\
\hline Magnésio (mg/l) & 3.02 & 2.43 & 19.5 & 2.93 & -20.58 & 3.0 \\
\hline Manganës (mo/l) & 0.21 & 0.02 & 90.5 & 0.01 & 50.00 & 952 \\
\hline Sódio (mg/l) & 32.34 & 31.54 & 2.5 & 31.13 & 1.30 & 3.7 \\
\hline Silicio (mg/l) & 5.53 & 5.2 & 6.0 & 4.69 & 9.81 & 15.2 \\
\hline
\end{tabular}

$*[(\mathrm{P} 1-\mathrm{P} 2) / \mathrm{P} 1] .100 \quad *[(\mathrm{P} 2-\mathrm{P} 3) / \mathrm{P} 2] .100 \quad[(\mathrm{P} 1-\mathrm{P} 3) / \mathrm{P} 1] .100$ 
TABEL 2.Dados obtidos e ayaliaçũo da eficiencia do sistema aguapé-solo filtrante. Periode de amostragem: Julho/1986

\begin{tabular}{|c|c|c|c|c|c|c|}
\hline PARAMETROS & $\begin{array}{c}\text { Agua de } \\
\text { Entrada } \\
\text { P1 }\end{array}$ & $\begin{array}{c}\text { Saída } \\
\text { Canal aquapé } \\
\text { P2 }\end{array}$ & $\begin{array}{l}\text { Eficiència (\$8) } \\
\text { Canal aguapé * }\end{array}$ & $\begin{array}{c}\text { Saida solo } \\
\text { filtrante } \\
\text { P3 }\end{array}$ & $\begin{array}{l}\text { Eficiência (\$) } \\
\text { Solo filttrante }\end{array}$ & $\begin{array}{l}\text { Eficência (\$) } \\
\text { do sistema } 9\end{array}$ \\
\hline D.B.0. (mg/1) & 4.36 & 0.83 & 81.0 & 0.69 & 16.9 & 84.2 \\
\hline Coli fecal (nmp) & 39000 & 30 & $>99.9$ & 36 & -20.0 & 99.9 \\
\hline Coli total (nmp) & 75000 & 4300 & 94.3 & 160 & 96.3 & 99.8 \\
\hline Turbidez (FTU) & 12.3 & 3 & 75.6 & 1.5 & 50.0 & 87.8 \\
\hline Cor (ppm PtCo) & $50 \overline{0}$ & 26 & 48.0 & 25 & 3.8 & 50.0 \\
\hline Nitrato (mg/l) & 0.59 & 1.06 & -79.7 & 1.23 & -16.0 & -108.5 \\
\hline N-amoniacal (mg/l) & 1.64 & 40.20 & $>87.8$ & 0.20 & - & $>87.4$ \\
\hline Bário (mg/) & 0.23 & 0.19 & 17.4 & 0.18 & 5.3 & 21.7 \\
\hline Cadmio (mg/l) & $\infty 0.01$ & 60.01 & - & $\infty .01$ & - & - \\
\hline Chumbo (mg/1) & $<0.10$ & 40.10 & - & $\$ 0.10$ & - & - \\
\hline Cobre $(m g / 7)$ & $<0.02$ & $<0.02$ & - & $\$ .02$ & - & - \\
\hline Cromo (mg/l) & 0.05 & $<0.05$ & - & 40.05 & - & - \\
\hline Zinco (mg/l) & 0.02 & $<0.02$ & - & 0.02 & - & 0.0 \\
\hline Sulfato (mg/i) & 28.65 & 28.46 & 0.7 & 29.15 & -2.4 & -1.7 \\
\hline Fósforo $(\mathrm{mg} / \mathrm{l})$ & 0.16 & 0.10 & $>37.5$ & 0.10 & - & $\$ 37.5$ \\
\hline Cloro (mg/i) & 21.49 & 23.15 & -7.7 & 22.13 & 4.4 & -3.0 \\
\hline Aluminio $(\mathrm{mg} / 1)$ & 0.47 & 0.2 & 57.4 & 0.13 & 35.0 & 72.3 \\
\hline Cólcio $(\mathrm{mg} / \mathrm{l})$ & 92 & 9.34 & -1.5 & 9.61 & -2.9 & -4.5 \\
\hline Ferro $(\mathrm{mg} / \mathrm{l})$ & 0.68 & 0.18 & 73.5 & 0.04 & 77.8 & 94.1 \\
\hline Potóssio $(m g h)$ & 4.26 & 3.88 & 8.9 & 4.64 & -19.6 & -8.9 \\
\hline Magnésio (mg/l) & 2.22 & 2.24 & -0.9 & 3.01 & -34.4 & -35.6 \\
\hline Manganès (mg/l) & 0.06 & 0.01 & $>83.3$ & $<0.01$ & - & $>83.3$ \\
\hline Sódio $(\mathrm{mg} / \mathrm{l})$ & 29.68 & 30.34 & -4.2 & 30.89 & 0.2 & -4.1 \\
\hline Silicio (mg/n) & 5.14 & 4.72 & 8.2 & 4.33 & 8.3 & 15.8 \\
\hline
\end{tabular}

$*[(P 1-P 2) / P 1] .100$

* $[(P 2-P 3) / P 2] .100$

$[(\mathrm{P} 1-\mathrm{P} 3) / \mathrm{P} 1] .100$ 
TABEL $3 . D a d o s$ obtidos araliaģa do efieitacia do sistema aguapé-solo filtrante. Periodo de amostragem: Agosto/1986

\begin{tabular}{|c|c|c|c|c|c|c|}
\hline PARAMETROS & $\begin{array}{l}\text { Aqua de } \\
\text { Entrada } \\
\text { P1 }\end{array}$ & $\begin{array}{c}\text { Saída } \\
\text { Canal aguapé } \\
\mathrm{P2}\end{array}$ & $\begin{array}{l}\text { Eficiência (\$) } \\
\text { Canal aguapé }\end{array}$ & $\begin{array}{c}\text { Saida solo } \\
\text { filtrante } \\
\text { P3 }\end{array}$ & $\begin{array}{l}\text { Eficiència (\$) } \\
\text { Solo filtrante }\end{array}$ & $\begin{array}{l}\text { Eficéncia (名) } \\
\text { do sistema }\end{array}$ \\
\hline D.B.0. $(\mathrm{mg} / \mathrm{l})$ & 6.43 & 2.74 & 57.4 & 0.68 & 75.2 & 89.4 \\
\hline Coli fecal (nmp) & 430000 & 67 & 99.9 & $<30$ & $>55.2$ & $>99.9$ \\
\hline Coli total (nmp) & $1.2 E+07$ & 2300 & 99.9 & 1290 & 43.9 & 99.9 \\
\hline Turbidez (FTU) & 11.62 & 2.25 & 80.6 & 1.55 & 31.1 & 86.7 \\
\hline Cor (ppm $P+C 0)$ & $\overline{75}$ & 36 & 50.7 & 26 & 27.8 & 64.4 \\
\hline Nitrato (mg/l) & 0.22 & 0.95 & -331.8 & 0.63 & 33.7 & -186.4 \\
\hline N-amoniacal $(\mathrm{mg} / \mathrm{l})$ & 2.20 & $<0.20$ & $>90.9$ & $<0.20$ & - & 290.9 \\
\hline Bário $(\mathrm{mg} / 1)$ & 0.08 & 0.05 & 37.5 & 0.05 & 0.0 & 37.5 \\
\hline Cadmio (mg/l) & $\infty .01$ & $\infty .01$ & - & $\infty .01$ & - & - \\
\hline Chumbo $(\mathrm{mg} / \mathrm{l})$ & 00.10 & $\$ 0.10$ & - & 0.10 & - & - \\
\hline Cobre (mg/n) & $<0.02$ & $\infty .02$ & - & $<0.02$ & - & - \\
\hline Cromo (mg/1) & 0.05 & 0.05 & - & 80.05 & - & - \\
\hline Zinco $(\mathrm{mg} / 1)$ & 0.02 & $<0.02$ & - & 40.02 & - & - \\
\hline Sulfato $(\mathrm{mg} / \mathrm{l})$ & 32.11 & 33.45 & -4.2 & 34.55 & -3.3 & -7.6 \\
\hline Fósfora $(m g / 1)$ & $<0.10$ & 0.10 & - & 0.10 & - & - \\
\hline Cloro $(m g / 1)$ & 25.33 & 27.5 & -8.6 & 24.65 & 10.4 & 2.7 \\
\hline Aluminio $(\mathrm{mg} / \mathrm{l})$ & 0.36 & 0.14 & 61.1 & 0.11 & 21.4 & 69.4 \\
\hline Cólcio (mg/) & 9.95 & 9.93 & 0.2 & 10.93 & -10.1 & -9.8 \\
\hline Ferro $(m g /)$ & 0.77 & 0.22 & 71.4 & 0.06 & 72.7 & 92.2 \\
\hline Potássia (mg/) & 4.33 & 3.9 & 9.9 & 4.02 & -3.1 & 7.2 \\
\hline Magnésio $(\mathrm{mg} / \mathrm{l})$ & 2.34 & 2.3 & 1.7 & 2.58 & $-12: 2$ & -10.3 \\
\hline Manganès (mg/l) & 0.13 & $<0.01$ & $>92.3$ & $<0.01$ & - & 292.3 \\
\hline Sódio (mg/l) & 33.47 & 32.91 & 1.7 & 32.38 & 1.6 & 3.3 \\
\hline Silicio $(\mathrm{mg} / \mathrm{l})$ & 5.97 & 5.45 & 8.7 & 5 & 8.3 & 16.2 \\
\hline
\end{tabular}


TABEL 4 .Dades obtidos araliaģ̄o da eficiència do sistema aguapé-solo fiitrante. Periodo de amostragem: Setembro/1986

\begin{tabular}{|c|c|c|c|c|c|c|}
\hline PARAMETROS & $\begin{array}{l}\text { Agua de } \\
\text { Entrada } \\
\text { P1 }\end{array}$ & $\begin{array}{c}\text { Saida } \\
\text { Canal aguapé } \\
\text { P2 }\end{array}$ & $\begin{array}{l}\text { Eficiência (\$) } \\
\text { Canal aguapé * }\end{array}$ & $\begin{array}{c}\text { Saida solo } \\
\text { filtrante } \\
\text { P3 }\end{array}$ & $\begin{array}{l}\text { Eficiencia (\$) } \\
\text { Solo filtrante }\end{array}$ & $\begin{array}{l}\text { Eficeincia (\$) } \\
\text { do sistema } 0\end{array}$ \\
\hline $0.8 .0 .(\mathrm{mg} / 1)$ & 6.01 & 1.58 & 73.7 & 0.87 & 44.9 & 85.5 \\
\hline Coli fecal (nmp) & 930000 & 36 & 99.9 & 30 & $: 16.6$ & 399.9 \\
\hline Coli total (nmp) & 930000 & 290 & 99.9 & 120 & 58.6 & 99.9 \\
\hline Turbidez (FTU) & 15.5 & 2.15 & 86.1 & 0.74 & 65.6 & 95.2 \\
\hline Cor (́ppm F(Co) & 80 & 25 & 68.6 & 10 & 60.0 & 87.5 \\
\hline Nitrato (mg/1) & 0.22 & 2.76 & -1154.5 & - & $-\cdots$ & - \\
\hline Namoniacal $(\mathrm{mg} / \mathrm{l})$ & 2.58 & 0.99 & 61.6 & - & $\cdots$ & - \\
\hline Bário (mg/) & 0.10 & 0.09 & 10.0 & - & - & - \\
\hline Cadmio (mg/i) & 0.01 & $<0.01$ & - & - & - & - \\
\hline Chumbo $(\mathrm{mg} / \mathrm{l})$ & $\$ 0.10$ & 40.10 & - & - & - & - \\
\hline Cobre (mg/l) & 0.03 & 0.03 & 0.0 & - & - & - \\
\hline Cromo $(\mathrm{mg} / 1)$ & 0.05 & $<0.05$ & - & - & - & - \\
\hline Zinco $(m g /)$ & $<0.02$ & $<0.02$ & - & - & - & - \\
\hline Sulfato (mg/l) & 20.71 & 18.49 & 10.7 & - & - & - \\
\hline Fósforo (mg/l) & 0.18 & 0.10 & $>44.4$ & - & - & - \\
\hline Cloro $(\mathrm{mg} / 1)$ & 27.68 & 2729 & 1.4 & - & - & - \\
\hline Aluminio $(\mathrm{mg} / \mathrm{l})$ & 0.76 & 0.26 & 65.8 & - & $=$ & - \\
\hline Cólcio $(\mathrm{mg} /)$ & 11.55 & 1123 & 2.8 & - & - & - \\
\hline Ferro $(\operatorname{mg} / 1)$ & 1.32 & 0.55 & 58.3 & - & - & - \\
\hline Potássio (mg/l) & 5.85 & 5.3 & 9.4 & - & - & - \\
\hline Magnésio (mg/l) & 2.69 & 2.67 & 0.7 & - & - & - \\
\hline Manganês (mg/l) & 0.17 & 0.12 & 29.4 & - & - & - \\
\hline Sódio (mg/l) & 42.81 & 42.44 & 0.9 & - & - & - \\
\hline Silicio (mg/1) & 5.91 & 5.46 & 7.6 & - & - & - \\
\hline
\end{tabular}


TABEL 5 .Dados obtidos e araliaçōo da eficiência do sistema aguapé-solo filtrante.

Periode de amostragem: Dutubro/1986

\begin{tabular}{|c|c|c|c|c|c|c|}
\hline PARAMETROS & $\begin{array}{l}\text { Agua de } \\
\text { Entrada } \\
\text { Pl }\end{array}$ & $\begin{array}{c}\text { Saída } \\
\text { Canal aguape } \\
\text { P2 }\end{array}$ & $\begin{array}{l}\text { Eficiência (क) } \\
\text { Canal aquapé }\end{array}$ & $\begin{array}{c}\text { Saida solo } \\
\text { fiitrante } \\
\text { P3 }\end{array}$ & $\begin{array}{l}\text { Eficiência (\%) } \\
\text { Solo filtrante }\end{array}$ & 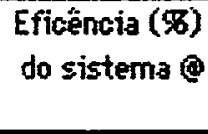 \\
\hline D.B.0. $(\mathrm{mg} / 1)$ & 6.51 & 2.49 & 61.8 & - & - & - \\
\hline Coli fecol (nmp) & 126500 & 561 & 99.6 & - & - & - \\
\hline Coli total (nmp) & 1365000 & 16150 & 98.8 & - & - & - \\
\hline Turbidez (FTU) & 17.45 & 2.82 & 83.8 & - & - & - \\
\hline Cor (ppm PtCo) & 57 & $40 \hat{0}$ & 29.8 & - & - & - \\
\hline Nitrato (mg/l) & - & - & - & - & - & - \\
\hline N-amoniacal (mg/l) & - & - & - & - & - & $\infty$ \\
\hline Bário (mg/l) & - & - & - & - & - & - \\
\hline Codmio (mg/l) & - & - & - & - & - & - \\
\hline Chumbo $(\mathrm{mg} / \mathrm{l})$ & - & - & - & - & - & - \\
\hline Cobre $(\mathrm{mg} / 1)$ & - & - & - & - & - & - \\
\hline Cromo (mg/) & - & - & - & - & - & - \\
\hline Zinea $(\mathrm{mg} / \mathrm{l})$ & - & - & - & - & - & - \\
\hline Sulfato $(\mathrm{mg} / \mathrm{l})$ & - & - & - & - & - & - \\
\hline Fósforo (mg/l) & - & - & - & - & - & - \\
\hline Cloro (mg/1) & - & - & - & - & - & - \\
\hline Aluminio (mg/l) & - & - & - & - & - & - \\
\hline Cólcio (mg/) & - & - & - & - & - & - \\
\hline Ferro $(\mathrm{mg} / \mathrm{l})$ & - & - & - & - & - & - \\
\hline Potássio (mg $/$ ) & - & - & - & - & - & - \\
\hline Magnésio (mg/l) & - & - & - & - & - & - \\
\hline Manganês (mọ/l) & - & - & - & - & - & - \\
\hline Südia (mg/l) & - & - & - & - & - & - \\
\hline Silicio $(\mathrm{mg} / \mathrm{l})$ & - & - & - & - & - & - \\
\hline
\end{tabular}

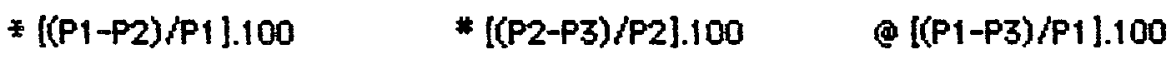


TABEL 6.Dados obtidos araliagäo da eficiência do sistema aguapé-solo filtrante. Período de amostragen: Horembro/1986

\begin{tabular}{|c|c|c|c|c|c|c|}
\hline PARAMETROS & $\begin{array}{c}\text { Agua de } \\
\text { Entrada } \\
\text { P1 }\end{array}$ & $\begin{array}{c}\text { Saida } \\
\text { Canal aguapé } \\
\text { P2 }\end{array}$ & $\begin{array}{l}\text { Eficiência (go) } \\
\text { Canal aguapé }\end{array}$ & $\begin{array}{c}\text { Saida solo } \\
\text { filtrante } \\
\text { P3 }\end{array}$ & $\begin{array}{l}\text { Eficiência (\$) } \\
\text { Solo filtrante }\end{array}$ & $\begin{array}{l}\text { Eficencia (\$) } \\
\text { do sistema }(9)\end{array}$ \\
\hline D.B.0. $(\mathrm{mg} / \mathrm{d})$ & 5.23 & 2.13 & 59.3 & 0.93 & 56.3 & 82.2 \\
\hline Coli fecal (nmp) & 4300 & 930 & 78.4 & 64 & 93.1 & 98.5 \\
\hline Coli total (nmp) & 430000 & 110000 & 74.4 & 440 & 99.6 & 99.9 \\
\hline Turbidez (FTU) & 12.65 & 4.73 & 62.6 & 3.05 & 35.5 & 75.9 \\
\hline Cor (ppm PtCo) & 63 & 53 & 15.9 & $3 i$ & 41.5 & 50.8 \\
\hline Nitrato $(\mathrm{mg} / \mathrm{l})$ & 0.37 & 0.03 & 91.9 & 0.77 & -2466.7 & -108.1 \\
\hline $\mathrm{N}$-amoniacal $(\mathrm{mg} / \mathrm{h})$ & 1.74 & 0.80 & 54.0 & $\infty .20$ & 775.0 & 888.5 \\
\hline Bírio (mg/l) & 0.13 & 0.07 & 46.2 & 0.05 & 28.6 & 61.5 \\
\hline Cadmio (mg/l) & $<0.01$ & 0.01 & - & $<0.01$ & - & - \\
\hline Chumbo (mg/1) & 40.10 & 0.10 & - & $<0.10$ & - & - \\
\hline Cobre $(\mathrm{mg} / \mathrm{h})$ & 0.03 & 0.02 & 33.3 & 0.03 & -50.0 & 0.0 \\
\hline $\operatorname{Cromo}(\mathrm{mg} / \mathrm{l})$ & 40.05 & 40.05 & - & $<0.05$ & - & - \\
\hline Zinco (mg/l) & 0.02 & $<0.02$ & - & 40.02 & - & - \\
\hline Sulfato (mg/1) & 17.71 & 17.65 & 0.3 & 18.77 & -6.3 & -6.0 \\
\hline Fásforo (mg/l) & 0.27 & 0.16 & 40.7 & 0.10 & $\times 37.5$ & 263.0 \\
\hline Cloro $(\mathrm{mg} h)$ & 26.27 & 29.11 & -10.8 & 28.8 & 1.1 & -9.6 \\
\hline Aluminio $(\mathrm{mg} / \mathrm{l})$ & 0.45 & 0.25 & 44.4 & 0.29 & -16.0 & 35.6 \\
\hline Cólcio (mg/) & 11.12 & 12.13 & -9.1 & 11.97 & 1.3 & -7.6 \\
\hline Ferro $(\mathrm{mg} / 1)$ & 0.89 & 0.09 & 89.9 & 0.1 & -111 & 88.8 \\
\hline Potóssio (mg/) & 7.03 & 6.28 & 10.7 & 6 & 4.5 & 14.7 \\
\hline Magnésio (mg/l) & 2.8 & 2.86 & -2.1 & 3.69 & -29.0 & -31.8 \\
\hline Manganês (mg/n) & 0.18 & 0.01 & 94.4 & 80.01 & - & 294.4 \\
\hline Sódio $(m g / 1)$ & 41.87 & 42.6 & -1.7 & 32.51 & 23.7 & 22.4 \\
\hline Silicio ( $\mathrm{mg} / \mathrm{l}$ ) & 5.31 & 5.34 & -0.6 & 5.46 & -22 & -2.8 \\
\hline
\end{tabular}


TABel 7. Dados obtidos e ayaliagüo da eficiäncia do sistema aguapé-solo filtrante. Periodo de amostragem: Dezembro/ 1986

\begin{tabular}{|c|c|c|c|c|c|c|}
\hline PARAMETROS & $\begin{array}{l}\text { Aqua de } \\
\text { Entrada } \\
\text { P1 }\end{array}$ & $\begin{array}{c}\text { Sáda } \\
\text { Canal aguapé } \\
\text { P2 }\end{array}$ & $\begin{array}{l}\text { Eficiència (\$) } \\
\text { Canal aguapé * }\end{array}$ & $\begin{array}{c}\text { Saida solo } \\
\text { filtrante } \\
\text { P3 }\end{array}$ & $\begin{array}{l}\text { Eficiência (\$) } \\
\text { Solo fiitrante }\end{array}$ & $\begin{array}{l}\text { Eficência ( }(\mathbb{B}) \\
\text { do sistema } Q\end{array}$ \\
\hline D.B.0. $(\mathrm{mg} / 1)$ & 4.9 & 2.25 & 54.1 & 1.33 & 40.9 & 72.9 \\
\hline Coli fecal (nmp) & 23000 & 1500 & 93.5 & 210 & 86.0 & 99.1 \\
\hline Coli total (nmp) & 2300000 & 230000 & 90.0 & 23000 & 90.0 & 99.0 \\
\hline Turbidez (FTU) & 128.6 & 6325 & 50.8 & 26.85 & 57.5 & 79.1 \\
\hline Cor (ppm Fico) & 287 & 120 & 58.2 & 63 & 30.8 & 71.1 \\
\hline Nitrato (mg/l) & 0.52 & 0.21 & 59.6 & 0.21 & 0.0 & 59.6 \\
\hline N-amoniacal $(\mathrm{mg} / \mathrm{l})$ & 0.48 & 0.25 & 47.9 & $<0.20$ & $>20.0$ & $>58.3$ \\
\hline Bório (mg/l) & 0.07 & 0.03 & 57.1 & 0.03 & 0.0 & 57.1 \\
\hline Cadmio (mg/l) & 0.01 & 0.01 & - & $<0.01$ & - & - \\
\hline Chumbo $(\mathrm{mg} / \mathrm{l})$ & 80.10 & 40.10 & - & $<0.10$ & - & - \\
\hline Cobre (mg/l) & 0.02 & 0.02 & 0.0 & 0.02 & 0.0 & 0.0 \\
\hline $\operatorname{Cromo}(\mathrm{mg} / \mathrm{l})$ & 40.05 & $<0.05$ & - & 60.05 & - & - \\
\hline Zinco $(\operatorname{mg} / 1)$ & 0.04 & 0.02 & $>50.0$ & $<0.02$ & - & $>50.0$ \\
\hline Sulfato (mgh) & 1129 & 3.39 & 70.0 & 19.06 & -462.2 & -68.8 \\
\hline Fósforo $(\mathrm{mg} / \mathrm{l})$ & 0.10 & 0.10 & - & 0.10 & - & - \\
\hline Cloro $(m g / 1)$ & 6.46 & 4.32 & 33.1 & 7.65 & -77.1 & -18.4 \\
\hline Aluminio $(\mathrm{mg} / \mathrm{l})$ & 1.12 & 0.3 & 73.2 & 0.24 & 20.0 & 78.6 \\
\hline Cólcio $(\mathrm{mg} / \mathrm{l})$ & 5.94 & 3.87 & 34.8 & 8.12 & -109.8 & -36.7 \\
\hline Ferro $(\mathrm{mg} / 1)$ & 2.44 & 1 & 59.0 & 0.13 & 87.0 & 94.7 \\
\hline Potássio (mg/) & 3.6 & 2.65 & 26.4 & 3.96 & -49.4 & -10.0 \\
\hline Magnésio $(\mathrm{mg} / \mathrm{l})$ & 1.91 & 1.16 & 39.3 & 2.03 & -75.0 & -6.3 \\
\hline Manganês (mg/l) & 0.14 & 0.07 & 50.0 & 0.01 & 85.7 & 92.9 \\
\hline Sódio (mg/l) & 9.64 & 5.43 & 43.7 & 14.97 & -175.7 & -55.3 \\
\hline Silicio (mg $/ 1)$ & 4.84 & 2.61 & 46.1 & 4.57 & -75.1 & 5.6 \\
\hline
\end{tabular}


TABEL A.Dados obtidas araliagũo da efieitncia do sistema aguapé-solo filtrante. Periode de anostragem: Janeiro/1987

\begin{tabular}{|c|c|c|c|c|c|c|}
\hline PARAMETROS & $\begin{array}{l}\text { Agua de } \\
\text { Entrada } \\
\text { P1 }\end{array}$ & $\begin{array}{c}\text { Saída } \\
\text { Canal aguapé } \\
\text { P2 }\end{array}$ & 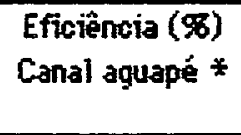 & $\begin{array}{c}\text { Saída solo } \\
\text { filtrante } \\
\text { P3 }\end{array}$ & $\begin{array}{l}\text { Eficiencia (G8) } \\
\text { Solo filtrante }\end{array}$ & $\begin{array}{r}\text { Eficência (\$) } \\
\text { do sistema } 9\end{array}$ \\
\hline D.B.0. $(\mathrm{mg} / 1)$ & 3.90 & 2.53 & 35.1 & 2.78 & -9.9 & 28.7 \\
\hline Coli fecal (nmp) & 379650 & 510 & 99.9 & $<30$ & $>94.1$ & $>99.9$ \\
\hline Coli total (nmp) & 1165000 & 8650 & 99.3 & 1187 & 86.3 & 99.9 \\
\hline Turbidez (FTU) & 129 & 45.18 & 65.0 & 3.48 & 92.3 & 97.3 \\
\hline Cor (ppm PtCo) & 390 & 189 & 51.5 & 37 & 80.4 & 90.5 \\
\hline Nitrato (mg/) & 0.47 & 60.10 & $>78.8$ & 0.10 & - & $>78.7$ \\
\hline $\mathrm{N}$-amoniacal (mg/) & 0.31 & 0.20 & 35.5 & $\$ .20$ & - & $\times 35.5$ \\
\hline Bário (mg/l) & 0.08 & 0.05 & 37.5 & 0.04 & 20.0 & 50.0 \\
\hline Cadmio (mg/l) & 40.01 & $<0.01$ & - & $<0.01$ & - & - \\
\hline Chumbo (mg/l) & 0.10 & $<0.10$ & - & 6.10 & - & - \\
\hline Cabre $(\mathrm{mg} / \mathrm{l})$ & 0.03 & 4.02 & $>33.3$ & $\infty .02$ & - & $>33.3$ \\
\hline Cromo (mg 11$)$ & $<0.05$ & 60.05 & - & $<0.05$ & - & - \\
\hline Zinco (mg/l) & 0.03 & $<0.02$ & $\$ 33.3$ & $\infty .02$ & - & .33 .3 \\
\hline Sulfato (mg/i) & 11.78 & 11.16 & 5.3 & 7.56 & 32.3 & 35.8 \\
\hline Fósforo $(\mathrm{mg} / \mathrm{l})$ & 0.12 & 00.10 & $>16.7$ & 0.10 & - & $>16.7$ \\
\hline Cloro $(\mathrm{mg} / \mathrm{l})$ & 6.33 & 5.62 & 11.2 & 5.76 & -2.5 & 9.0 \\
\hline Aluminio (mg/l) & 0.94 & 0.34 & 63.8 & 0.19 & 44.1 & 79.8 \\
\hline Cólcio (mg/1) & 6.59 & 6.4 & 2.9 & 10.57 & -65.2 & -60.4 \\
\hline Ferro (mgh) & 4.41 & 1.66 & 62.4 & 0.21 & 87.3 & 952 \\
\hline Potóssio (mg/) & 3.87 & 3.19 & 17.6 & 3.67 & -15.0 & 5.2 \\
\hline Magnésio $(\mathrm{mg} / \mathrm{l})$ & 2.15 & 2.04 & 5.1 & 2.66 & -30.4 & -23.7 \\
\hline Manganês (mg/l) & 0.14 & 0.1 & 28.6 & 0.64 & -540.0 & -357.1 \\
\hline Sódio $(\mathrm{mg} / \mathrm{l})$ & 9.31 & 7.68 & 17.5 & 9.31 & -21.2 & 0.0 \\
\hline Silicio $(\mathrm{mg} / \mathrm{l})$ & 5.86 & 4.97 & 15.2 & 5.35 & -7.6 & 8.7 \\
\hline
\end{tabular}


TABEL 9.Dados obtidos aysliaçüo da eficiência do sistema aguapé-solo filtrante. Periodo de amostragem: Fevereiro/1987

\begin{tabular}{|c|c|c|c|c|c|c|}
\hline PARAMETROS & $\begin{array}{l}\text { Agua de } \\
\text { Entrada } \\
\text { Pl }\end{array}$ & $\begin{array}{c}\text { Saida } \\
\text { Canal aquapé } \\
\text { P2 }\end{array}$ & $\begin{array}{l}\text { Eficiência (\$) } \\
\text { Canal aquapé }\end{array}$ & $\begin{array}{c}\text { Saida solo } \\
\text { filtrante } \\
\text { P3 }\end{array}$ & $\begin{array}{l}\text { Eficiëncia (\$) } \\
\text { Solo filtrante }\end{array}$ & $\begin{array}{l}\text { Eficência (果) } \\
\text { do sistema }\end{array}$ \\
\hline 0.8.0. $(\mathrm{mg} / \mathrm{l})$ & - & - & - & - & - & - \\
\hline Coli feosl (nmp) & 9300 & 930 & 90.0 & $<30$ & $>96.7$ & 299.7 \\
\hline Coli total (nmp) & 230000 & 2300 & 99.0 & 2300 & 0.0 & 99.0 \\
\hline Turbidez (FTU) & 104.5 & 38.7 & 63.0 & 4.7 & 87.9 & 95.5 \\
\hline $\operatorname{Cor}(\mathrm{ppm} P \mathrm{PtCo})$ & 317 & 152 & 52.1 & 33 & 75.3 & 89.6 \\
\hline Nitrato (mg/l) & 1.35 & 0.8 & 40.7 & 1.55 & -93.8 & -14.8 \\
\hline Namoniacal $(\mathrm{mg} / \mathrm{l})$ & 0.27 & $<0.20$ & $>25.9$ & $\infty .20$ & - & $>25.9$ \\
\hline Bário (mg/1) & 0.04 & 0.03 & 25.0 & 0.02 & 33.3 & 50.0 \\
\hline Cadmia (mg/l) & $\infty .01$ & 0.01 & - & 0.01 & - & - \\
\hline Chumbo (mg/1) & 0.10 & $<0.10$ & - & 0.10 & - & - \\
\hline Cobre (mg/l) & $<0.02$ & 0.02 & - & $\infty .02$ & - & - \\
\hline Croma $(\mathrm{mg} / \mathrm{l})$ & 0.05 & $<0.05$ & - & $\infty .05$ & - & - \\
\hline Zinco (mg/l) & 0.04 & 0.02 & 250.0 & 0.05 & $\gamma-150.0$ & -25.0 \\
\hline Sulfato (mg/1) & 9.54 & 5.17 & 45.8 & 1.6 & 69.1 & 83.2 \\
\hline Fósforo (mg/l) & 0.1 & 0.1 & 0.0 & 0.1 & 0.0 & 0.0 \\
\hline Cloro (mg/1) & 3.5 & 3.45 & 1.4 & 3.12 & 9.6 & 10.9 \\
\hline Aluminio (mg/l) & 2.01 & 0.49 & 75.6 & 0.22 & 55.1 & 89.1 \\
\hline Cáleio (mg/l) & 4.64 & 4.23 & 8.8 & 5.74 & -35.7 & -23.7 \\
\hline Ferro $(\mathrm{mg} / \mathrm{l})$ & 3.11 & 0.8 & 74.3 & 0.37 & 53.8 & 88.1 \\
\hline Potóssio (mg/) & 2.72 & 1.9 & 30.1 & 1.55 & 18.4 & 43.0 \\
\hline Magnésio (ma/l) & 1.79 & 1.46 & 18.4 & 4.2 & -187.7 & -134.6 \\
\hline Manganês (mg/l) & 0.17 & 0.02 & 88.2 & 0.37 & -1750.0 & -117.6 \\
\hline Sódia (mg/l) & 7.15 & 6.25 & 12.6 & 5 & 20.0 & 30.1 \\
\hline Siticio $(\mathrm{mg} / \mathrm{l})$ & 4.4 & 3.6 & 18.2 & 1.4 & 61.1 & 68.2 \\
\hline
\end{tabular}


ThBEL 10.Dados obtidos e ayaliagüo da efieitencia do sistema aguapé-solo filtrante. Periodo de amostragem: Marģo/1987

\begin{tabular}{|c|c|c|c|c|c|c|}
\hline PARAMETROS & $\begin{array}{l}\text { Aqua de } \\
\text { Entrada } \\
\text { Pl }\end{array}$ & $\begin{array}{c}\text { Saída } \\
\text { Canal aquapé } \\
\text { P2 } \\
\end{array}$ & $\begin{array}{l}\text { Eficiência (g) } \\
\text { Canal aguapé }\end{array}$ & $\begin{array}{c}\text { Saida solo } \\
\text { filtrante } \\
\text { P3 } \\
\end{array}$ & $\begin{array}{l}\text { Eficiência (\$) } \\
\text { Sola filtrante }\end{array}$ & $\begin{array}{l}\text { Eficência (\$) } \\
\text { do sistema }\end{array}$ \\
\hline D.B.O. $(\mathrm{mg} / \mathrm{l})$ & 3.75 & 2.14 & 42.9 & 1.27 & 40.7 & 66.1 \\
\hline Coli feoal (nmp) & - & - & - & 230 & - & - \\
\hline Coli total (nmp) & 430000 & 43000 & 90.0 & 4300 & 90.0 & 99.0 \\
\hline Turbidez (FTU) & 87 & 16.4 & 81.1 & 2.3 & 86.0 & 97.4 \\
\hline Cor (ppm FtCo) & 324 & 71 & 78.1 & $4 \mathbf{i}$ & 42.3 & 87.3 \\
\hline Nitrato (mg/) & 0.54 & 0.13 & 75.9 & 0.25 & -92.3 & 53.7 \\
\hline$N$-amoniacal $(\mathrm{mg} / \mathrm{l})$ & 0.32 & $<0.20$ & $>37.5$ & $<0.20$ & - & 337.5 \\
\hline Bório (mg/1) & 0.05 & 0.04 & 20.0 & 0.03 & 25.0 & 40.0 \\
\hline Cadmio (mg/i) & 0.01 & $<0.01$ & - & $<0.01$ & - & - \\
\hline Chumbo (mg/l) & 0.13 & 60.10 & 323.1 & 0.10 & - & $>23.1$ \\
\hline Cabre $(\mathrm{mg} / 1)$ & 60.02 & $<0.02$ & - & 60.02 & - & - \\
\hline Cromo (mg $/ 1)$ & $<0.05$ & 60.05 & - & $\infty .05$ & - & - \\
\hline Zinco $(\mathrm{mg} / \mathrm{l})$ & 0.04 & $<0.02$ & $>50.0$ & 0.05 & $s-150.0$ & -25.0 \\
\hline Sulfato (mg/1) & 3.01 & 7.4 & -145.8 & 8.2 & -10.8 & -172.4 \\
\hline Fósfora (mg/1) & 0.13 & $<0.10$ & $\times 23.1$ & 0.10 & - & $>23.1$ \\
\hline $\operatorname{Cloro}(\mathrm{mg} / \mathrm{l})$ & 6.85 & 6.32 & 7.7 & 7.47 & -18.2 & -9.1 \\
\hline Aluminio (mg/l) & 123 & 0.31 & 74.8 & 0.16 & 48.4 & 87.0 \\
\hline Cólcio (mg/l) & 5.39 & 5.65 & -4.8 & 7.93 & -40.4 & -47.1 \\
\hline Ferro (mg/l) & 2.18 & 0.67 & 69.3 & 1.38 & -106.0 & 36.7 \\
\hline Potóssio $(\mathrm{mg} / \mathrm{l})$ & 3.02 & 2.68 & 11.3 & 2.77 & -3.4 & 8.3 \\
\hline Magnésio (mg/h) & 1.84 & 2.07 & -12.5 & 2.33 & -12.6 & -26.6 \\
\hline Manganês (mg/l) & 0.12 & 0.03 & 75.0 & 0.34 & -1033.3 & -183.3 \\
\hline Sádio (mg/1) & 7.77 & 10.16 & -30.8 & 11.92 & -17.3 & -53.4 \\
\hline Silicio $(\mathrm{mg} / \mathrm{l})$ & 5.59 & 4.91 & 12.2 & 5 & -1.8 & 10.6 \\
\hline
\end{tabular}


TABEL 11 .Dados obtidos e araliaģão da eficiência do sistema aguapé-solo filtrante. Período de amostragem: Abril/1987

\begin{tabular}{|c|c|c|c|c|c|c|}
\hline PARAMETROS & $\begin{array}{l}\text { Aqua de } \\
\text { Entrada } \\
\text { PI }\end{array}$ & $\begin{array}{c}\text { Saida } \\
\text { Canal aquapé } \\
\mathrm{P2}\end{array}$ & $\begin{array}{l}\text { Eficiência (罗) } \\
\text { Canal aquapé * }\end{array}$ & $\begin{array}{c}\text { Saida solo } \\
\text { filtrante } \\
\text { P3 }\end{array}$ & $\begin{array}{l}\text { Eficiëncia (\$) } \\
\text { Solo filtrante }\end{array}$ & $\begin{array}{l}\text { Eficencia (\$) } \\
\text { do sistema } 9\end{array}$ \\
\hline D.B.0. (mg/l) & 3.10 & 1.35 & 56.5 & 1.23 & 8.9 & 60.3 \\
\hline Coli fecal (nmp) & 43000 & 230 & 99.5 & - & - & - \\
\hline \multicolumn{2}{|c|}{ Coliforme total (nmp)' 2300000} & 4300 & 99.8 & 23000 & -434.9 & 99.0 \\
\hline Turbidez (FTU) & 29 & 1.9 & 93.4 & 1.4 & 26.3 & 952 \\
\hline $\operatorname{Cớ}(p p \bar{m}$ PtCo) & 68 & 23 & 73.9 & 20 & 13.0 & 77.3 \\
\hline Nitrato $(\mathrm{mg} / 1)$ & 0.65 & 0.26 & 60.0 & 0.19 & 26.9 & 70.8 \\
\hline N-amoniacal (mg/l) & 0.42 & 0.20 & $>95.2$ & $<0.20$ & - & $>95.2$ \\
\hline Bário (mg $/ 1)$ & 0.05 & 0.05 & 0.0 & 0.03 & 40.0 & 40.0 \\
\hline Cadmio $(m g / h)$ & $\infty .01$ & $<0.01$ & - & 0.01 & - & - \\
\hline Chumbo (mg/l) & $<0.10$ & 0.10 & - & 0.10 & - & - \\
\hline Cobre $(\mathrm{mg} / 1)$ & 0.02 & $\leftrightarrow 0.02$ & - & 0.02 & - & - \\
\hline Cromo $(\mathrm{mg} / 1)$ & 0.05 & 0.05 & - & 0.05 & . 0.0 & 0.0 \\
\hline Zinco $(\mathrm{mg} / 1)$ & $<0.02$ & $<0.02$ & - & 0.02 & - & - \\
\hline Sulfato (mg/n) & 12.6 & 11.42 & 9.4 & 13.61 & -19.2 & -8.0 \\
\hline Fósforo $(\mathrm{mg} / \mathrm{l})$ & 0.11 & 0.12 & -9.1 & 0.1 & 16.7 & 9.1 \\
\hline Cloro $(\mathrm{mg} / \mathrm{l})$ & 11.64 & 11.75 & -0.9 & 11.52 & 2.0 & 1.0 \\
\hline Aluminio (mg/1) & 0.38 & 0.16 & 57.9 & 0.15 & 6.3 & 60.5 \\
\hline Cálcio (mgh) & 6.61 & 6.72 & -1.7 & 6.16 & 8.3 & 6.8 \\
\hline Ferro $(\mathrm{mg} / 1)$ & 1.18 & 0.19 & 83.9 & 0.07 & 63.2 & 94.1 \\
\hline Potássio (mg/l) & 3.74 & 3.72 & 0.5 & 3.2 & $14.0 \ldots$ & 14.4 \\
\hline Magnésio (mg/l) & 2.15 & 2.26 & -5.1 & 1.82 & 19.5 & 15.3 \\
\hline Manganês (mg/i) & 0.09 & 0.03 & 66.7 & 0.14 & -366.7 & -55.6 \\
\hline Sódio $(\mathrm{mg} / 1)$ & 16.28 & 19.11 & -17.4 & 15.53 & 18.7 & 4.6 \\
\hline Silicio (ma/1) & 5.76 & 5.53 & 4.0 & 5.3 & 4.2 & 8.0 \\
\hline
\end{tabular}


TABEL 12.Dados obtides e araliaçäo da eficiencia do sistema aguapé-solo filtrante. Periodo de amostragem: Maio/1987

\begin{tabular}{|c|c|c|c|c|c|c|}
\hline PARAMETROS & $\begin{array}{l}\text { Agua de } \\
\text { Entrada } \\
\text { P1 }\end{array}$ & $\begin{array}{c}\text { Saida } \\
\text { Canal aquapé } \\
\$ 2\end{array}$ & $\begin{array}{l}\text { Eficiëncia (\$) } \\
\text { Canal aguapé }\end{array}$ & $\begin{array}{c}\text { Saida solo } \\
\text { filtrante } \\
\text { P3 }\end{array}$ & $\begin{array}{l}\text { Eficiencia (保) } \\
\text { Solo filtrante }\end{array}$ & $\begin{array}{l}\text { Eficencia (\$) } \\
\text { do sistema }\end{array}$ \\
\hline D.B.0. (mgil) & 4.9 & 1.11 & 77.3 & 1.01 & 9.0 & 79.4 \\
\hline Coli fecal (nmp) & 430000 & 110 & 99.9 & $<30$ & $>72.7$ & 299.9 \\
\hline Coli total (nmp) & 2.3E+07 & 9300 & 99.9 & 2100 & 77.4 & 99.9 \\
\hline Turbidez (FTU) & 140 & 31 & 77.9 & 3.2 & 89.7 & 97.7 \\
\hline Cor (ppm Ptico) & 590 & 93 & 842 & 33 & 64.5 & 34.4 \\
\hline Nitrato $(\mathrm{mg} / \mathrm{l})$ & 0.49 & 0.19 & 612 & 0.04 & 78.9 & 91.8 \\
\hline$N$-amoniacal $(\mathrm{mg} / \mathrm{l})$ & 0.20 & $\$ 0.20$ & - & $\$ .20$ & - & - \\
\hline Bório (mg $/$ ) & 0.10 & 0.05 & 50.0 & 0.03 & 40.0 & 70.0 \\
\hline Cadmio $(\mathrm{mg} / 1)$ & 80.01 & $<0.01$ & - & $\$ 0.01$ & - & - \\
\hline Chumbo (mg/l) & 0.23 & $<0.10$ & $>56.5$ & 6.10 & - & - \\
\hline Cobre $(\mathrm{mg} / \mathrm{l})$ & $\infty .02$ & 0.02 & - & $\hookleftarrow 0.02$ & - & - \\
\hline Cromo $(\mathrm{mg} / \mathrm{h})$ & 0.06 & 0.05 & 16.7 & 40.05 & - & $>16.6$ \\
\hline Zinco $(\mathrm{mg} / 1)$ & 0.06 & 0.04 & 33.3 & $\infty 0.02$ & $>50.0$ & 766.7 \\
\hline Sulfato $(\mathrm{mg} / 1)$ & 10.73 & 8.25 & 23.1 & 10.91 & -32.2 & -1.7 \\
\hline Fósforo $(\mathrm{mg} /)$ & 0.19 & 0.10 & $>47.4$ & 0.10 & - & 347.4 \\
\hline $\operatorname{Cloro}(\mathrm{mg} / 1)$ & 7.01 & 7.12 & -1.6 & 6.89 & 3.2 & 1.7 \\
\hline Aluminio ( $\mathrm{mg} / \mathrm{l})$ & 2.49 & 0.45 & 81.9 & 0.26 & 42.2 & 89.6 \\
\hline Cólcio $(\mathrm{mg} / \mathrm{h})$ & 7.04 & 6.46 & 8.2 & 6.16 & 4.6 & 12.5 \\
\hline Ferro (mg/l) & 4.43 & 0.53 & 88.0 & 0.12 & 77.4 & 97.3 \\
\hline Potássio (mg/o) & 4.33 & 4.27 & 1.4 & 3.77 & 11.7 & 12.9 \\
\hline Magnésio (mg/l) & 2.62 & 2.14 & 18.3 & 1.91 & 10.7 & 27.1 \\
\hline Manganès (mg/l) & 0.27 & 0.01 & 96.3 & 0.2 & -1900.0 & 25.9 \\
\hline Súdio $(\mathrm{mg} / \mathrm{l})$ & 10.72 & 9.51 & 11.3 & 9.87 & -3.8 & 7.3 \\
\hline Silicio $(\mathrm{mg} / \mathrm{l})$ & 7.43 & 4.99 & 32.8 & 4.89 & 2.0 & 34.2 \\
\hline
\end{tabular}


TABEL A 13.Dados obtidos e araliaģĩo da eficiência do sistema aguapé-solo filtrante. Periodo de amestragem: Junho/ 1987

\begin{tabular}{|c|c|c|c|c|c|c|}
\hline PARAMETROS & $\begin{array}{l}\text { Agua de } \\
\text { Entrada } \\
\text { P1 }\end{array}$ & $\begin{array}{c}\text { Saída } \\
\text { Canal aquapé } \\
\text { P2 }\end{array}$ & $\begin{array}{l}\text { Eficiência (安) } \\
\text { Canal aguapé }\end{array}$ & $\begin{array}{c}\text { Saida solo } \\
\text { filtrante } \\
\text { P3 }\end{array}$ & $\begin{array}{l}\text { Eficiência (\$) } \\
\text { Solo tiltrante * }\end{array}$ & $\begin{array}{l}\text { Eficência (\%) } \\
\text { do sistema }\end{array}$ \\
\hline D.B.0. (mg/i) & 5.05 & 2.33 & 53.9 & 2.11 & 9.4 & 58.2 \\
\hline Coli fecal (nmp) & 230000 & 36 & 99.9 & 36 & 0.0 & 99.9 \\
\hline Coli total (nmp) & 430000 & 430 & 99.9 & 230 & 46.5 & 99.9 \\
\hline Turbidez (FTU) & 40.5 & 7.5 & 81.5 & 2.2 & 70.7 & 94.6 \\
\hline Cor (ppm PtCo) & 138 & 50 & 63.8 & is & 64.0 & 87.0 \\
\hline Nitrato $(\mathrm{mg} / \mathrm{l})$ & 0.24 & 0.33 & -37.5 & 0.32 & 3.0 & -33.3 \\
\hline$N$-amoriacal $(\mathrm{mg} / 1)$ & 0.53 & $\$ 0.20$ & 362.3 & $\infty 0.20$ & 20.0 & $>62.2$ \\
\hline Eário (mg/1) & 0.06 & 0.05 & 16.7 & 0.03 & 40.0 & 50.0 \\
\hline Cadmio $(\mathrm{mg} / \mathrm{l})$. & $<0.01$ & $<0.01$ & - & 8.01 & - & - \\
\hline Chumbo (mg/1) & 60.10 & $<0.10$ & - & 40.10 & - & - \\
\hline Cobre (mg/l) & 0.02 & 0.02 & 0.0 & 0.02 & 0.0 & 0.0 \\
\hline Cromo (mg/1) & 40.05 & $<0.05$ & - & $\$ 0.05$ & - & - \\
\hline Zinco $(\mathrm{mg} / \mathrm{l})$ & 0.03 & $<0.02$ & 133.3 & 60.02 & - & $>33.3$ \\
\hline Sulfato $(\mathrm{mg} / 1)$ & 13.68 & 13.16 & 3.8 & 13.65 & -3.7 & 0.2 \\
\hline Fósforo (mg/l) & 0.15 & 0.10 & $>33.3$ & 0.10 & - & $\times 33.3$ \\
\hline Cloro (mg/l) & 8.81 & 8.96 & -1.7 & 9.23 & -3.0 & -4.8 \\
\hline Aluminio (mg/i) & 0.58 & 0.43 & 25.9 & 0.37 & 14.0 & 36.2 \\
\hline Cólcio (mg/1) & 6.13 & 6.27 & -2.3 & 6.52 & -4.0 & -6.4 \\
\hline Ferro $(\mathrm{mg} / 1)$ & 1.42 & 0.49 & 65.5 & 0.14 & 71.4 & 90.1 \\
\hline Potássio (mg/) & 3.5 & 3.54 & -1.1 & 3.64 & -2.8 & -4.0 \\
\hline Magnésio (mg/i) & 2.02 & 2.14 & -5.9 & 2.19 & -2.3 & -8.4 \\
\hline Manganês $(\mathrm{mg} / \mathrm{l})$ & 0.1 & 0.01 & 90.0 & 0.09 & -800.0 & 10.0 \\
\hline Sódio $(\operatorname{mg} / 1)$ & 13.32 & 13.06 & 2.0 & 13.19 & -1.0 & 1.0 \\
\hline Silicio (mg/l) & 5.83 & 3.51 & 39.8 & 5.21 & -48.4 & 10.6 \\
\hline
\end{tabular}


TABEL $\$$ 14. Dados obtidos e araliaçāo da eficiência do sistema de solos filtrantes consecutiros.

Periode de amostragem: junho/ 1986.

\begin{tabular}{|c|c|c|c|}
\hline PARAMETROS & $\begin{array}{c}\text { Aqua de } \\
\text { Entrada } \\
\text { P1 }\end{array}$ & $\begin{array}{c}\text { Saida } \\
\text { Solo filtrante } \\
\text { P2 }\end{array}$ & $\begin{array}{l}\text { Eficiência (品) } \\
\text { do sistema }\end{array}$ \\
\hline $0.8 .0 .(\mathrm{mg} / 1)$ & 5.54 & 1.01 & 81.8 \\
\hline Coli fecal (nmp) & 93000 & 23000 & 75.3 \\
\hline Coli total (nmp) & 430000 & 23000 & 94.7 \\
\hline Turbidez (FTU) & 16.4 & 4.5 & 72.6 \\
\hline Cor (ppm PtCo) & 56 & 25 & 55.4 \\
\hline Mitrato $(\mathrm{mg} / \mathrm{l})$ & 0.27 & 0.88 & -225.9 \\
\hline N-amoniacal (mg/l) & & 0.20 & 387.4 \\
\hline Bário (mg/l) & 0.28 & 0.37 & -32.1 \\
\hline Cadmio (mg/h) & $<0.01$ & 0.01 & - \\
\hline Chumbo (mg/l) & $<0.10$ & 6.10 & - \\
\hline Cobre $(m g / 1)$ & $<0.02$ & $\infty .02$ & - \\
\hline Cromo (mg/) & 0.06 & 0.07 & -16.7 \\
\hline Zinco $(\mathrm{mg} / 1)$ & 0.04 & $<0.02$ & $>50.0$ \\
\hline Sulfato (mg/l) & 29.73 & 31.78 & -6.9 \\
\hline Fósforo $(\mathrm{mg} / 1)$ & 0.19 & 0.12 & 36.8 \\
\hline Cloro $(\mathrm{mg} / \mathrm{l})$ & 23.27 & 23.94 & -2.9 \\
\hline Aluminio (mg/l) & 0.48 & 0.32 & 33.3 \\
\hline Cólcio (mg/l) & 10.06 & 8.55 & 15.0 \\
\hline Ferra $(\mathrm{mg} / 1)$ & 1.06 & 0.2 & 81.1 \\
\hline Potássio $(\mathrm{mg} / \mathrm{l})$ & 4.19 & 4.77 & -13.8 \\
\hline Magnesio (mgll) & 3.02 & 2.68 & 11.3 \\
\hline Manganês (mg/1) & 0.21 & 0.02 & 90.5 \\
\hline Sódio $(\mathrm{mg} / \mathrm{l})$ & 32.34 & 32.41 & -0.2 \\
\hline Silicio (mg/1) & 5.53 & 3.72 & 32.7 \\
\hline
\end{tabular}

* [(P1-P2)/P1].100 
TABEL 15. Dados obtidos e araliaçäo da eficiencia do sistema de solos filtrantes consecutivos.

Periode de amostragem: julho/1986.

\begin{tabular}{|c|c|c|c|}
\hline PARAMETROS & $\begin{array}{l}\text { Agua de } \\
\text { Entrada } \\
\text { Pl }\end{array}$ & $\begin{array}{c}\text { Saida } \\
\text { Solo fittrante } \\
\text { P2 }\end{array}$ & $\begin{array}{l}\text { Eficiênoia (\$6) } \\
\text { do sistema }\end{array}$ \\
\hline D.8.0. (nog/) & 4.36 & 0.75 & 82.8 \\
\hline Coli fecal (nmp) & 39000 & 110 & 99.7 \\
\hline Coli total (nmp) & 75000 & 4300 & 94.3 \\
\hline Turbidez (FTU) & 12.3 & 2.1 & 82.9 \\
\hline Cor (ppm PtCo) & 50 & 25 & 500.0 \\
\hline Nitrato $(\mathrm{mg} / \mathrm{l})$ & 0.59 & 0.91 & -54.2 \\
\hline N-amoniacal (mg/l) & 1.64 & 0.20 & $>87.8$ \\
\hline Bário (mg/1) & 0.23 & 0.14 & 39.1 \\
\hline Cadmio (mg/l) & 0.01 & 0.01 & - \\
\hline Chumbo (mg/l) & 40.10 & $<0.10$ & - \\
\hline Cobre (mag/l) & $\$ 0.02$ & $<0.02$ & - \\
\hline Cromo $(\mathrm{mg} / \mathrm{h})$ & $<0.05$ & 0.05 & - \\
\hline Zineo $(\mathrm{mg} / 1)$ & 0.02 & $<0.02$ & - \\
\hline Sulfato $(\mathrm{mg} / \mathrm{l})$ & 28.65 & 29.31 & -2.3 \\
\hline Fósforo $(\mathrm{mg} / \mathrm{l})$ & .0 .16 & 0.10 & $>37.5$ \\
\hline Cloro (mg/) & 21.49 & 2224 & -3.5 \\
\hline Aluminio $(\mathrm{mg} / \mathrm{l})$ & 0.47 & 0.21 & 55.3 \\
\hline Cólcio (mg/l) & 92 & 9.75 & -6.0 \\
\hline Ferra $(\mathrm{mg} / 1)$ & 0.68 & 0.17 & 75.0 \\
\hline Potóssio (mg/) & 4.26 & 3.96 & 7.0 \\
\hline Magnésio (mg/h) & 2.22 & 2.81 & -26.6 \\
\hline Manganès (mg/l) & 0.06 & $\infty .01$ & 283.3 \\
\hline Sódio $(m g / 1)$ & 29.68 & 29.25 & 1.4 \\
\hline Silicio (mg/l) & 5.14 & 4.41 & 142 \\
\hline
\end{tabular}

$*[(\mathrm{P} 1-\mathrm{P} 2) / \mathrm{P} 1] .100$ 
T ABEL A 16. Dados obtidos ayaliagāo da eficiencia do sistema de solos filtrantes consecutiyos.

Periodo de amostragem: agosto 1986.

\begin{tabular}{|c|c|c|c|}
\hline PARAMETROS & $\begin{array}{l}\text { Áqua de } \\
\text { Entrada } \\
\text { P! }\end{array}$ & $\begin{array}{c}\text { Saida } \\
\text { Solo filtrante } \\
\text { P2 }\end{array}$ & $\begin{array}{l}\text { Eficiência (\$) } \\
\text { do sistema }\end{array}$ \\
\hline D.B.0. $(\mathrm{mg} / \mathrm{l})$ & 6.43 & 0.86 & 86.6 \\
\hline Coli focal (nmp) & 430000 & 4671 & 98.9 \\
\hline Coli total (nmo) & $1.2 E+07$ & 116050 & 99.1 \\
\hline Turbidez (FTU) & 11.62 & 1.36 & 68.3 \\
\hline Prpm PtCoi & 73 & 22 & 59.9 \\
\hline intrato tmailo & 0.22 & 0.87 & -295.5 \\
\hline 7- & 2.2 & 0.20 & $: 90.9$ \\
\hline Earo $1 \mathrm{mg} / \mathrm{ll}$ & 0.08 & 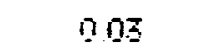 & 62.5 \\
\hline Eumio inga & 001 & 0.01 & - \\
\hline Hunbo main) & 0.10 & 0.10 & - \\
\hline Coto imọill & $\sin$ & 00.02 & - \\
\hline Eromo ingily & 0.05 & 0.05 & - \\
\hline Eines img/1) & 9.92 & 0.02 & - \\
\hline suifato (mg/i) & 32.11 & 32.34 & -5.7 \\
\hline Fusforo $(\mathrm{mg} / \mathrm{l})$ & 0.10 & 0.10 & - \\
\hline Oloro $(\mathrm{mg} / \mathrm{l})$ & 25.33 & 24.56 & 310 \\
\hline Aiumnno (nogil) & 0.36 & 0.13 & 6.9 \\
\hline Golowo (mg/) & 9.95 & 11.00 & -11.4 \\
\hline Ferro (mg/l) & 0.77 & 0.15 & 80.5 \\
\hline Fotóssio (mg/) & 4.35 & 4.23 & 2.3 \\
\hline Magnesio (mg/l) & 2.34 & 3.03 & -29.5 \\
\hline Mang̣anès (mogl) & 0.15 & 0.02 & 84.6 \\
\hline Sodio $(\mathrm{rrg} / \mathrm{l})$ & 33.47 & 31.67 & 5.4 \\
\hline Silioio $(\mathrm{mg} / \mathrm{l})$ & 5.97 & 4.73 & 20.8 \\
\hline
\end{tabular}

$*[(P 1-P 2) / P 1] .100$ 
TABEL \& 17. Dados obtidos e ayaliağüo da eficiencia do sistema de solos filtrantes sonsecutiyos.

Periodo de amostragen: norembro 1986.

\begin{tabular}{|c|c|c|c|}
\hline FAFAMETROS & $\begin{array}{c}\text { Hụu de } \\
\text { Eitroda } \\
\text { F! }\end{array}$ & $\begin{array}{c}\text { Saida } \\
\text { Solo fintr snte } \\
\text { P2 }\end{array}$ & $\begin{array}{l}\text { Eficiëncla }(\mathrm{s}) \\
\text { dü sieterns }\end{array}$ \\
\hline DE.O. (moii) & 5.25 & 0.78 & 85.1 \\
\hline Wit foral (nmo) & 4300 & $=40$ & 54.4 \\
\hline Coili total inmai & 430000 & 9800 & 978 \\
\hline Turbidee (FTU) & 12.65 & 2.34 & 81.5 \\
\hline $\mathrm{OP}$ (ppm P+Co) & $\leq 3$ & 26 & 58.7 \\
\hline Witra to imgilj & $0.3 i$ & 0.37 & 0.0 \\
\hline M-amóniacal (nog/l) & 1.74 & 020 & 298.5 \\
\hline Eario $(\mathrm{mg} / \mathrm{l}$ & 0.13 & 0.04 & 69.2 \\
\hline Sodmio img/i) & 0.01 & 0.01 & - \\
\hline Chumbo (ng/l) & 0.10 & 0.10 & - \\
\hline Cobre (mg/1) & 0.015 & 0.02 & $\times 33.3$ \\
\hline Cromo (mg/i) & 0.05 & - & - \\
\hline Zinco (mq/l) & 0.02 & 0.02 & - \\
\hline Sulfato (mg/l) & 17.71 & 19.94 & -12.6 \\
\hline Fúsforo $(\mathrm{mg} / 1)$ & 0.27 & 0.10 & 265.0 \\
\hline Cloro (mg/i) & 26.27 & 22.12 & 15.8 \\
\hline Ảurninio $(\operatorname{mg} / 1)$ & 0.45 & 0.25 & 44.4 \\
\hline Gilcio (mgil) & 11.12 & 13.55 & -22.6 \\
\hline Forro (mg/1) & 0.89 & 0.1 & 88.8 \\
\hline Fatássio (rmaly) & 7.03 & 5 & 14.7 \\
\hline Magnesio (mg/a) & 29 & 359 & -31.8 \\
\hline Manuanes imọ $/ 1$ & 0.18 & 00.01 & 294.4 \\
\hline Sodio $(\operatorname{mog} /)$ & 41.67 & $32.5 i$ & 2.4 \\
\hline Ellowo imno & 5.31 & 546 & -28 \\
\hline
\end{tabular}

$+[(P 1-P 2): P 1 ! .100$ 
TABEL A 18. Dados obtidos e araliaģäo da eficiència do sistema de solos filtrantes gonsecutiyos.

Periodo de amosiragem: dezembro/1986.

\begin{tabular}{|c|c|c|c|}
\hline PARAMETROS & $\begin{array}{l}\text { Agula de } \\
\text { Eritrada } \\
\text { Pl }\end{array}$ & $\begin{array}{c}\text { Saida } \\
\text { Solo filtrante } \\
\text { F2 }\end{array}$ & $\begin{array}{l}\text { Eficiëncis }(8) \\
\text { do sistema }\end{array}$ \\
\hline 0.B.0. (rngil) & 4.9 & 1.72 & 64.9 \\
\hline Coli fecal (nmp) & 23000 & 430 & 98.1 \\
\hline Goli tatal (nmp) & 2300000 & 23000 & 99.0 \\
\hline Turbidez (FTU) & 128.6 & 17.25 & 86.6 \\
\hline Cor fam P+Co! & 237 & 56 & 80.5 \\
\hline Nitrato (mọ/i) & 0.52 & 0.01 & 299.1 \\
\hline A-anamiacos (moll) & 0.48 & 0.20 & 50.3 \\
\hline Bario (moglig) & 0.07 & 0.04 & 42.9 \\
\hline Coumo (ma/l) & 0.01 & 0.01 & - \\
\hline Chumbo ingil) & 0.10 & 0.10 & - \\
\hline Cotre (mugil) & 0.02 & 0.02 & - \\
\hline Erorino imgio & 0.05 & .0 .05 & - \\
\hline Finen (mall) & 0.04 & 000 & 500 \\
\hline Sulfoto inua & 11.29 & 11.15 & 1.4 \\
\hline Fusforo (ring/l) & 0.10 & 0.10 & - \\
\hline cloro (mgilo & 646 & 603 & 5.7 \\
\hline Hiluntrio (notid) & 1.12 & 0.27 & 75.9 \\
\hline $8000(\mathrm{mg} h)$ & 5.94 & 11.60 & -963 \\
\hline Ferrotng/l) & 2.44 & 0.23 & 90.6 \\
\hline Fotássio (mgic) & 3.6 & 4.19 & -16.4 \\
\hline Magnésio (mg/l) & 1.91 & 3.14 & -64.4 \\
\hline Manganès (mạili) & 0.14 & 0.19 & -35.7 \\
\hline Südio $(\operatorname{ming} / 1)$ & 9.64 & 12.82 & -33.0 \\
\hline Silino (mall) & 4.84 & 5.73 & -18.4 \\
\hline
\end{tabular}

$\div[(P 1-P 2) / P 1] 100$ 
TABEL A 19. Dados obtidos a ayaliaçö́ da efietência do sistema de solos filtrantes consecutivos.

Periodo de amostragem: janeirof 1987.

\begin{tabular}{|c|c|c|c|}
\hline PARAMETROS & $\begin{array}{c}\text { Agua de } \\
\text { Entrada } \\
\text { PI }\end{array}$ & $\begin{array}{c}\text { Saida } \\
\text { Solo filtr ante } \\
\text { P2 }\end{array}$ & $\begin{array}{l}\text { Eficiência (\$6) } \\
\text { do sistema }\end{array}$ \\
\hline D.B.0. $(\mathrm{mg} / \mathrm{l})$ & 3.9 & 1.3 & 66.7 \\
\hline Coli fecal (nmp) & 379650 & 115 & 99.9 \\
\hline Coli total (nmp) & 1165000 & 11955 & 99.0 \\
\hline Turbidez (FTU) & 129 & 12.45 & 90.3 \\
\hline Cor (ppm PtCo) & 590 & 56 & 85.6 \\
\hline Nitrato (mg/) & 0.47 & 0.11 & 76.6 \\
\hline H-amoniacal (mg/l) & 0.31 & $<0.20$ & $>35.5$ \\
\hline Bario (mg/l) & 0.08 & 0.05 & 37.5 \\
\hline Cadmio (mg/) & $<0.01$ & $<0.01$ & - \\
\hline Chumbo $(\mathrm{mg} / 1)$ & 0.10 & 40.10 & - \\
\hline Cobre $(\mathrm{mg} / \mathrm{l})$ & 0.03 & 40.02 & 233.3 \\
\hline Cromo $(\mathrm{mg} / 1)$ & $<0.05$ & $<0.05$ & - \\
\hline Zinco $(\mathrm{mg} / \mathrm{l})$ & 0.03 & 0.02 & 33.3 \\
\hline Sulfato (mg/l) & 11.78 & 7.83 & 33.5 \\
\hline Fósforo (mg/l) & 0.12 & 0.10 & $>16.7$ \\
\hline Cloro (mg/i) & 6.33 & 4.78 & 24.5 \\
\hline Aluminio $(\mathrm{mg} / \mathrm{l})$ & 0.94 & 0.18 & 80.9 \\
\hline Cóleio $(\mathrm{mg} / 1)$ & 6.59 & 13.6 & -106.4 \\
\hline Ferro $(m g / h)$ & 4.41 & 0.52 & 88.2 \\
\hline Potássio (mgh) & 3.87 & 4.1 & -5.9 \\
\hline Magnésio (mg/l) & 2.15 & 3.81 & -77.2 \\
\hline Manganês ( $\mathrm{mg} / \mathrm{l}$ ) & 0.14 & 0.75 & -435.7 \\
\hline Sódio $(m g / 1)$ & 9.31 & 8.83 & 5.2 \\
\hline Silicio (mg/l) & 5.86 & 5.96 & -1.7 \\
\hline
\end{tabular}

$*[(P 1-P 2) / P 1] .100$ 
TABEL 20 . Dados abtidos e ayaliaçón da eficitencia do sistema de solos filtrantes consecutivos.

Periodo de amostragem: feyereiro/1987.

\begin{tabular}{|c|c|c|c|}
\hline PARAMETROS & $\begin{array}{l}\text { Agua de } \\
\text { Entrada } \\
\text { P1 }\end{array}$ & $\begin{array}{c}\text { Saida } \\
\text { Solo filtrante } \\
\text { P2 } \\
\end{array}$ & $\begin{array}{l}\text { Eficiência }(\mathbb{8}) \\
\text { do sistema }\end{array}$ \\
\hline $0.8 .0 .(\mathrm{mg} / \mathrm{l})$ & - & - & - \\
\hline Coli fecal (nmp) & 9300 & 830 & 299.7 \\
\hline Coli total (nmp) & 230000 & 2300 & 99.0 \\
\hline Turbidez (FTU) & 104.5 & 4.2 & 96.0 \\
\hline Cor (ppm FiCo) & 317 & 30 & 30.5 \\
\hline Bitrato (ma/l) & 1.35 & 3.4 & -151.9 \\
\hline N-amoniacal ( $\mathrm{mg} / \mathrm{l})$ & 0.27 & $\infty .20$ & $>25.9$ \\
\hline Bario (mg/7) & 0.04 & 0.01 & 75.0 \\
\hline Cadmio (mg/l) & 0.01 & 0.01 & - \\
\hline Chumbo (mg/l) & 0.10 & $0.10^{\circ}$ & - \\
\hline Cobre (mg/l) & 0.02 & 0.02 & - \\
\hline Cromo $(\mathrm{mg} / 1)$ & 0.05 & $<0.05$ & - \\
\hline Zinco $(\mathrm{mg} / 1)$ & 0.04 & 0.22 & -450.0 \\
\hline Sulfato $(\mathrm{mg} / \mathrm{l})$ & 9.54 & 3.42 & 64.2 \\
\hline Fósforo (mg/i) & 0.1 & 0.1 & 0.0 \\
\hline Cloro (mg/l) & 3.5 & 3.84 & -9.7 \\
\hline Aluminio $(\mathrm{mg} / 1)$ & 2.01 & 0.1 & 95.0 \\
\hline Cólcio (mg/i) & 4.64 & 8.51 & -83.4 \\
\hline Ferro $(\mathrm{mg} / 1)$ & 3.11 & 0.46 & 85.2 \\
\hline Potóssio $(\mathrm{mg} / \mathrm{l})$ & 2.72 & 1.76 & 35.3 \\
\hline Magnésio (mg/1) & 1.79 & 2.52 & -40.8 \\
\hline Manganès (mg/l) & 0.17 & 0.18 & -5.9 \\
\hline Sódio (mg/l) & 7.15 & 7.15 & 0.0 \\
\hline Silicio (ma/1) & 4.4 & 2.25 & 48.9 \\
\hline
\end{tabular}

$*[(\mathrm{P} 1-\mathrm{P} 2) / \mathrm{P} 1] .100$ 
TABEL h 21 . Dados obtidos a araliagóo da eficiência do sistema de solos filtrantes consecutivos.

Periodo de amostragem: margo/1987.

\begin{tabular}{|c|c|c|c|}
\hline PARAMETROS & $\begin{array}{l}\text { Aqua de } \\
\text { Entrada } \\
\text { Pl }\end{array}$ & $\begin{array}{c}\text { Saida } \\
\text { Solo filtrante } \\
F_{2} \\
\end{array}$ & $\begin{array}{l}\text { Eficiência (\$6) } \\
\text { do sistema }\end{array}$ \\
\hline O.E.0. $(\mathrm{mg} / 1)$ & 3.75 & 1.47 & 60.8 \\
\hline Coli fecal (nmp) & - & - & - \\
\hline Coli total (nmp) & 430000 & 9300 & 97.8 \\
\hline Turbidez (FTU) & 87 & 10.05 & 88.4 \\
\hline Cor (ppm PtCo) & 324 & 53 & 83.6 \\
\hline Nitrato $(\mathrm{mg} / \mathrm{l})$ & 0.54 & 0.04 & 92.6 \\
\hline N-amoniacal (mg/1) & 0.32 & 0.20 & $>37.5$ \\
\hline Bario $(\mathrm{mg} / \mathrm{l})$ & 0.05 & 0.02 & 60.0 \\
\hline Cadmio (mg/1) & 0.01 & 0.01 & - \\
\hline Chumbo $(\mathrm{mg} / \mathrm{l})$ & 0.13 & 40.10 & $>23.1$ \\
\hline Cabre $(\mathrm{mg} / 1)$ & 0.02 & $<0.02$ & - \\
\hline Cromo (mg/1) & 0.05 & $<0.05$ & - \\
\hline Zinco $(\mathrm{mg} / \mathrm{l})$ & 0.04 & $<0.02$ & $->50.0$ \\
\hline Sulfato (ma $/ 1)$ & 3.01 & 3.69 & -22.6 \\
\hline Fósforo $(\mathrm{mg} / \mathrm{l})$ & 0.13 & $\$ 0.10$ & 323.1 \\
\hline Cloro (mg/1) & 6.85 & 6.73 & 1.8 \\
\hline Alurninio $(\mathrm{mg} / \mathrm{l})$ & 1.23 & 0.24 & 80.5 \\
\hline Cólcio $(\mathrm{mg} / 1)$ & 5.39 & 8.26 & -53.2 \\
\hline Ferro $(m g / 1)$ & 2.13 & 0.59 & 72.9 \\
\hline Potóssio (mg/1) & 3.02 & 2.83 & 6.3 \\
\hline Magnésio (mg/l) & 1.84 & 2.3 & -25.0 \\
\hline Manganès $(\mathrm{mo} / \mathrm{l})$ & 0.12 & 0.53 & -341.7 \\
\hline Sádio $(m g / 1)$ & 7.77 & 11.23 & -44.5 \\
\hline Silicio (mg/1) & 5.59 & 4.74 & 15.2 \\
\hline
\end{tabular}

$*[(\mathrm{P} 1-\mathrm{P} 2) / \mathrm{P} 1] .100$ 
TABEL A 22. Dados obtidos e araliaçäo da efieitencia do sistema de solos filtrantes consecutiros.

Periodo de amostragem: abril/1987.

\begin{tabular}{|c|c|c|c|}
\hline PARAMETROS & $\begin{array}{l}\text { houa de } \\
\text { Entrada } \\
\text { P1 }\end{array}$ & $\begin{array}{c}\text { Saida } \\
\text { Sola filtrante } \\
\text { P2 }\end{array}$ & $\begin{array}{l}\text { Eficiência (呆) } \\
\text { do sistema * }\end{array}$ \\
\hline D.B.0. $(\mathrm{mg} / 1)$ & 3.1 & - & - \\
\hline Coli fecol (nmp) & 43000 & 23000 & 46.5 \\
\hline Coli total (nmp) & 2300000 & 23000 & 99.0 \\
\hline Turbidez (FTU) & 29 & 4.03 & 86.1 \\
\hline $\operatorname{Cor}($ ppm P+Co) & 88 & 25 & 75.9 \\
\hline Nitrato (mg/l) & 0.65 & 0.48 & 26.2 \\
\hline N-amoniacal $(\mathrm{mg} / 1)$ & 0.42 & 0.20 & $>52.4$ \\
\hline Bario (mg/l) & 0.05 & 0.03 & 40.0 \\
\hline Cadmio (mg/i) & 0.01 & $<0.01$ & - \\
\hline Chumbo (mg/1) & 0.10 & 0.10 & - \\
\hline Cobre $(\mathrm{mg} / \mathrm{l})$ & 0.02 & $<0.02$ & - \\
\hline Cromo (mg/i) & 0.05 & 0.05 & 0.0 \\
\hline Zinco $(m g / 1)$ & $<0.02$ & 0.02 & - \\
\hline Sulfato (mg $h)$ & 12.6 & 18.47 & -46.6 \\
\hline Fósfora $(m g / l)$ & 0.11 & $<0.10$ & $>9.1$ \\
\hline Cloro $(\mathrm{mg} / \mathrm{l})$ & 11.64 & 12.32 & -5.8 \\
\hline Aluminio $(\mathrm{mg} / \mathrm{l})$ & 0.38 & 0.18 & 52.6 \\
\hline Cóleto (mg/i) & 6.61 & 8.39 & -26.9 \\
\hline Ferro (mg/1) & 1.18 & 0.39 & 66.9 \\
\hline Potássio (mg/l) & 3.74 & 4.23 & -13.1 \\
\hline Magnésio (mg/l) & 2.15 & 2.55 & -18.6 \\
\hline Manganês (mg/1) & 0.09 & 0.23 & -155.6 \\
\hline Sódio $(m g / 1)$ & 16.28 & 15.78 & 3.1 \\
\hline Silicio (mg/l) & 5.76 & 6.09 & -5.7 \\
\hline
\end{tabular}

* [(P1-P2)/P1].100 
TABELA 23. Dados obtidos e araliaçäo da eficiència do sistema de solos filtrantes consecutiros.

Período de amostragem: maio/1987.

\begin{tabular}{|c|c|c|c|}
\hline PARAMETROS & $\begin{array}{l}\text { Agua de } \\
\text { Entrada } \\
\text { P1 }\end{array}$ & $\begin{array}{c}\text { Saída } \\
\text { Solo filtrante } \\
\mathrm{F} 2 \\
\end{array}$ & $\begin{array}{l}\text { Eficiência (\$) } \\
\text { do sistema }\end{array}$ \\
\hline D.B.0. $(\mathrm{mg} / 1)$ & 4.9 & 1.66 & 66.1 \\
\hline Coli fecal (nmp) & 430000 & $<30$ & 399.9 \\
\hline Coli total (nmp) & $2.3 E+07$ & 4300 & 99.9 \\
\hline Turbidez (FTU) & 140 & 51 & 63.6 \\
\hline Cor (ppm PtCo) & 590 & $2 \vec{r}$ & 95.4 \\
\hline Nitrato $(\mathrm{mg} / \mathrm{l})$ & 0.49 & 0.25 & 49.0 \\
\hline N-amoniacal (mg/l) & $<.20$ & $<0.20$ & - \\
\hline Bario $(\mathrm{mg} / \mathrm{l})$ & 0.10 & 0.04 & 60.0 \\
\hline Cadmio (mg/1) & 0.01 & $<0.01$ & - \\
\hline Chumbo $(\mathrm{mg} / \mathrm{l})$ & 0.23 & 0.10 & $>56.5$ \\
\hline Cobre $(\mathrm{mg} / 1)$ & 0.02 & 0.02 & - \\
\hline Cromo (mg $h)$ & 0.06 & $<0.05$ & 316.7 \\
\hline Zinco $(\mathrm{mg} / \mathrm{l})$ & 0.06 & 0.03 & 50.0 \\
\hline Sulfato (mg/i) & 10.73 & 14.35 & -33.7 \\
\hline Fásforo $(\mathrm{mg} / \mathrm{l})$ & 0.19 & $\infty .10$ & 347.4 \\
\hline Cloro $(\mathrm{mg} / \mathrm{l})$ & 7.01 & 6.77 & 3.4 \\
\hline Aluminio $(\mathrm{mg} / \mathrm{l})$ & 2.49 & 0.55 & 77.9 \\
\hline Cólcio (mg/1) & 7.04 & 5.91 & 16.1 \\
\hline Ferro (mg/l) & 4.43 & 0.72 & 83.7 \\
\hline Potóssio (mg/1) & 4.33 & 3.92 & 9.5 \\
\hline Magnésio (mg/l) & 2.62 & 1.99 & 24.0 \\
\hline Manganës (mg/1) & 0.27 & 0.14 & 48.1 \\
\hline Sódio (mg/l) & 10.72 & 10.35 & 3.5 \\
\hline Silicio $(\mathrm{ma} / \mathrm{l})$ & 7.43 & 5.81 & 21.8 \\
\hline
\end{tabular}

$*[(\mathrm{P} 1-\mathrm{P} 2) / \mathrm{P} 1] .100$ 
TABEL A 24. Dados obtidos e araliaçũo da eficiencia do sistema de solos filtrantes consecutiyos.

Periodo de amostragem: JUNHO/1987.

\begin{tabular}{|c|c|c|c|}
\hline PARAMETROS & $\begin{array}{l}\text { Aqua de } \\
\text { Entrada } \\
\text { P1 }\end{array}$ & $\begin{array}{c}\text { Saida } \\
\text { Solo filtrante } \\
\text { P2 }\end{array}$ & $\begin{array}{l}\text { Eficiência (8) } \\
\text { do sistema }\end{array}$ \\
\hline D.B.O. (mg/o) & 5.05 & 2.41 & 52.3 \\
\hline Coli fecal (nmp) & 23000 & 30 & $>99.9$ \\
\hline Coli total (nmp) & 430000 & 1500 & 99.7 \\
\hline Turbidez (FTU) & 40.5 & 6.4 & 84.2 \\
\hline Cor (ppm PtCo) & 138 & 30 & 78.3 \\
\hline Nits atu (my $/ 1)$ & 0.24 & 0.10 & 58.3 \\
\hline $\mathrm{N}$-amoniacal $(\mathrm{mg} / \mathrm{l})$ & 0.53 & $<0.20$ & $>62.3$ \\
\hline Baria (mg/l) & 0.06 & 0.03 & 50.0 \\
\hline Cadmio $(\mathrm{mg} / \mathrm{l})$ & 0.01 & 0.01 & - \\
\hline Chumbo $(\mathrm{mg} / \mathrm{l})$ & 0.10 & $<0.10$ & - \\
\hline Cabre (mg/) & 0.02 & $<0.02$ & - \\
\hline Cromo (mg/l) & $\infty .05$ & 40.05 & - \\
\hline Zinco $(\mathrm{mg} / \mathrm{l})$ & 0.03 & 60.02 & $>33.3$ \\
\hline Sulfato (mg $/$ ) & 13.68 & 14.07 & -2.9 \\
\hline Fósforo (mg/l) & 0.15 & $<0.10$ & $>33.3$ \\
\hline Chora $(\mathrm{mg} / 1)$ & 8.81 & 9.02 & -2.4 \\
\hline Aluminio $(\mathrm{mg} / \mathrm{l})$ & 0.58 & 0.41 & 29.3 \\
\hline Cálcio (mg/i) & 6.13 & 5.5 & 10.3 \\
\hline Ferro (mg/l) & 1.42 & 0.3 & 78.9 \\
\hline Potássio (mg/l) & 3.5 & 3.76 & -7.4 \\
\hline Magnésio (mg/h) & 2.02 & 2.14 & -5.9 \\
\hline Manganês (mg/l) & 0.1 & 0.12 & -20.0 \\
\hline Sódio (mg/l) & 13.32 & 12.31 & 7.6 \\
\hline Silicio (mg/l) & 5.83 & 5.21 & 10.6 \\
\hline
\end{tabular}

$*[(\mathrm{P} 1-\mathrm{P} 2) / \mathrm{P} 1] .100$ 


\section{כ. ANALISE [ DISCUSSAODOS DADUS OETIDOS}

\section{S. i Lficiencia dos processos estudodos}

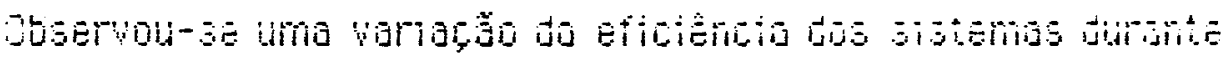

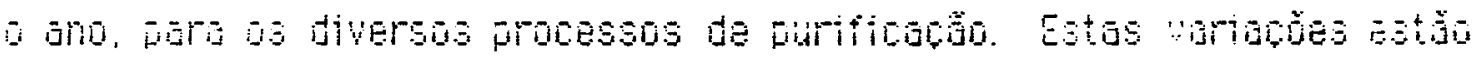
igadis principalmente ans processus biolugicos alse be desenvolwem. como: fises de desenvolvimento das plantas flutiantes e do srrá; Jimensöes do sistema ridicular; necessidades isiobigicos das piantas; atividades morobiologicas associadas; energia solar dispinival:

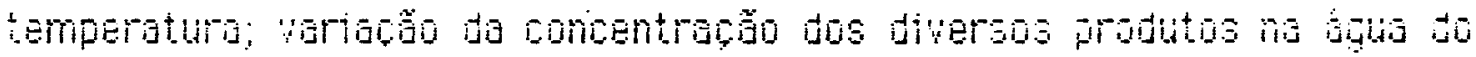
iio, Etic.

5. I. I sistemo $I$ : conal com aguape a salas filtrontes

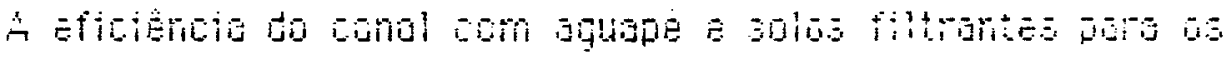

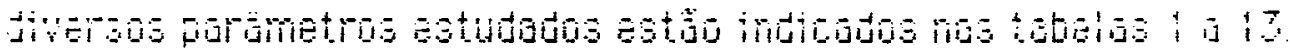

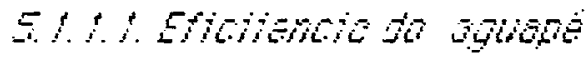

otsevou-se que a efictencia do canal de ogupe, para os 


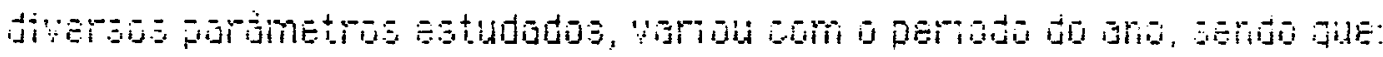

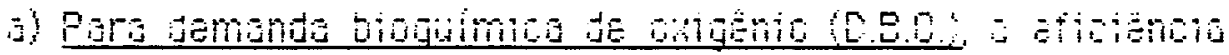

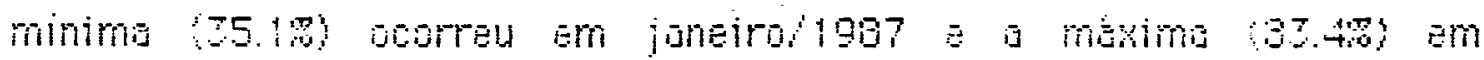
junhu/ 1906.

5) Para colifomes fecais a eficiencio minmos (78. 4 io ocorred em nuvembro/1986 a a maxima (99.98) nos meses te juho, agosto.

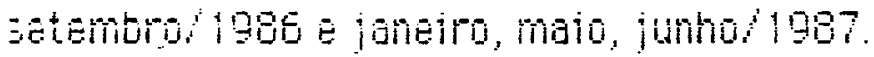

b) Para colifarmes totais a eficiencia minima (74.78) bcorreu em novembro/1900 e a móxima (99.98) nos meses de jgosto, setembro/1966 e maio, junho/1987.

d) Pari turbidez, a eficiencia mimima $50.8 \%$ soutreu em deaenoro 1906 e a móxima $(98,4 \%)$ em atrili 1907.

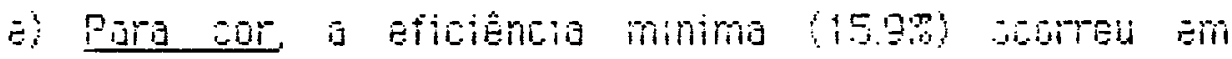

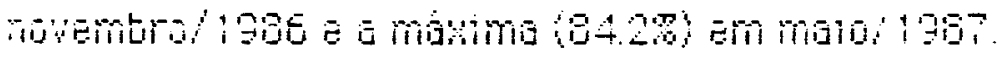

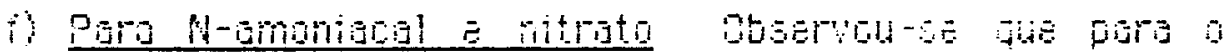

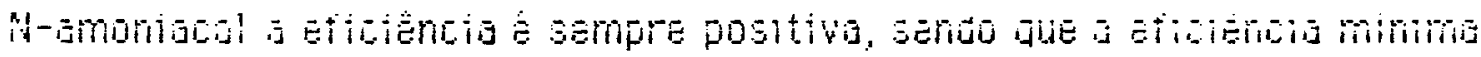

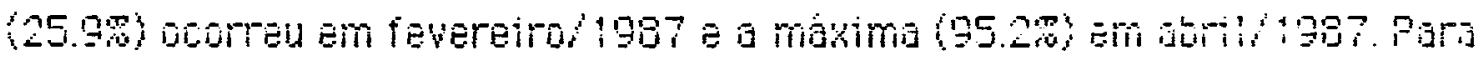
o nitrato a eficiencia mínima (40.7\%) ucorreu em fevereiro 1907 a a mínima (91.98), em novembro/1986. Entretanto observou-se que js teores de nitrato aumentaram no canal de aguapé em alguns meses dö ano. Este aumento pode ser devido a dois mecanismos:

- transformação da amònia em nitrato;

- decomposiçõ̃o da materia orgânica, associada a um processo Je dinitrificoç̃o.

7) Para ierro, aluminia manganes e bária doserwou-se awe a

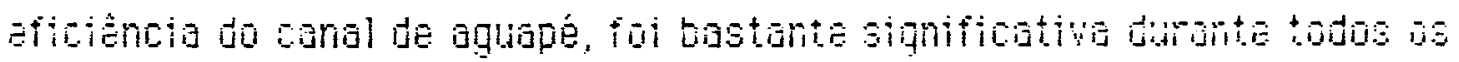


meses do ano. Somente no mes de junho/ 1986 , observou-se um aumento de $25 \%$ do barro no canal com aguapé.

1) Para cadimio chumbo cobre cromo a zinco otservou-se que a concentraço destes elementos na agua de entrata do sistema, no

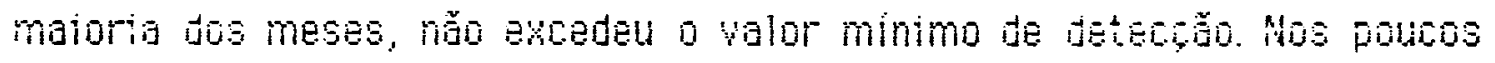

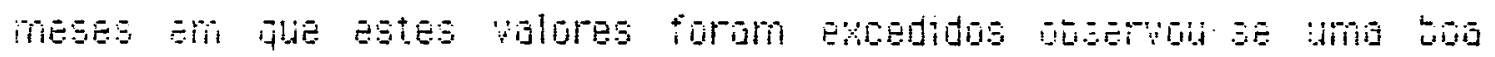

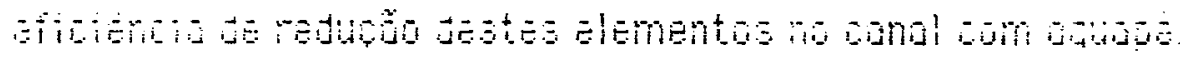

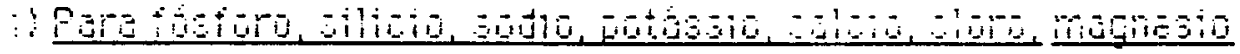

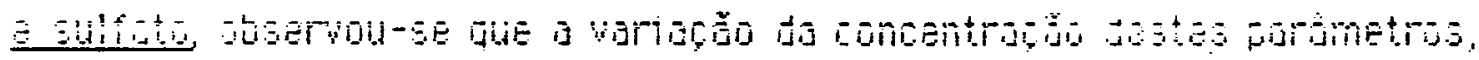

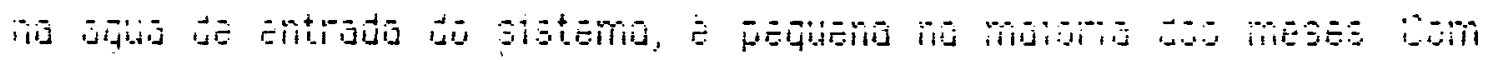

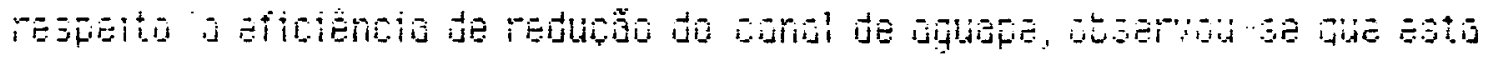

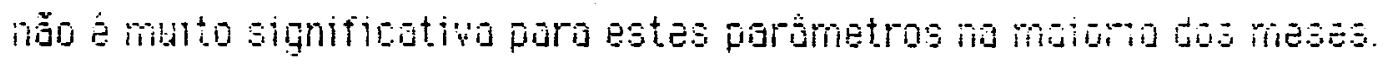

5. t.2. Enothoi do awo hionte

Doservou-se que a eficiência do solo filtrante piara os diversos paràmetros analisados, variou com o periodo do ano, sendo que:

a) Para demanda bioquimica de oxigento (0.8.0. no eficiencia minima (8.98) ocorreu em abril/1987 e a máxima (75.28) em jgosto 1906. Dbservou-se também um aumnto de $9.9 \%$ no mès de jineirot 967 do D.8.0. no solo iiltrante.

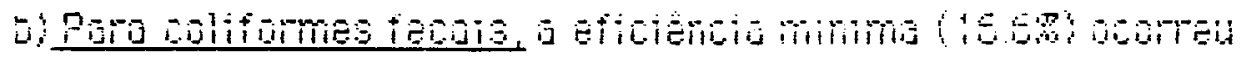

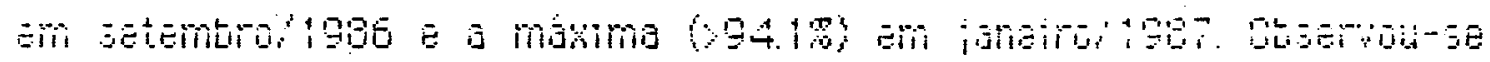

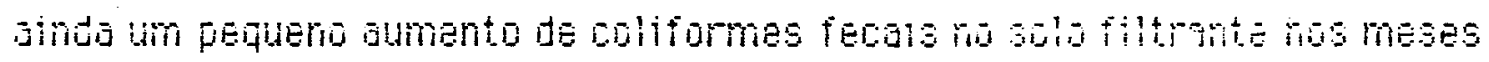
de junho, julho/196s. Este aumento deve ter boorido pela fito de se

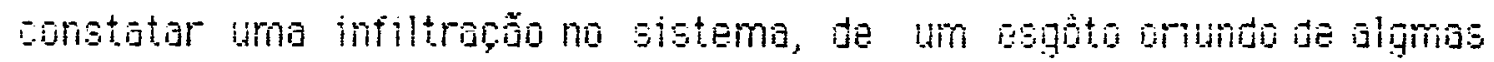




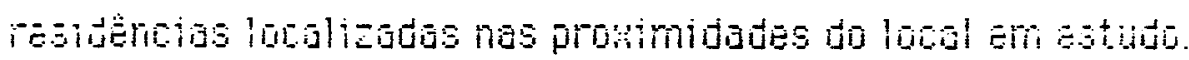

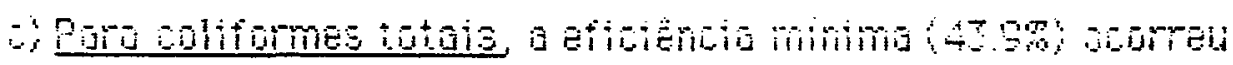

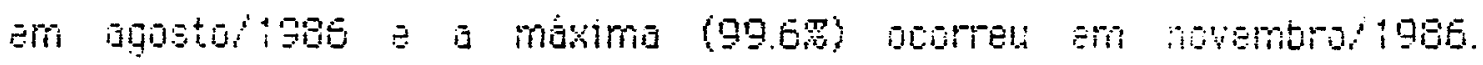

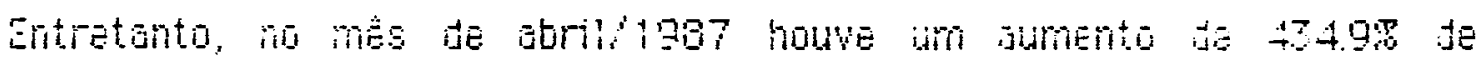

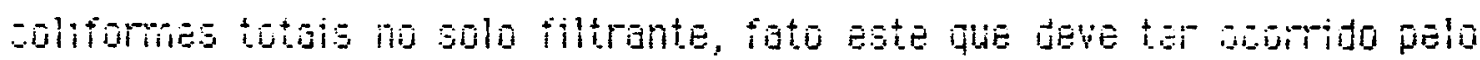
inesno motio citado no item o acima.

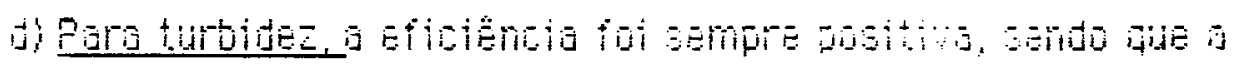

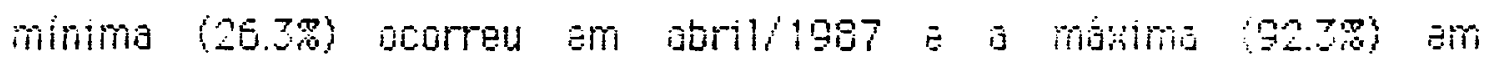
joneirot 1967.

e) Para cor a eficiência foi sempre positivi, sendo que a

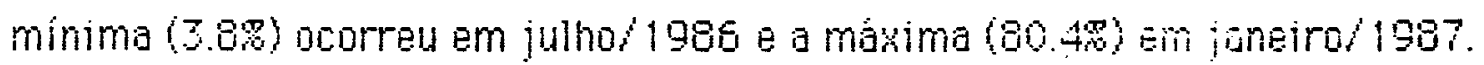

f) Para N-amoniacal e nitrato Observou-se que a joncentraço

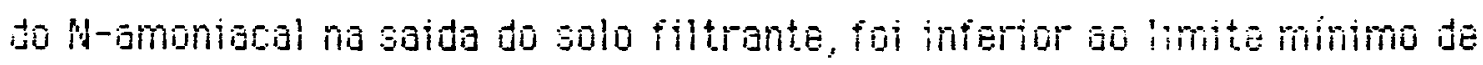

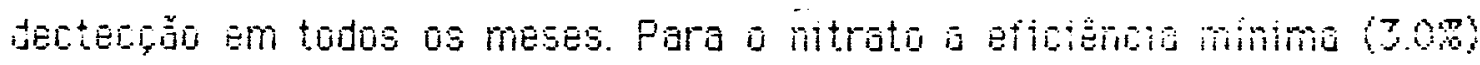

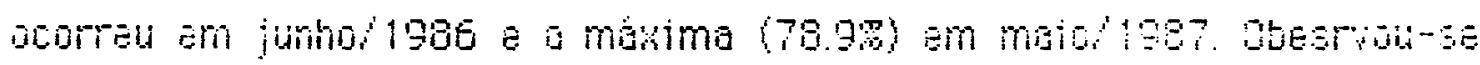

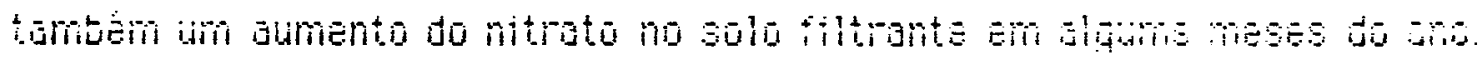

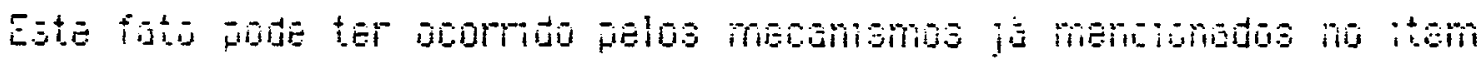
5.1.i.i.

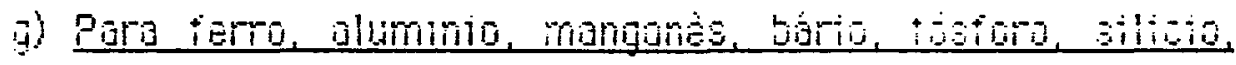

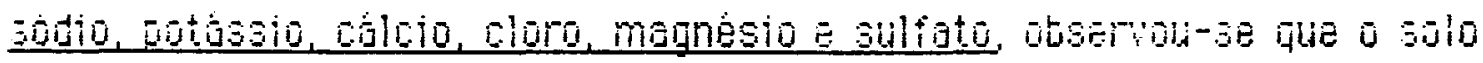
filtante eficiente na maioria dos meses. Entretanto, juserou-se tamómin um aumento da concentraçăo destes parametros, em alguns penodos.

h) Para codmio chumbo cobre cromo e Enco observou-se que a concentraçäo destes elementos nö Excedel os valores minimos de Jeteco:̈o na maioria dos meses. na saida do solo filtrinte. Entretonto houre um abmento de $20 \%$ do cromo em jumo/1985, de $50 \%$ do cobre en 
nowentro 1966 e de $150 \%$ do zinco em jeneirol 1967 , no saida do solo ilitiante.

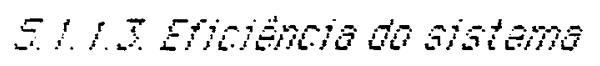

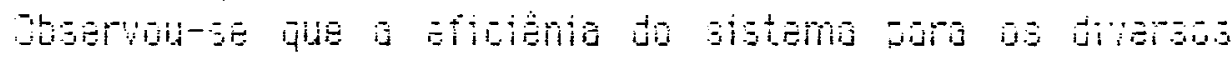

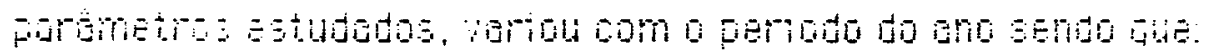

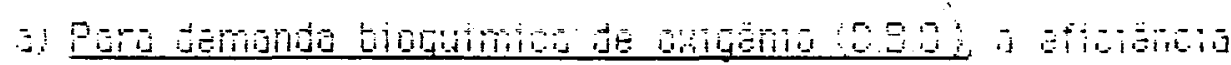

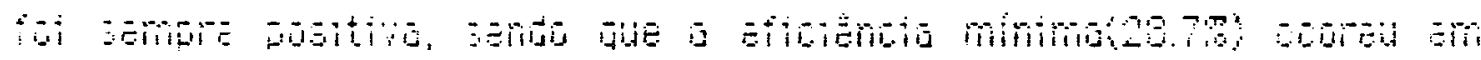

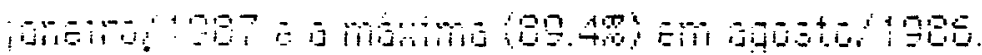

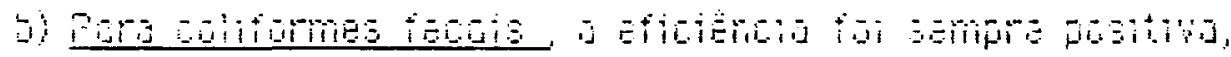

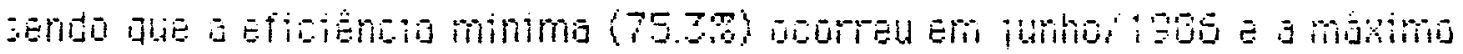

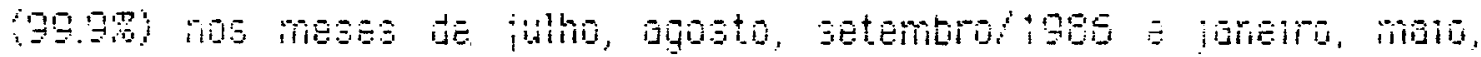
juho/ 1987.

c) Para coliformes totais a eficiencia for sempre positiva, sendo que a eficiència minima $(94.78)$ ocorreu em junho/ 1986 e a máxima (99.9\%) nos meses de agosto, setembro, novembro/ 1986 e jarieiro, maio. junhol $198 \mathrm{r}$.

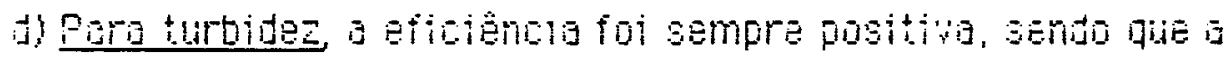

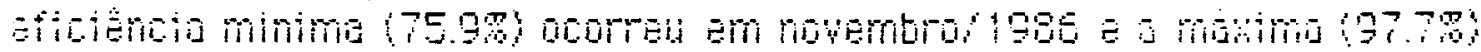
Enimiois: 1907.

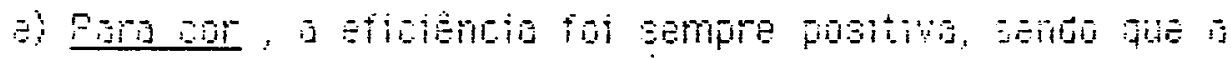

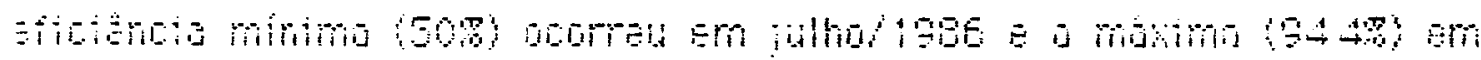
miso'ige? 
1) Para d-amoniacal e nitrato . Para o H-amoniacal a eficiencia foi sempre positiva, sendo que a eficiencia minma (25.9\%) bobreu em

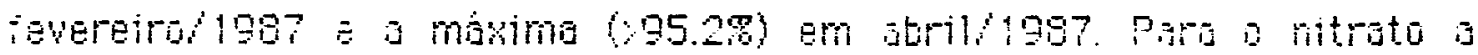

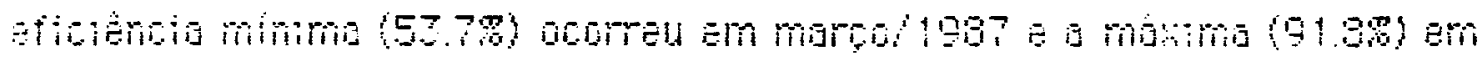

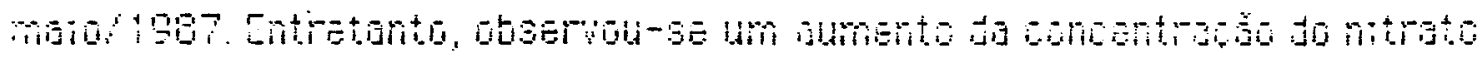

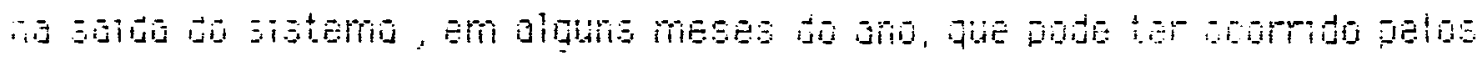

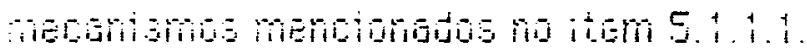

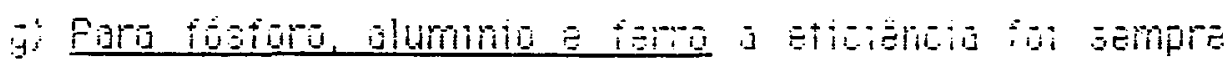

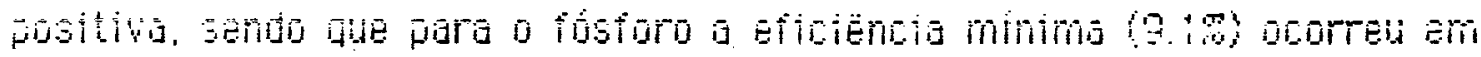
jerilil9o7 a is moxima (c63\%) em novembro/1986. Pori o juminio a Eficiêncio minima (35.6\%) ocorreu em novembro/ 1906 e a niásima (69.68) Em maio/1987. Para o ferro a eficiencia minima (CE.7\%) ocorreu em março/1987 e a máxima $(97.38)$ em maio/ 1987.

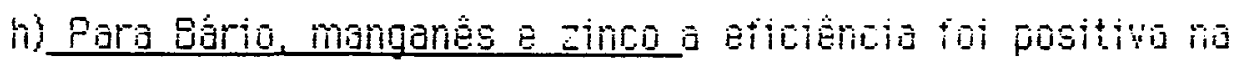

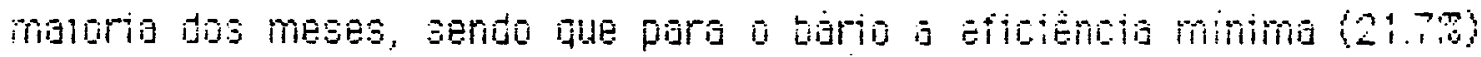

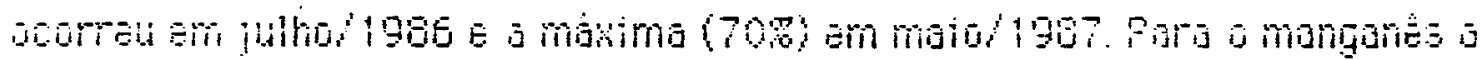

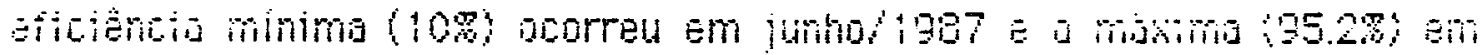

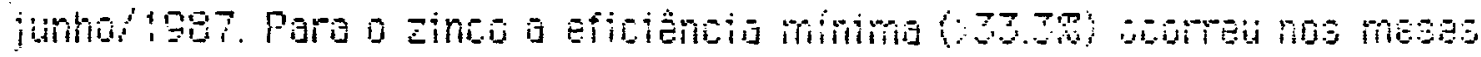

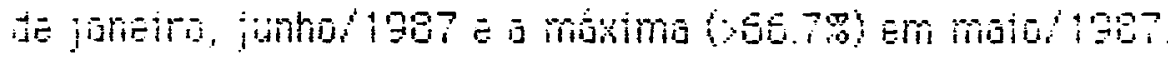

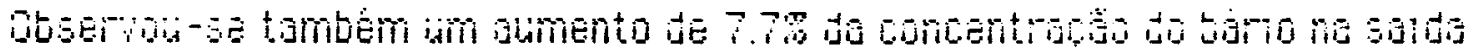

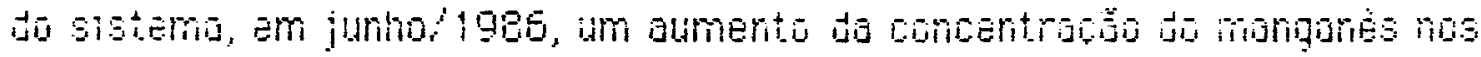
meses de janeiro, feverero, marco, atril/987, harido de 5538 i 757. 1.8 , um aumento de $25 \%$ da concentraça do zinco nos meses de ievereiro, março/ 1987.

i) Para codmio, chumba cobre e croma observou-se que a concentraçăo destes elementos na saida do sistema na maioria dos meses 
Estovim abano do limite minmo de dectecono.

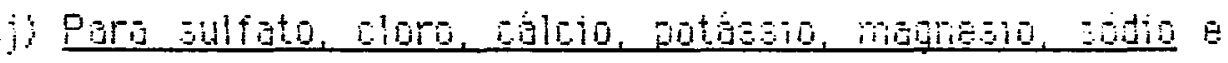
silicin otservou-se aue a eficiencia do sistema paris estes piormetros, foi

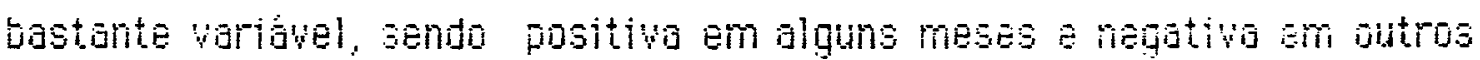
meses.

\section{1.2. Sisteme 71 - Salas filtrantes cansecutivas}

A Efictencia dos solos filtrantes consecitivos, fara ds

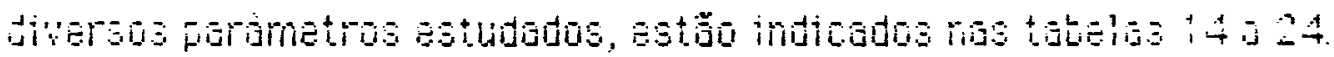

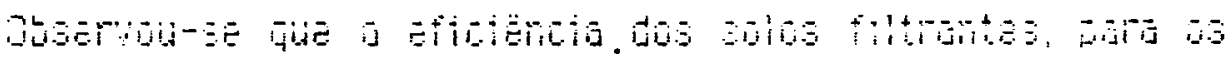

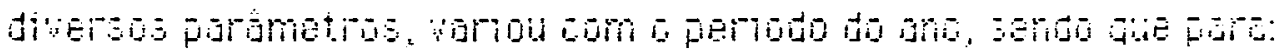

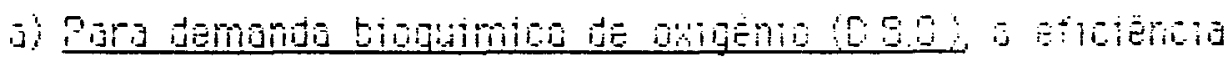

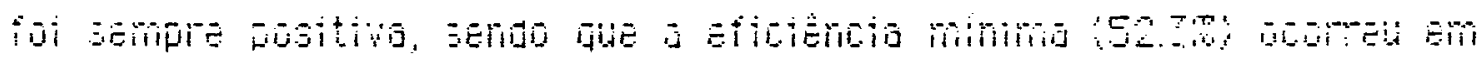

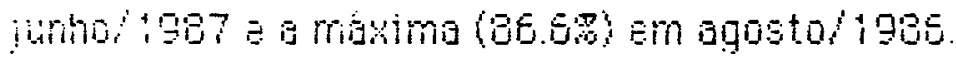

5) Para coliformes fecois a eficiencia fó sempre positivo, sendo que a eficiencia minima (46.5\%) ocorreu em atrili 1987 a a nákina (99.98) nos meses de janeiro, maio, junho/1987.

c) Para coliformes totais, a eficiência foi sempre positiva, sendo que a eficiência minima (94.38) ocorres em julho/1986 a a maxima $(99.98)$ em maio/ 1987.

1) Para turbidez a eficiencia foi sempre positivia, sendo que o

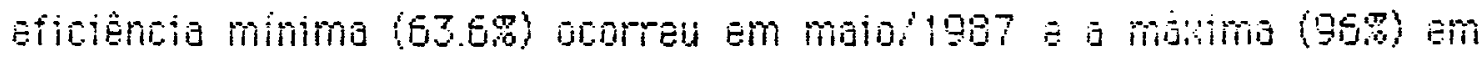
forereiro/ 1987.

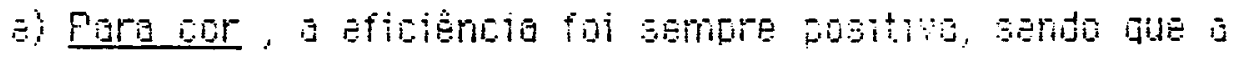

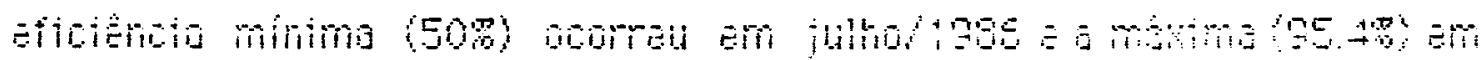


maio/1987.

1) Para N-amoniacal e nitrato. Para o N-amoniacal a eficiencia foi sempre positiva, sendo que a eficiencia minima (c5.98) acorreu em fevereiro/1907 e a máxima $(990.9 \%)$ em agosto/ 1986.

Pario

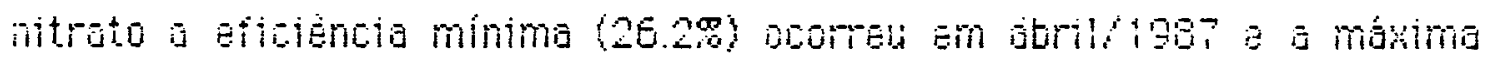

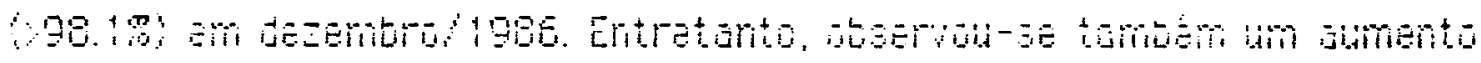

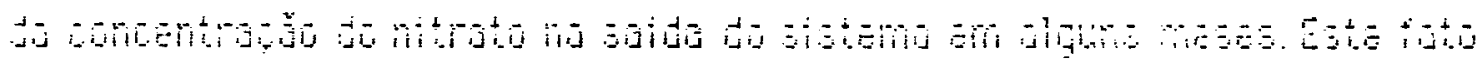

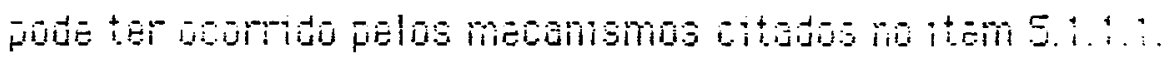

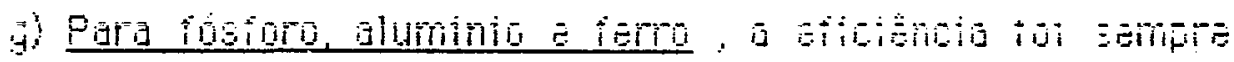

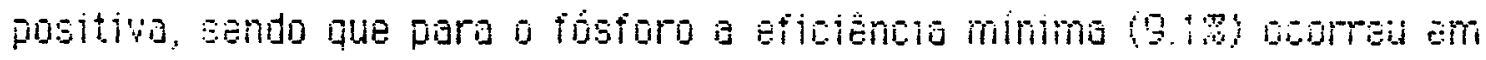
abril/1987 a a móxima (638) em novembro/ 1986 . observid-se tamben que a concentraça do fusforo na saida do sistema estava abaiko do limite mínimo de detecç̃o, com exceção apenos no mês de junho 1986.

Para o aluminio a eficiencia minima (29.38) ocomeu en junho/1907 a a máxima (95:) em fevereiro/1987.

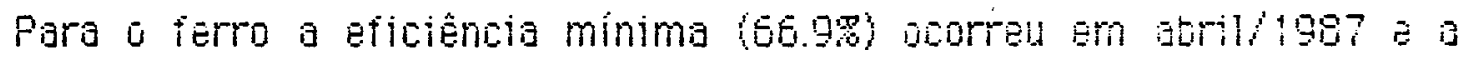
mơxima (90.68) em dezembro/1986.

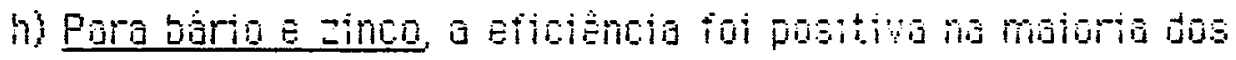

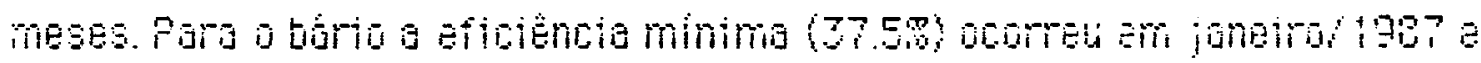

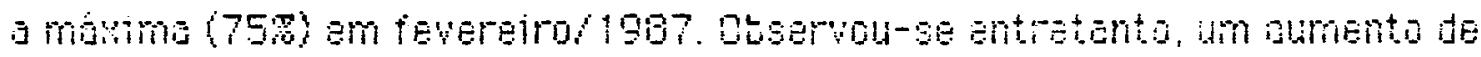

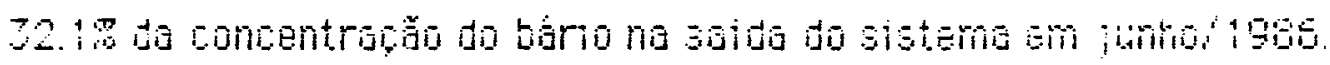

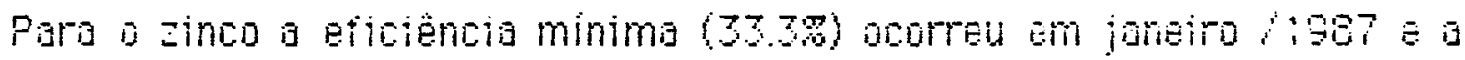
máxima (508) nos meses de junho, dezembro/1986 e morco, mijo/ 1987.

1) Paro codmio, chumbo cotre e como, boseriou-se que is concentraça destes elementos na saida do sistema, estiva abainu do 


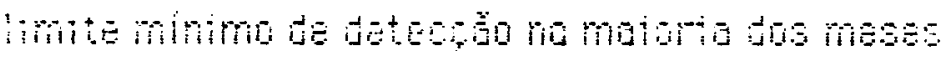

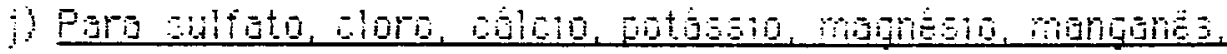

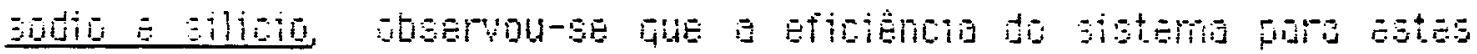

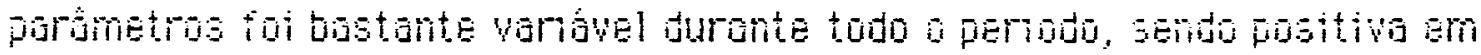
jlgums meses e negativa em outros.

\subsection{Mudança da classificaçäo da água para abastecimento}

Eequndo Artigo 79 do Decreto ne 8460, de ob/69/1976, que

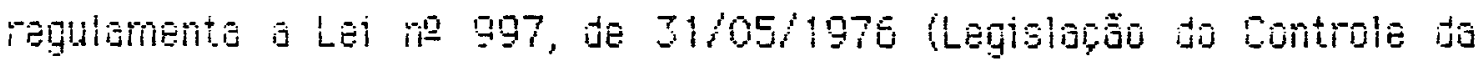

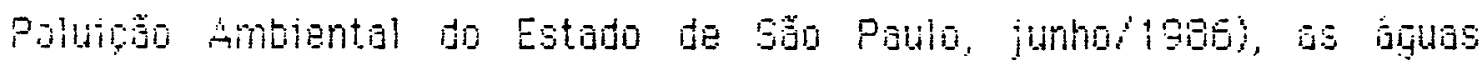
interiores stuadas no territirio do Estado, para as atelos deste

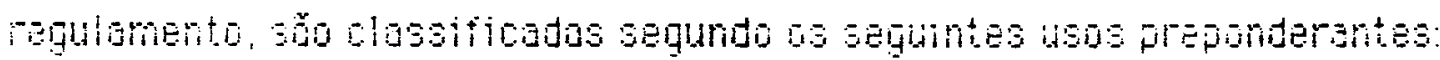

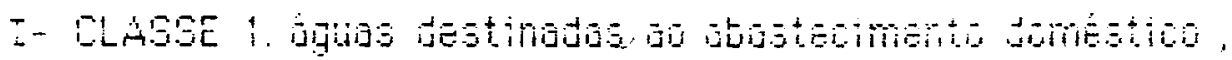

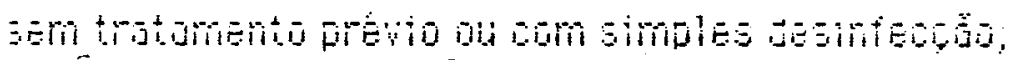

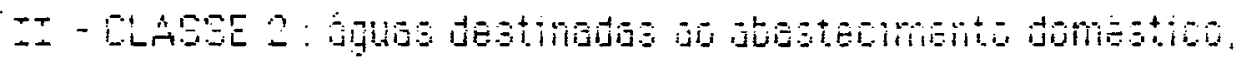

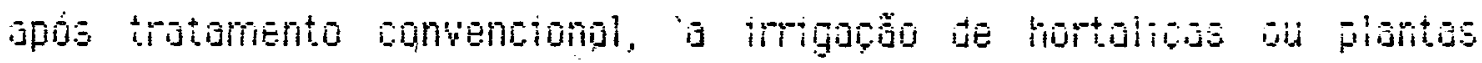
frutiferoe e a recreaço de contato primario (nataça, esaui-aquetico e mergulho:;

III - CLASSE 3 : águas destinadas ao abstecinento domestico, após tratamento convencional, ia preservaciöo de peixes em geral e de outro elementos da fauna e da flora e ia dessedentação de animais;

IV - CLASSE 4 : Gguas destinadas ao abastecimento duméstico.

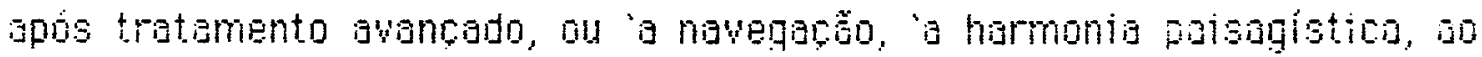
ibastechento industrial, a ingaröo a usos menos exigentes. 
As tguas do Rio Piracicaba estăo enquadradias na classe 2 pelo Art. 79 citado. 0 Art. 11 do mesmo decreto especifica que, nas aguas de classe 2 năo poderŏo ser lançados efluentes, mesmo tratados, que prejudiquem sua qualidade pela alteração dos valores dos diversos paràmetrus exigidos por este artigo.

Durante a periodo de jumb/loge a jurholigor iorim

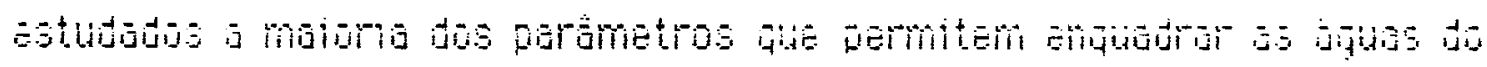
Pio Pircicoba dentro do sia categona.

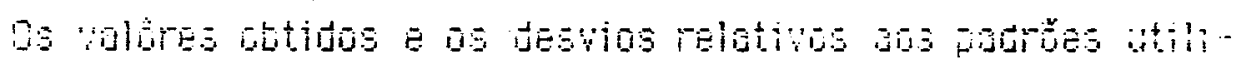

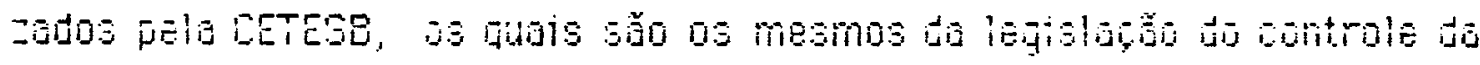

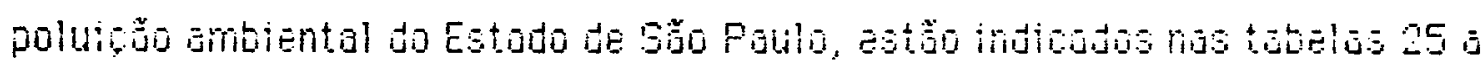
40.

\subsection{Sistamo 1 - Canai cam aguapé a saias hiliranies}

Us dados abtidas e os desuins relativas aos padröes utilizados pela CETESB, para o sistema I, estão indicados nas tabelas 25 a 37.

5.2.1. Agu de entrodo do sistemo logu do Alo precrost

Dbservou-se que pare ne parsmetroe estudedos, a 3949 do no

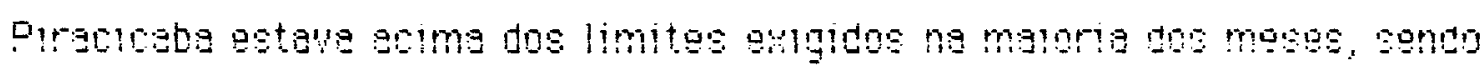
que

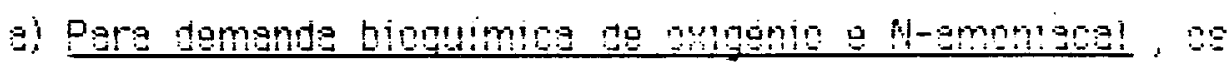
limites meximos exigidos forem excedidos am 6 moses do fariogo em estudo; 
b) Para coliformes fecais e totidis, as limites nimimos exigidos form excedidos em todos os meses dis pentodo en estuda;

C) Pord chumbo a cromo os limitas naminos anigidos foram ERcedidos em 2 meses do perrodo em estuda;

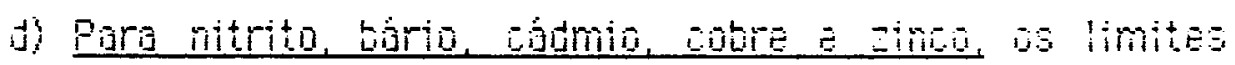
nóximos exigidos nio foram excedidos am henhum mes do perioto en Estudo.

\subsection{Conol com aguape}

Dbservou-se que após passar pelo canal com aguajé, o maiotia Jos paràmetros estudados estavam abako dos limites miximos akgidos, sendo que:

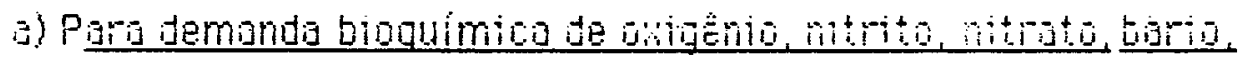

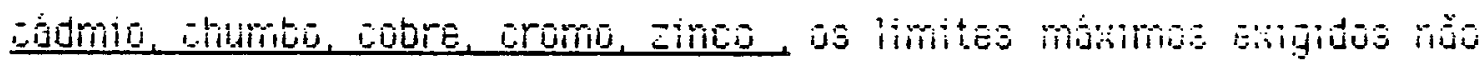
forum excedidos en henhum mes du periodo en estudo.

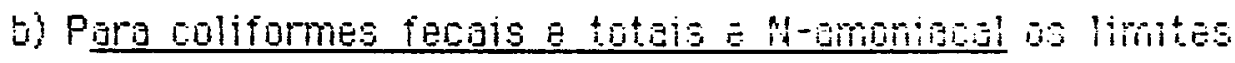
móximus exigidos foram excedidos em 2 meses para coli iecoi , en 7 neses paro coli total, e em 2 meses para o N-amoniocal.

\subsection{S Sido do sistemo}

Dbservou-se que após passar pela sistema, a maroria dos parâmetros estudados estavam abaiko dos limites mínimos exig̣idos, sendo que: 


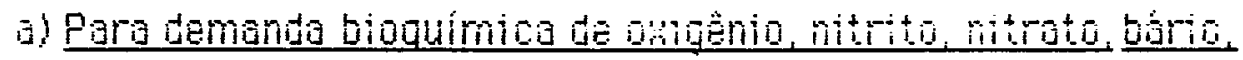
cadmia chunbo, cobre, cromo zinco e p-amoniacel os limites maximos exigidos năo foram excidedos em nenhum mês do periodo em setudo;

b) Para coliformes fecais e totais as limites máximos exigidos foram excedidos em 2 meses para coli fecal e I meses para coli total.

\subsection{Sisteme $I I$ - Salas filtantes cansecutinas}

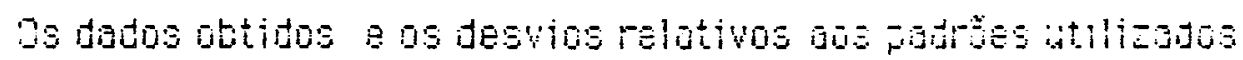

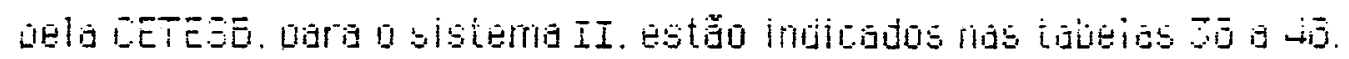

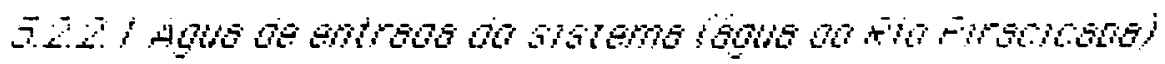

Jâ discutido no item 5.2 .1 .1

52.25 sido of siotens

Observou-se que, após passar pelo sitema; a maioria dos paràmetros estudados, estavam adaixa jos iimites máximos exigious. senoo ane:

a) Fara iemanda bigquimica de axigènio nitnto mirato oăro

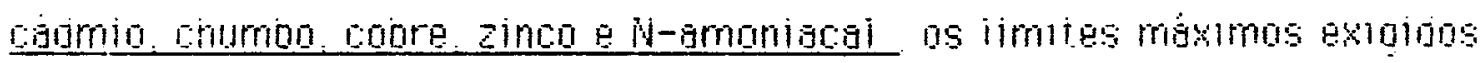
nä̃ ioram excejions em nenhum mês do gerioujo em estudo.

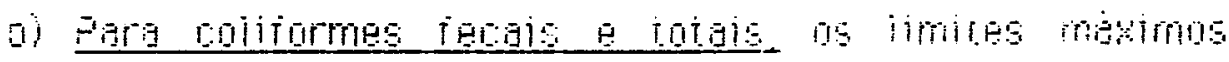
Exigidos roram excedidas em 2 meses dara coil iecal e 7 meses dara coil 
total, no periodo em estudo;

-) Para o romo a limite maximo exigido iot excedido Em jpenos i mes do periodo em estudo. 
TABEL A 25. Desvio relativo do sistema aguapé-solo filtrante em relaģáo aos padrōes de referência utilizados pela CETEsB

Período de amostragem: Junho/ 1986.

\begin{tabular}{|c|c|c|c|c|c|c|c|}
\hline PARAMETROS & $\begin{array}{c}\text { PADROES } \\
\text { REFERENCIA } \\
\text { PR } \\
\end{array}$ & $\begin{array}{l}\text { Agua de Enitra- } \\
\text { da (Rio Pira- } \\
\text { cicaba) P1 }\end{array}$ & $\begin{array}{c}\text { DR * } \\
\text { Rio Piracicaba } \\
(g) \\
\end{array}$ & $\begin{array}{c}\text { Saída } \\
\text { Canal aguapé } \\
\text { F2 } \\
\end{array}$ & $\begin{array}{c}\text { DR\# } \\
\text { Canal aguapé } \\
(\$) \\
\end{array}$ & $\begin{array}{c}\text { Saida solo } \\
\text { filtrante } \\
\text { P3 } \\
\end{array}$ & $\begin{array}{l}\text { DR } 0 \\
\text { Sistema } \\
\text { (\$) }\end{array}$ \\
\hline D.B.0. (ng/l) & 5 & 5.54 & 10.8 & 0.92 & -81.6 & 0.69 & -86.2 \\
\hline Coli fecal (nmp) & 1000 & 93000 & 9200.0 & 1500 & 50.0 & 2300 & 130.0 \\
\hline Coli total (nmp) & 5000 & 430000 & 8500.0 & 23000 & 360.0 & 23000 & 360.0 \\
\hline Nitrito $(m g / 1)$ & 1 & - & - & - & - & - & - \\
\hline Nitrato (mg/l) & 10 & 0.27 & -97.3 & 1.15 & -88.5 & 0.73 & -92.7 \\
\hline N-amoriacal (mg/1 & 0.5 & 1.59 & 218.0 & $<0.20$ & $>-60.0$ & $<0.20$ & $>-60.0$ \\
\hline Bário (mg li) & 1 & 0.28 & -72.0 & 0.35 & -65.0 & 0.3 & -70.0 \\
\hline Códmio (mg/l) & 0.01 & $<0.01$ & 0.0 & $<0.01$ & 0.0 & 0.01 & 0.0 \\
\hline Chumbo (mg/1) & 0.1 & $<0.10$ & 0.0 & $<0.10$ & 0.0 & $<0.10 \overline{0}$ & 0.0 \\
\hline Cabre $(\mathrm{mg} / \mathrm{l})$ & 1 & $<0.02$ & $>-98.0$ & $<0.02$ & $2-98.0$ & 40.02 & $r-98.0$ \\
\hline Cromo (mg/l) & 0.05 & 0.06 & 20.0 & 0.05 & 0.0 & 0.06 & 20.0 \\
\hline 2 inco (mg/l) & 5 & 0.04 & -99.2 & $\$ 0.02$ & $>-99.6$ & 40.02 & $>-99.6$ \\
\hline
\end{tabular}

$*[(\mathrm{P} 1-\mathrm{PR}) / \mathrm{PR}] .100$

\#[(P2-PR )/PR $] .100$

(G' [(PS-PR)/FR].100 
TABEL A 26. Desvio relativo do sistema aguapé-solo filtrante em relaçōo aos padrōes de referència utilizados pela CETESB

Periodo de amostragem : Jutho/1986.

\begin{tabular}{|c|c|c|c|c|c|c|c|}
\hline PARAMETROS & $\begin{array}{c}\text { PADROES } \\
\text { REFERENCIA } \\
\text { PR }\end{array}$ & $\begin{array}{l}\text { Agua de Entra- } \\
\text { da (Rio Pira- } \\
\text { cicabs) P1 }\end{array}$ & $\begin{array}{c}\text { DR* } \\
\text { Rio Pirjoicaba } \\
\text { (\$) }\end{array}$ & $\begin{array}{c}\text { Sáda } \\
\text { Canal aguapé } \\
\text { P2 }\end{array}$ & $\begin{array}{c}\text { DR * } \\
\text { Canal aguapé } \\
(\$)\end{array}$ & $\begin{array}{l}\text { Saída solo } \\
\text { filtrante } \\
\text { F3 }\end{array}$ & $\begin{array}{l}\text { DR } 9 \\
\text { Sistems } \\
\text { (B) }\end{array}$ \\
\hline D.B.0. (mg/1) & 5 & 4.36 & -12.8 & 0.83 & -83.4 & 0.69 & -86.2 \\
\hline Coli fecal (nmp) & 1000 & 39000 & 3800.0 & $<30$ & $>-97.00$ & 36 & -96.4 \\
\hline Coli total (nmp) & 5000 & 75000 & 1400.0 & 4300 & -14.0 & 160 & -96.8 \\
\hline Nitrito (mg/l) & 1 & - & - & - & - & - & - \\
\hline Nitrato (mg/l) & 10 & 0.59 & -94.1 & 1.06 & -89.4 & 1.23 & -87.7 \\
\hline N-amoniacal (mg/l & 0.5 & 1.64 & 228.0 & $<0.20$ & $>-60.0$ & $<0.20$ & $>-6000$ \\
\hline Bário (mg/l) & 1 & 0.23 & -77.0 & 0.19 & -81.0 & 0.18 & -82.0 \\
\hline Cadmio (mg/l) & 0.01 & $<0.01$ & 0.0 & $<0.01$ & 0.0 & $<0.01$ & 0.0 \\
\hline Chumbo (mg/1) & 0.1 & $<0.10$ & 0.0 & $<0.10$ & 0.0 & $<0.10$ & 0.0 \\
\hline Cobre (mg/l) & 1 & $<0.02$ & $>-98.0$ & $<0.02$ & $>-98.0$ & $<0.02$ & $>-98.0$ \\
\hline Cromo $(\mathrm{mg} / 1)$ & 0.05 & $<0.05$ & 0.0 & $<0.05$ & 0.0 & $<0.05$ & 0.0 \\
\hline Zineo $(\mathrm{mg} / \mathrm{l})$ & 5 & 0.02 & -99.6 & $<0.02$ & $>-99.6$ & 0.02 & -99.6 \\
\hline
\end{tabular}

* [(P1-PR $) / P R] .100$

* [(P2-FR $] / F R] .100$

$9[(P 3-P R) / F R] .100$ 
TABEL A 27. Desvio relativo do sistema aguapé-solo filtrante em relaçōo aos padrōes de referência utilizados pela CETESB

Periodo de amostragem: Agosto/1986.

\begin{tabular}{|c|c|c|c|c|c|c|c|}
\hline PARAMETROS & $\begin{array}{c}\text { PADROES } \\
\text { REFERENCIA } \\
\text { PR } \\
\end{array}$ & $\begin{array}{l}\text { Agua de Entra- } \\
\text { da (Rio Pira- } \\
\text { cicaba) P1 }\end{array}$ & $\begin{array}{c}\text { DR* } \\
\text { Rio Piracicaba } \\
(\mathrm{S}) \\
\end{array}$ & $\begin{array}{c}\text { Saída } \\
\text { Canal aguapé } \\
\text { P2 } \\
\end{array}$ & $\begin{array}{c}\text { DR \# } \\
\text { Canal agu.jpé } \\
\text { (g) }\end{array}$ & $\begin{array}{c}\text { Saida solo } \\
\text { filtrante } \\
\text { P3 } \\
\end{array}$ & $\begin{array}{l}\text { DR Q } \\
\text { Sistema } \\
\text { (\$) } \\
\end{array}$ \\
\hline D.B.0. (mg/1) & 5 & 6.43 & 28.6 & 2.74 & -452 & 0.68 & -86.4 \\
\hline Coli fecal (nmp) & 1000 & 430000 & 42900.0 & 67 & -933 & 30 & -97.0 \\
\hline Coli total (nmp) & 5000 & 12250000 & 244900.0 & 2300 & -540 & 1290 & -74.2 \\
\hline Nitrito (mg/l) & 1 & - & - & - & - & - & - \\
\hline Nitrato $(\mathrm{mg} / \mathrm{l})$ & 10 & 0.22 & -97.8 & 0.95 & -90.5 & 0.63 & -93.7 \\
\hline $\mathrm{N}$-amoniacal (mg/1 & 0.5 & 2.20 & 340.0 & $<0.20$ & $>-60.0$ & $<0.20$ & $>-60.0$ \\
\hline Bário $(\mathrm{mg} / \mathrm{l})$ & 1 & 0.08 & -92.0 & 0.05 & -95.0 & 0.05 & -95.0 \\
\hline Cadmio (ming/l) & 0.01 & $<0.01$ & 0.0 & $<0.01$ & 0.0 & $<0.01$ & 0.0 \\
\hline Churnbo (mg/l) & 0.1 & $<0.10$ & 0.0 & $<0.10$ & 0.0 & $<0.10$ & 0.0 \\
\hline Cobre (mg/l) & 1 & $<0.02$ & $>-98.0$ & $<0.02$ & $>-98.0$ & $<0.02$ & $>-98.0$ \\
\hline Cromo $(\mathrm{mg} / \mathrm{l})$ & 0.05 & $<0.05$ & 0.0 & $<0.05$ & 0.0 & $<0.05$ & 0.0 \\
\hline Zinco $(\mathrm{mg} / \mathrm{l})$ & 5 & 0.02 & -99.6 & $<0.02$ & $3-99.6$ & 40.02 & $>-99.6$ \\
\hline
\end{tabular}

$*[(\mathrm{P} 1-\mathrm{PR}) / \mathrm{FR}] .100$

\#[(P2-PR)/FR $] .100$

9 [(P3-PR $) / P R] .100$ 
TABEL 28. Desrio relativo do sistema aguapé-solo filtrante em relaçāo aos padróes de referência utilizados pela CETESB

Períado de anostragem: Setembro/1986.

\begin{tabular}{|c|c|c|c|c|c|c|c|}
\hline FARAMETRÜS & $\begin{array}{c}\text { PADROES } \\
\text { REFERENCIA } \\
\text { FR }\end{array}$ & $\begin{array}{l}\text { Agua de Eritra- } \\
\text { da (Rio Pira- } \\
\text { oicata) P1 }\end{array}$ & $\begin{array}{c}\text { OR * } \\
\text { Rio Piracioata } \\
\text { (炁) }\end{array}$ & $\begin{array}{c}\text { Sáda } \\
\text { Canal aguapé } \\
\text { F2 }\end{array}$ & $\begin{array}{c}\text { DR \# } \\
\text { Canal sguape } \\
\text { (\%) }\end{array}$ & $\begin{array}{c}\text { Sáda solo } \\
\text { filtrarite } \\
\text { F3 }\end{array}$ & $\begin{array}{l}\text { OR } 10 \\
\text { Sistema } \\
(\%)\end{array}$ \\
\hline D.B.0.(mg/1) & 5 & 6.01 & 20.2 & 1.58 & -68.4 & 0.87 & -82.6 \\
\hline Coli foosl (nmp) & 1000 & 930000 & 92900.0 & 36 & -96.4 & $<30$ & $=-97.0$ \\
\hline Coli total (nmp) & 5000 & 930000 & 15500.0 & 290 & -94.2 & 120 & -97.6 \\
\hline Nitrito (mg/l) & 1 & $<0.01$ & $>-99.0$ & 0.01 & $>-99.0$ & - & - \\
\hline Nitrato (mg/l) & 10 & 0.22 & -97.8 & 2.76 & -72.4 & - & - \\
\hline N-amoriacal (mig/l & 0.5 & 2.58 & 416.0 & 0.99 & 98.0 & - & - \\
\hline Bário (mg/l) & 1 & 0.10 & -90.0 & 0.09 & -91.0 & - & - \\
\hline Cadmio (mg/l) & 0.01 & $<0.01$ & 0.0 & $<0.01$ & 0.0 & - & - \\
\hline Churntió (mgli) & 0.1 & $<0.10$ & 0.0 & $<0.10$ & 0.0 & - & - \\
\hline Cutire (mg/o) & 1 & 0.03 & -97.0 & 0.03 & -97.0 & - & - \\
\hline Cromo (mg/i) & 0.05 & 0.05 & 0.0 & $<0.05$ & 0.0 & - & - \\
\hline Ziriso $(\mathrm{ming} / \mathrm{l})$ & 5 & $<0.02$ & $x-99 E$ & $<0.02$ & $>-99.6$ & - & - \\
\hline
\end{tabular}

$*[(P 1-P R) / P R] .100$

* $[(P 2-P R) / P R] .100$

( $[($ P3-PR)/FR $] .100$ 
TABEL A 29. Desvio relativo do sistema aguapé-solo filtrante em relagóo aos padrōes de referência utilizados pela CETESB

Período de amostragem: Outubro/1986.

\begin{tabular}{|c|c|c|c|c|c|c|c|}
\hline FARAIMETRŌS & $\begin{array}{c}\text { PADROES } \\
\text { REFERENACIA } \\
\text { PR } \\
\end{array}$ & $\begin{array}{l}\text { Agua de Entra- } \\
\text { da (Rio Pira- } \\
\text { oicaba) PI }\end{array}$ & $\begin{array}{c}\text { OR } \\
\text { Rio Piracicaba } \\
\text { (茂) }\end{array}$ & $\begin{array}{c}\text { Saída } \\
\text { Carial aguapé } \\
\mathrm{P2} \\
\end{array}$ & $\begin{array}{c}\text { DR\# } \\
\text { Canal aguapú } \\
(\%) \\
\end{array}$ & $\begin{array}{c}\text { Saída solo } \\
\text { filtrante } \\
\text { F3 } \\
\end{array}$ & $\begin{array}{l}\text { DR } \Phi \\
\text { Sistema } \\
\text { (s) }\end{array}$ \\
\hline D.B.0. (mg/1) & 5 & 6.51 & 30.2 & 2.49 & -50.2 & - & - \\
\hline Coli feoal (nmp) & 1000 & 126500 & 12550.0 & 561 & -439 & - & - \\
\hline Coli total (rimp) & 5000 & 1365000 & 27200.0 & 16150 & 223.0 & - & - \\
\hline Nitrito (mig/) & 1 & - & $>-99.0$ & - & - & - & - \\
\hline Nitrato (mg/l) & 10 & - & - & - & - & - & - \\
\hline N-amoniacal (mo/l & 0.5 & - & - & - & - & - & - \\
\hline Bário $(m, y)$ & 1 & - & - & - & - & - & - \\
\hline Códmio (mg/l) & 0.01 & - & - & - & - & - & - \\
\hline Chumbo (mg/l) & 0.1 & - & - & - & - & - & - \\
\hline Cotre (mg/j) & 1 & - & - & - & - & - & - \\
\hline Cromo (mg/l) & 0.05 & - & - & - & - & - & - \\
\hline Zinco $(\operatorname{rng} / \mathrm{l})$ & 5 & - & - & - & - & - & - \\
\hline
\end{tabular}

* $[(\mathrm{P} 1-\mathrm{PR}) / \mathrm{PR}] .100$

\# $[(F / 2-P R) / P R] .100$

(9. $[(P 3-P R) / P R] .100$ 
T ABEL A 30. Desrio relatiro do sistema aguapé-solo filtrante em relaçōo aos padrōes de referência utilizados pela CETESB

Períado de amostragem: Narembro/1986.

\begin{tabular}{|c|c|c|c|c|c|c|c|}
\hline FARAMETROAS & $\begin{array}{c}\text { PADROES } \\
\text { REFERENCIA } \\
\text { PR } \\
\end{array}$ & $\begin{array}{l}\text { Agua de Entra- } \\
\text { da (Rio Fira- } \\
\text { cicata) P1 }\end{array}$ & $\begin{array}{c}\text { DR * } \\
\text { Rio Piracicaba } \\
(\$)\end{array}$ & $\begin{array}{c}\text { Saída } \\
\text { Canal aguapé } \\
\text { P2 } \\
\end{array}$ & $\begin{array}{c}D R \# \\
\text { Canal aguape } \\
(g)\end{array}$ & $\begin{array}{c}\text { Saida solo } \\
\text { filtranite } \\
\text { F3 } \\
\end{array}$ & $\begin{array}{l}\text { OR O } \\
\text { Sistema } \\
(\%)\end{array}$ \\
\hline D.B.0.(mg/i) & 5 & 5.23 & 4.6 & 2.13 & -57.4 & 0.93 & -81.4 \\
\hline Coli fecal (nmp) & 1000 & 4300 & 330.0 & 930 & -7.0 & 64 & -93.6 \\
\hline Coli total (rimp) & 5000 & 430000 & 8500.0 & 110000 & 2100.0 & 440 & -91.2 \\
\hline Nitrito (mg/l) & 1 & $<0.01$ & $>-99.0$ & $<0.01$ & $>-99.0$ & $<0.01$ & $3-99$ \\
\hline Nitrsto $(\mathrm{mg} / \mathrm{l})$ & 10 & 0.37 & -96.3 & 0.03 & -99.7 & 0.77 & -92.3 \\
\hline N-amoniacal (mg/l & 0.5 & 1.74 & 248.0 & 0.80 & 60.0 & $<0.20$ & $3-60.0$ \\
\hline Bório (mg/l) & 1 & 0.13 & -87.0 & 0.07 & -93.0 & 0.05 & -95.0 \\
\hline Códmio (mg/l) & 0.01 & $<0.01$ & 0.0 & $<0.01$ & 0.0 & $<0.01$ & 0.0 \\
\hline Chumbo (mg/) & 0.1 & $<0.10$ & 0.0 & $<0.10$ & 0.0 & $<0.10$ & 0.0 \\
\hline Cobre (nig/l) & 1 & 0.03 & -97.0 & 0.02 & $-98 . \overline{0}$ & 0.05 & -97.0 \\
\hline Cromo (mg/i) & 0.05 & $<0.05$ & 0.0 & $<0.05$ & 0.0 & $<0.05$ & 0.0 \\
\hline Zinco $(\mathrm{mg} / \mathrm{l})$ & 5 & $\leq 0.02$ & $>-99.6$ & $\leq 0.02$ & $>-996$ & 60.02 & $3-99.6$ \\
\hline
\end{tabular}

* [(P1-PR $) / \mathrm{PR}] .100$

* [(P2-PR)/PR].100

(G) [(P3-PR)/PR].100 
TABELA 31 . Desrio relativo do sistema aguapé-solo filtrante em relagão aos padrōes de referéncia utilizados pela CETESB

Periodu de amostragem: Dezembro/1986.

\begin{tabular}{|c|c|c|c|c|c|c|c|}
\hline PARAMETROS & $\begin{array}{l}\text { PADROES } \\
\text { REFERENCIA } \\
\text { PR }\end{array}$ & $\begin{array}{l}\text { Agua de Eritra- } \\
\text { da (Rio Pira- } \\
\text { cicaba) F.1 }\end{array}$ & $\begin{array}{c}\text { DR* } \\
\text { Rio Piracicaba } \\
\text { (\$) }\end{array}$ & $\begin{array}{c}\text { Saída } \\
\text { Canal aguapé } \\
\mathrm{F}_{2}\end{array}$ & $\begin{array}{c}\text { OR \# } \\
\text { Carial aguapé } \\
\text { (鸟) }\end{array}$ & $\begin{array}{c}\text { Saida solo } \\
\text { filtrarite } \\
\text { F3 }\end{array}$ & $\begin{array}{c}\text { DR O } \\
\text { Sistema } \\
\text { (\%) }\end{array}$ \\
\hline D.E.O. (mg/l) & 5 & 4.9 & -2.0 & 2.25 & -55.0 & 1.33 & -73.4 \\
\hline Coli feoal (nmp) & 1000 & 23000 & 2200.0 & 1500 & 50.0 & 210 & -79.0 \\
\hline Coli total (nmip) & 5000 & 2300000 & 45900.0 & 230000 & 4500.0 & 23000 & 360.0 \\
\hline Nitrito $(\mathrm{mg} / 1)$ & 1 & $<0.01$ & $>-99.0$ & $<0.01$ & $>-99.0$ & $<0.01$ & $>-99.0$ \\
\hline Nitrato (mg/l) & 10 & 0.52 & -94.8 & 0.21 & -97.9 & 0.21 & -97.9 \\
\hline N-amoniacal (mg/l & 0.5 & 0.48 & -4.0 & 0.25 & -50.0 & $<0.20$ & $>-60.0$ \\
\hline Bário (mg/l) & 1 & 0.07 & -93.0 & 0.03 & -97.0 & 0.03 & -97.0 \\
\hline Cádmio (mg/l) & 0.01 & $<0.01$ & 0.0 & $<0.01$ & 0.0 & $<0.01$ & 0.0 \\
\hline Chumbo (mg/) & 0.1 & $<0.10$ & 0.0 & $<0.10$ & 0.0 & $<0.10$ & 0.0 \\
\hline Cotre (mg/l) & 1 & 0.02 & -98.0 & 0.02 & -98.0 & 0.02 & -98.0 \\
\hline Cromo (mg/l) & 0.05 & $<0.05$ & 0.0 & $<0.05$ & 0.0 & $<0.05$ & 0.0 \\
\hline Zinco (rng $/ 1)$ & 5 & 0.04 & -99.2 & $<0.02$ & $>-99.6$ & $<0.02$ & $>-99.6$ \\
\hline
\end{tabular}

$*[(P 1-P R) / P R] .100$

\#[(P2-PR)/PR $] .100$

6 $[(P 3-P R) / P R] .100$ 
TABELA 32. DesYio relatiro do sistema aguapé-solo filtrante em relaçóo aos padrốes de referência utilizados pela CETESB

Período de amostragem: Janeiro/1987.

\begin{tabular}{|c|c|c|c|c|c|c|c|}
\hline PARAMMETRŪS & $\begin{array}{c}\text { PAOROES } \\
\text { REFERENICIA } \\
\text { PR }\end{array}$ & $\begin{array}{l}\text { Agua de Entra- } \\
\text { da (Rio Pira- } \\
\text { cicaba) P1 }\end{array}$ & $\begin{array}{c}\text { OR* } \\
\text { Rio Pirasicati } \\
\text { (\%) }\end{array}$ & $\begin{array}{c}\text { Saída } \\
\text { Carial aguapé } \\
\text { P2 }\end{array}$ & $\begin{array}{c}\text { DR \# } \\
\text { Canal suyuapé } \\
\text { (क) }\end{array}$ & $\begin{array}{c}\text { Saida solio } \\
\text { tiltrante } \\
\text { F3 }\end{array}$ & $\begin{array}{l}\text { OR } 9 \\
\text { Sistema } \\
\text { (\%) }\end{array}$ \\
\hline$O . B .0 .(\mathrm{mg} / 1)$ & 5 & 3.9 & -22.0 & 2.53 & -49.4 & 2.78 & -44.4 \\
\hline Coli feoal (nmp) & 1000 & 379650 & 37865.0 & 510 & -49.0 & 30 & $>-97.0$ \\
\hline Coli total (nmp) & 5000 & 1165000 & 23200.0 & 8650 & 73.0 & 1187 & -76.3 \\
\hline Nitrito (mig/1) & 1 & $<0.01$ & $>-99.0$ & $<0.01$ & $>-99.0$ & $<0.01$ & $>-99.0$ \\
\hline Nitrato (mgl) & 10 & 0.47 & -9.5 .3 & $<0.10$ & $>-99.0$ & $<0.10$ & $>-99.0$ \\
\hline M-arnoniacal (mg/) & 0.5 & 0.31 & -38.0 & 0.20 & -60.0 & $<0.20$ & $>-60.0$ \\
\hline Bário $(m g / 1)$ & 1 & 0.08 & -92.0 & 0.05 & -95.0 & 0.04 & -96.0 \\
\hline Códrnio (mg/l) & 0.01 & $<0.01$ & 0.0 & 80.01 & 0.0 & $\leqslant 0.01$ & 0.0 \\
\hline Chumbo (mg/l) & 0.1 & $<0.10$ & 0.0 & 80.10 & 0.0 & $<0.10$ & 0.0 \\
\hline Cobre (mg/l) & 1 & 0.03 & -97.0 & 60.02 & $>-98.0$ & $\$ 0.02$ & $>-98.0$ \\
\hline Cromo $(\mathrm{mig} / \mathrm{l})$ & 0.05 & $<0.05$ & 0.0 & \$0.05 & 0.0 & 40.05 & 0.0 \\
\hline Zinco (ma/l) & 5 & 0.03 & -99.4 & $<0.02$ & $>-99.6$ & $<0.02$ & $>-99.6$ \\
\hline
\end{tabular}

* [(P1-PR $) / F R] .100$

* [(P2-PR) $/ F R] .100$

6 [(P3-FR $) / F R] .100$ 
TABEL 33 . Desvio relatiro do sistema aguapé-solo filtrante em relaçóo aos padrōes de referència utilizados pela CETESB

Períado de amostragem: Fevereiro/1987.

\begin{tabular}{|c|c|c|c|c|c|c|c|}
\hline FARAMETROS & $\begin{array}{l}\text { PADROES } \\
\text { REFERENCIA } \\
\text { PR }\end{array}$ & $\begin{array}{l}\text { Agua de Eritra- } \\
\text { da (Rio Pira- } \\
\text { cicaba) P1 }\end{array}$ & $\begin{array}{c}D R \\
\text { Rio Piraciosba } \\
(\%)\end{array}$ & $\begin{array}{c}\text { Saída } \\
\text { Canal aguapé } \\
\text { P2 }\end{array}$ & $\begin{array}{c}\text { DR } \\
\text { Canal aguapé } \\
(\mathscr{K})\end{array}$ & $\begin{array}{c}\text { Saída solo } \\
\text { filtrante } \\
\text { F3 }\end{array}$ & $\begin{array}{l}\text { DR } \\
\text { Sistems } \\
(8)\end{array}$ \\
\hline D.B.0. (mg/l) & 5 & - & - & - & - & - & - \\
\hline Coli feosi (nmp) & 1000 & 9300 & 830.0 & 930 & -7.0 & $<30$ & $3-97.0$ \\
\hline Coli total (nmp) & 5000 & 230000 & 4500.0 & 2300 & -54.0 & 230010 & -54.0 \\
\hline Nitrito $(\mathrm{mg} / \mathrm{l})$ & 1 & $<0.01$ & $>-99.0$ & $<0.01$ & $>-99.0$ & $<0.01$ & $>-99.0$ \\
\hline Nitrato (mg/l) & 10 & 1.35 & $-8 E .5$ & 0.80 & -92.0 & 1.55 & -84.5 \\
\hline N-amoniacal (moll & 0.5 & 0.27 & -46.0 & 40.20 & $>-60.0$ & $<0.20$ & $>-60.0$ \\
\hline Bário (mg/l) & 1 & 0.04 & -96.0 & 0.03 & -97.0 & 0.02 & -98.0 \\
\hline Cádmio (mg/l) & 0.01 & $<0.01$ & 0.0 & $<0.01$ & 0.0 & $<0.01$ & 0.0 \\
\hline Chumbo (mg/l) & 0.1 & $<0.10$ & 0.0 & $<0.10$ & 0.0 & $<0.10$ & 0.0 \\
\hline Cobre $(\mathrm{mg} / \mathrm{l})$ & 1 & $<0.02$ & $>-98.0$ & $<0.02$ & $>-98.0$ & $<0.02$ & $3-98.0$ \\
\hline Cromo $(\mathrm{mg} / \mathrm{l})$ & 0.05 & $<0.05$ & 0.0 & $<0.05$ & 0.0 & $<0.05$ & 0.0 \\
\hline Zinoo $(\mathrm{mg} / \mathrm{l})$ & 5 & 0.04 & -99.2 & $<0.02$ & $2-99.6$ & 0.05 & 0.0 \\
\hline
\end{tabular}

* [(P1-PR $) / P R] .100$

\#[(P2-PR)/PR $] .100$

$@[(\mathrm{~F} 3-P R) / P R] .100$ 
TABEL A 34. Desyio relatiyo do sistema aguapé-solo filtrante em relagão aos padrōes de referéncia utilizados pela CETESB

Periodo de amostragem: Margo/1987.

\begin{tabular}{|c|c|c|c|c|c|c|c|}
\hline FARAMETRUS & $\begin{array}{c}\text { PADROES } \\
\text { REFERENCIA } \\
\text { PR }\end{array}$ & $\begin{array}{l}\text { Agua de Entra- } \\
\text { da (Rio Pira- } \\
\text { cicaba) F1 }\end{array}$ & $\begin{array}{c}\text { DR } \\
\text { Rio Piracicaba } \\
\text { (g) }\end{array}$ & $\begin{array}{c}\text { Saída } \\
\text { Canal aguapé } \\
\text { P2 }\end{array}$ & $\begin{array}{c}\text { DR } \\
\text { Canal squape } \\
(x)\end{array}$ & $\begin{array}{c}\text { Saida solo } \\
\text { filtranite } \\
\text { F3 }\end{array}$ & $\begin{array}{c}\text { OR } \\
\text { Sistema } \\
(\mathrm{E})\end{array}$ \\
\hline $0 . \mathrm{D.0.}(\mathrm{mg} / \mathrm{l})$ & 5 & 3.75 & -25.0 & 2.14 & -57.2 & 1.27 & -74.6 \\
\hline Coli feoal (nmp) & 1000 & - & - & - & - & 230 & -77.0 \\
\hline Coli total (nmp) & 5000 & 430000 & 8500.0 & 43000 & $7 \in 0.0$ & 4300 & -14.0 \\
\hline Nitrito (mg/l) & 1 & $<0.01$ & $=-99.0$ & $<0.01$ & $>-99.0$ & $<0.01$ & $>-99.0$ \\
\hline Nitrato (mig/l) & 10 & 0.54 & -94.6 & 0.13 & -98.7 & 0.25 & -97.5 \\
\hline N-amoriacal $(\mathrm{mg} / \mathrm{l}$ & 0.5 & 0.32 & -36.0 & $<0.02$ & $>-60.0$ & $<0.20$ & $3-60.0$ \\
\hline Bário (miglo) & 1 & 0.05 & -95.0 & 0.04 & -96.0 & 0.03 & -97.0 \\
\hline Códmio (mg/l) & 0.01 & $<0.01$ & 0.0 & < & 0.0 & $<0.01$ & 0.0 \\
\hline Chumbo (mg/l) & 0.1 & 0.13 & 30.0 & $<0.10$ & 0.0 & $<0.10$ & 0.0 \\
\hline Cobre (mg/l) & 1 & $<0.02$ & $>-98.0$ & $<0.02$ & $>-98.0$ & $<0.02$ & -98.0 \\
\hline Cromo (my/l) & 0.05 & $<0.05$ & 0.0 & $<0.05$ & 0.0 & $<0.05$ & 0.0 \\
\hline Zinco (nngli) & 5 & 0.04 & -99.2 & $<0.02$ & $>-99.6$ & 0.05 & -99.0 \\
\hline
\end{tabular}

$*[(P 1-P R) / F R] .100$

\#[(P2-PR)/FR $] .100$

(ai $[(\mathrm{PZ}-\mathrm{FR}) / \mathrm{PR}] .100$ 
TABEL A 35. Dešio relativo do sisteina aguapé-solo filtrante en relag̣áo aos padrōes de referência utilizados pela CETESB

Periodo de amostragem: Abril/1987

\begin{tabular}{|c|c|c|c|c|c|c|c|}
\hline FARAMETROS & $\begin{array}{c}\text { PADROES } \\
\text { REFERENCIA } \\
\text { PR }\end{array}$ & $\begin{array}{l}\text { Agua de Entra- } \\
\text { da (Rio Pira- } \\
\text { cicaba) Pl }\end{array}$ & $\begin{array}{c}\text { DR* } \\
\text { Rio Piracicaba } \\
\text { (\%) }\end{array}$ & $\begin{array}{c}\text { Saída } \\
\text { Canal aguapé } \\
\text { P2 }\end{array}$ & $\begin{array}{c}\text { DR * } \\
\text { Canal aguapé } \\
\text { (\$) }\end{array}$ & $\begin{array}{c}\text { Saida solo } \\
\text { filtrante } \\
\text { F3 }\end{array}$ & $\begin{array}{l}\text { DR } 9 \\
\text { Sistema } \\
\text { (क) }\end{array}$ \\
\hline $0.8 .0 .(\mathrm{mg} / 1)$ & 5 & 3.1 & -38.0 & 1.35 & -73.0 & 1.23 & -75.4 \\
\hline Coli fecal (nmp) & 1000 & 43000 & 4200.0 & 230 & -77.0 &. & - \\
\hline Coli total (nmp) & 5000 & 2300000 & 45900.0 & 4300 & -14.0 & 23000 & 360.0 \\
\hline Nitrito $(\mathrm{mg} / 1)$ & 1 & $<0.01$ & $3-99.0$ & $<0.01$ & $>-99.0$ & $<0.01$ & $3-99.0$ \\
\hline Nitrato $(\mathrm{mg} / \mathrm{l})$ & 10 & 0.65 & -93.5 & 0.26 & -97.4 & 0.19 & -98.1 \\
\hline N-amoniacal (mg/l & 0.5 & 0.42 & -16.0 & $<0.20$ & $>-60.0$ & $<0.20$ & $>-60.0$ \\
\hline Bário (mg/l) & 1 & 0.05 & -95.0 & 0.05 & -95.0 & 0.03 & -97.0 \\
\hline Cádrnio $(\mathrm{mg} / \mathrm{l})$ & 0.01 & $<0.01$ & 0.0 & 60.01 & 0.0 & $<0.01$ & 0.0 \\
\hline Chumbo (mg/l) & 0.1 & $<0.10$ & 0.0 & $<0.10$ & 0.0 & $<0.10$ & 0.0 \\
\hline Cotre $(\mathrm{mg} / \mathrm{l})$ & 1 & $<0.02$ & $>-98.0$ & $<0.02$ & $>-98.0$ & $<0.02$ & $>-98.0$ \\
\hline Cromo (mg/l) & 0.05 & 0.05 & 0.0 & 0.05 & 0.0 & 0.05 & 0.0 \\
\hline Zinco $(\mathrm{mg} / \mathrm{l})$ & 5 & $<0.02$ & $>-99.6$ & $<0.02$ & $>-99.6$ & $<0.02$ & $>-99.6$ \\
\hline
\end{tabular}

$*[(F 1-F R) / F R] .100$

* [(P2-PR $) / P R] .100$

(1) [(PZ-PR)/PR] 100 
TABELA 36. Desrio relativo do sistema aguapé-solo filtrante em relagâo aos padröes de referência utilizados pela CETESB

Período de amostragem : Maio/1987.

\begin{tabular}{|c|c|c|c|c|c|c|c|}
\hline F'AR AMMETRÜS & $\begin{array}{l}\text { PALROES } \\
\text { REFERENCIA } \\
\text { PR }\end{array}$ & $\begin{array}{l}\text { Agua de Eritra- } \\
\text { da (Rio Pira- } \\
\text { cicatia) PI }\end{array}$ & $\begin{array}{c}\text { DR * } \\
\text { Rio Piracioaba } \\
\text { (\#) }\end{array}$ & $\begin{array}{c}\text { Saída } \\
\text { Carial aguapé } \\
\text { F2 }\end{array}$ & $\begin{array}{c}\text { DR \# } \\
\text { Canal aguapé } \\
\text { (\#) }\end{array}$ & $\begin{array}{c}\text { Saida zolo } \\
\text { filtranite } \\
\text { F3 }\end{array}$ & $\begin{array}{l}\text { DR G } \\
\text { Sistema } \\
\text { (\$) }\end{array}$ \\
\hline D.E.O. (ngg/1) & 5 & 4.90 & -2.0 & 1.11 & -77.8 & 1.01 & -79.8 \\
\hline Coli feosi (nmp) & 1000 & 430000 & 42900.0 & 110 & -89.0 & 80 & -97.0 \\
\hline Coli total (rimp) & 5000 & 23000000 & 459900.0 & 9300 & 86.0 & 2100 & -58.0 \\
\hline Nitrito (mg/1) & 1 & $<0.01$ & $2-99.0$ & 80.01 & $>-99.0$ & $<0.01$ & $>-99.0$ \\
\hline Nitrato (mg/l) & 10 & 0.49 & -95.1 & 0.19 & -98.1 & 0.04 & -99.6 \\
\hline N-amoniacal (mg/l) & 0.5 & $<0.20$ & $x-60.0$ & $<0.20$ & $>-60.0$ & $<0.20$ & $>-60.0$ \\
\hline Bária (rngll) & 1 & 0.10 & -90.0 & 0.05 & -95.0 & 0.03 & -97.0 \\
\hline Códmio $(\mathrm{mg} / \mathrm{l})$ & 0.01 & $<0.01$ & $0 . \overline{0}$ & $<0.01$ & 0.0 & $<0.01$ & 0.0 \\
\hline Churnibo (mg/) & 0.1 & 0.23 & 130.0 & $<0.10$ & 0.0 & 0.10 & 0.0 \\
\hline Cotire (mg/l) & 1 & $<0.02$ & $>-98.0$ & $<0.02$ & $>-98.0$ & 60.02 & $3-98.0$ \\
\hline Cramo (mg/i) & 0.05 & 0.06 & 20.0 & 0.05 & 0.0 & $<0.05$ & 0.0 \\
\hline Zinco $(\mathrm{mg} / \mathrm{l})$ & 5 & 0.06 & -98.8 & 0.04 & -99.2 & $<0.02$ & $>-99.6$ \\
\hline
\end{tabular}

$*[(\mathrm{~F} 1-\mathrm{PR}) / \mathrm{FR}] .100$

\#[(F2-PR $) / F R] .100$

(9! $[(\mathrm{F} 3-\mathrm{PR}) / \mathrm{PR}] .100$ 
TABEL 37 . Desyio relatira do sistema aguapé-sola filtrante em relagóo aos padröes de referäncia utilizados pela CETESB

Periodo de amostragem : Junho/1987.

\begin{tabular}{|c|c|c|c|c|c|c|c|}
\hline FARAMETRIDS & $\begin{array}{c}\text { PADROES } \\
\text { REFERENCIA } \\
\text { PR } \\
\end{array}$ & $\begin{array}{l}\text { Agua de Entra- } \\
\text { da (Rio Pira- } \\
\text { cicaba) PI }\end{array}$ & $\begin{array}{c}\text { DR * } \\
\text { Rio Piraoicaba } \\
\text { (承 }\end{array}$ & $\begin{array}{c}\text { Saída } \\
\text { Canal aguapé } \\
\text { F2 } \\
\end{array}$ & $\begin{array}{c}\text { DR \# } \\
\text { Canal aguapé } \\
(\%) \\
\end{array}$ & $\begin{array}{c}\text { Saida solo } \\
\text { filtrante } \\
\text { F3 } \\
\end{array}$ & $\begin{array}{l}\text { DR } 1 \\
\text { Sistema } \\
\text { (\%) }\end{array}$ \\
\hline D.B.0. (mg/l) & 5 & 5.05 & 1.0 & 2.33 & -53.4 & 2.11 & -57.8 \\
\hline Coli feoal (nmp) & 1000 & 230000 & 22900.0 & 36 & -96.4 & 36 & -96.4 \\
\hline Coli total (nmp) & 5000 & 430000 & 8500.0 & 430 & -91.4 & 230 & -95.4 \\
\hline Nitrito $(m g / 1)$ & 1 & $<0.01$ & $>-99.0$ & $<0.01$ & $>-99.0$ & $<0.01$ & $>-99.0$ \\
\hline Nitrato $(\mathrm{mg} / 1)$ & 10 & 0.24 & -97.6 & 0.33 & -96.7 & 0.32 & -96.8 \\
\hline |A-amoniacal (mg/l & 0.5 & 0.53 & 6.0 & 0.20 & -60.0 & $\$ 0.20$ & -60.0 \\
\hline Búrio (miglo) & 1 & 0.06 & -94.0 & 0.105 & -95.0 & 0.03 & -97.0 \\
\hline Cádmio (mg/l) & 0.01 & $<0.01$ & 0.0 & $<0.01$ & 0.0 & $<0.01$ & 0.0 \\
\hline Chumbo (mg/1) & 0.1 & 0.10 & 0.0 & 0.10 & 0.0 & 0.10 & 0.0 \\
\hline Cotre (mg/l) & 1 & 0.02 & -98.0 & 0.03 & -97.0 & 0.03 & -97.0 \\
\hline Cromo (mg/l) & 0.05 & $<0.05$ & 0.0 & $<0.05$ & 0.0 & $<0.05$ & 0.0 \\
\hline Ziroo $(\mathrm{mg} / \mathrm{l})$ & 5 & 0.03 & -99.4 & $<0.02$ & $3-99.6$ & $\leqslant 0.02$ & $3-99.6$ \\
\hline
\end{tabular}

$*[(P 1-P R) / P R] .100$

\# $[(\mathrm{F} 2-\mathrm{PR}) / \mathrm{FR}] .100$

(9) [(P3-FP)/PR].100 
TABEL A 38. Desyio relatiyo do sistema solos filtrantes consecutiros em relação aos padrōes de referência utilizados pela CETESB

Periodo de amostragem: sunho/1986.

\begin{tabular}{|c|c|c|c|c|c|}
\hline F ARAMETRŪS & $\begin{array}{c}\text { PACROES } \\
\text { REFERENCIA } \\
\text { PR }\end{array}$ & $\begin{array}{l}\text { Agua de Entra- } \\
\text { da (Rio Pira- } \\
\text { gicaba) P1 }\end{array}$ & $\begin{array}{c}\text { DR * } \\
\text { Rio Piracioaba } \\
(9)\end{array}$ & $\begin{array}{c}\text { Saída } \\
\text { Solo filtrante } \\
\text { P2 } \\
\end{array}$ & $\begin{array}{l}\text { DR \# } \\
\text { Sistemis } \\
(\%)\end{array}$ \\
\hline D.B.O. (mg/l) & 5 & 5.54 & 10.8 & 1.01 & -79.8 \\
\hline Coli fecal (nmp) & 1000 & 93000 & 9200.0 & 23000 & 2200.0 \\
\hline Coli total (nmp) & 5000 & 430000 & 8500.0 & 23000 & 360.0 \\
\hline Nitrito $(\mathrm{mg} / \mathrm{l})$ & 1 & - & - & - & - \\
\hline Mitrato (nig/) & 10 & 0.24 & -97.6 & 0.88 & -91.2 \\
\hline N-amoniacal (mg/l & 0.5 & 1.59 & 218.0 & $<0.20$ & $>-60.0$ \\
\hline Bário (mg/l) & 1 & 0.28 & -72.0 & 0.37 & -63.0 \\
\hline Códnio (mg/l) & 0.01 & $<0.01$ & 0.0 & $<0.01$ & 0.0 \\
\hline Chumbo (mg/l) & 0.1 & $<0.10$ & 0.0 & $<0.10$ & 0.0 \\
\hline Cotre (mgl) & 1 & $<0.02$ & $>-98.0$ & $<0.02$ & $>-98.0$ \\
\hline Cromo (mg/1) & 0.05 & 0.06 & 20.0 & 0.07 & 40.0 \\
\hline Zinoo (mg/l) & 5 & 0.04 & -99.2 & $<0.02$ & $>-99.6$ \\
\hline
\end{tabular}

$*[(P 1-P R) / F R] 100$

* [(P2-PR $) / F R] .100$ 
TABELA 39. Desrio relativo do sistema solos filtrantes consecutiros em relaçäo aos padrōes de referência utilizados pela CETESB

Período de amostragem: Julho/1986.

\begin{tabular}{|c|c|c|c|c|c|}
\hline FARATAETROS & $\begin{array}{c}\text { PAOROES } \\
\text { REFERENCIA } \\
\text { PR } \\
\end{array}$ & $\begin{array}{l}\text { Agua de Entra- } \\
\text { da (Rio Pira- } \\
\text { cicaba) F1 }\end{array}$ & $\begin{array}{c}\text { DR* } \\
\text { Rio Piracicaba } \\
(\mathbb{8})\end{array}$ & $\begin{array}{c}\text { Saida } \\
\text { Solo filtrante } \\
\text { P2 } \\
\end{array}$ & $\begin{array}{c}\text { DR \# } \\
\text { Sistema } \\
(\pi)\end{array}$ \\
\hline D.B.0. (mg/1) & 5 & 4.36 & -12.8 & 0.75 & -85.0 \\
\hline Coli feoal (nmp) & 1000 & 39000 & 3800.0 & 110 & -89.0 \\
\hline Coli total (nmp) & 5000 & 75000 & 1400.0 & 4300 & -14.0 \\
\hline Nitrito (mg/1) & 1 & - & - & - & - \\
\hline Nitrato (mg/l) & 10 & 0.59 & -94.1 & 0.91 & -90.9 \\
\hline M-arnoniacal (ming & 0.5 & 1.64 & 228.0 & : $<0.20$ & $>-60.0$ \\
\hline Börio (mg/l) & 1 & 0.23 & -77.0 & 0.14 & -86.0 \\
\hline Codmio (mg/l) & 0.01 & $<0.01$ & 0.0 & $<0.01$ & 0.0 \\
\hline Churribo (mg/1) & 0.1 & $<0.10$ & 0.0 & $<0.10$ & 0.0 \\
\hline Cotire (mg/l) & 1 & $<0.02$ & $>-98.0$ & $<0.02$ & $>-98.0$ \\
\hline Cromo (mg/l) & 0.05 & $<0.05$ & 0.0 & 0.05 & 0.0 \\
\hline Zirico (nog/) & 5 & 0.02 & -99.6 & $<0.02$ & $>-99.6$ \\
\hline
\end{tabular}

$*[(P 1-P R) / F R] .100$

\#[(P2-PR $) / F R] .100$ 
TABEL 40. Desyio relatiro do sistema solos filtrantes consecutiros em relação aos padróes de referênuia utilizados pela CETESB

Periodo de amostragem: Agosto/1986.

\begin{tabular}{|c|c|c|c|c|c|}
\hline PARAMETROS & $\begin{array}{c}\text { PADROES } \\
\text { REFERENCIA } \\
\text { PR } \\
\end{array}$ & $\begin{array}{l}\text { Agua de Entra- } \\
\text { da (Rio Pira- } \\
\text { cicaba) P1 }\end{array}$ & $\begin{array}{c}\text { DR* } \\
\text { Rio Piracicaba } \\
(8) \\
\end{array}$ & $\begin{array}{c}\text { Saída } \\
\text { Sulo filtrante } \\
\text { P2 } \\
\end{array}$ & $\begin{array}{c}\text { DR \# } \\
\text { Sistering } \\
(9) \\
\end{array}$ \\
\hline D.B.0. (mg/1) & 5 & 6.43 & 28.6 & 0.86 & -82.8 \\
\hline Coli fecal (nmp) & 1000 & 430000 & 42900.0 & 4671 & 367.1 \\
\hline Coli total (rimp) & 5000 & 12250000 & 244900.0 & 116050 & 2221.0 \\
\hline Nitrito (rng/l) & 1 & - & - & - & - \\
\hline Nitrato (mg/l) & 10 & 0.22 & -97.8 & 0.87 & -91.3 \\
\hline N-amoniacal (mg/l & 0.5 & 2.20 & 340.0 & 80.20 & $>-60.0$ \\
\hline Bário (myg/o) & 1 & 0.08 & -92.0 & 0.03 & -97.0 \\
\hline Codmio (mg/l) & 0.01 & $<0.01$ & 0.0 & $<0.01$ & 0.0 \\
\hline Chumbo (mg/l) & 0.1 & $<0.10$ & 0.0 & 0.10 & 0.0 \\
\hline Cotre $(\mathrm{mg} / \mathrm{l})$ & 1 & $<0.02$ & $3-98.0$ & $<0.02$ & $>-98.0$ \\
\hline Cromo (mg/l) & 0.05 & $<0.05$ & 0.0 & 40.05 & 0.0 \\
\hline 2 inico $(\mathrm{mg} / \mathrm{l})$ & 5 & 0.02 & -99.6 & $<0.02$ & $>-99.6$ \\
\hline
\end{tabular}

$*[(\mathrm{P} 1-\mathrm{PR}) / \mathrm{PR}] .100$

\# [(F2-PR $) /$ PR $] .100$ 
TABEL A 41. Desrio relatiro do sistema solos filtrantes consecutivos em relagöo aos padröes de referència utilizados pela CETESB

Período de amostragem: Norembro/1986.

\begin{tabular}{|c|c|c|c|c|c|}
\hline FARAIMTRŪS & $\begin{array}{l}\text { PADROES } \\
\text { REFERENCIA } \\
\text { PR }\end{array}$ & $\begin{array}{l}\text { Agua de Entra- } \\
\text { da (Rio Pira- } \\
\text { dicaba) F1 }\end{array}$ & $\begin{array}{c}\text { DR* } \\
\text { Rio Piracicaba } \\
\text { (汭) }\end{array}$ & $\begin{array}{c}\text { Saída } \\
\text { Solo filtrante } \\
\text { F2 }\end{array}$ & $\begin{array}{l}\text { DR \# } \\
\text { Sistems } \\
(\%)\end{array}$ \\
\hline D.B.0. (mg/l) & 5 & 5.23 & 4.6 & 0.78 & -84.4 \\
\hline Coli feoal (nmp) & 1000 & 4300 & 330.0 & 240 & -76.0 \\
\hline Coli total (nimp) & 5000 & 430000 & 8500.0 & 9300 & 86.0 \\
\hline Nitrito (mg/l) & 1 & $<0.01$ & $>-99.0$ & $<0.01$ & $>-99.0$ \\
\hline Nitrato ( $\mathrm{mg} / 1)$ & 10 & 0.37 & -96.3 & 0.37 & -96.3 \\
\hline N-amoniacal (rog l & 0.5 & 1.74 & 248.0 & $<0.20$ & $>-60.0$ \\
\hline Bório (mg/l) & 1 & 0.13 & -87.0 & 0.04 & -96.0 \\
\hline Códmio (mg/l) & 0.01 & $<0.01$ & 0.0 & $<0.01$ & 0.0 \\
\hline Chumbo (mg/l) & 0.1 & $<0.10$ & 0.0 & $<0.10$ & 0.0 \\
\hline Cotre (mg/) & 1 & 0.03 & -97.0 & 60.02 & $>-98.0$ \\
\hline Cromo (nig/l) & 0.05 & $<0.05$ & 0.0 & - & - \\
\hline Zirico (mg/1) & 5 & $<0.02$ & $>-99.6$ & $<\overline{0} .02$ & $>-99.6$ \\
\hline
\end{tabular}

* [(P1-PR]/FR] 100

* [(P2-PR)/PR].100 
TABEL. 42. Desvio relatiYo do sistema solos filtrantes consecutivos em relaçōo aos padrōes de referência utilizados pela CETESB

Periodo de amostragem: Dezembro/1986.

\begin{tabular}{|c|c|c|c|c|c|}
\hline & FADROES & Água de Entra- & DR* & Saída & $D R *$ \\
\hline FARAMETROS & $\begin{array}{c}\text { REFERENCIA } \\
\text { PR }\end{array}$ & $\begin{array}{l}\text { da (Rio Pira- } \\
\text { cicaba) P1 }\end{array}$ & $\begin{array}{c}\text { Rio Pir acioaba } \\
\text { (尹) }\end{array}$ & $\begin{array}{c}\text { Solo filtrante } \\
\text { P2 }\end{array}$ & $\begin{array}{l}\text { Sistemi } \\
\text { (X) }\end{array}$ \\
\hline D.B.0.(mg/l) & 5 & 4.90 & -2.0 & 1.72 & $-65 . \epsilon$ \\
\hline Culi fecal (nmp) & 1000 & 23000 & 2200.0 & 430 & -57.0 \\
\hline Coli total (nmp) & 5000 & 2300000 & 45900.0 & 23000 & 360.0 \\
\hline Nitrito $(m g / 1)$ & 1 & $<0.01$ & $>-99.0$ & 80.01 & $>-99.0$ \\
\hline Nitrato (mg/l) & 10 & 0.52 & -94.8 & 80.01 & $>-99.9$ \\
\hline $\mathrm{N}$-amoniacal (mg/l & 0.5 & 0.48 & -4.0 & $<0.20$ & $>-60.0$ \\
\hline Bário (mg/l) & 1 & 0.07 & -93.0 & 0.04 & -96.0 \\
\hline Cádmio (mg/l) & 0.01 & $<0.01$ & 0.0 & $<0.01$ & 0.0 \\
\hline Chumbo (mg/l) & 0.1 & $<0.10$ & 0.0 & $<0.10$ & 0.0 \\
\hline Cotire $(m g / 1)$ & 1 & 0.02 & -98.0 & $<0.02$ & $>-98.0$ \\
\hline Cromo $(\mathrm{mg} / 1)$ & 0.05 & $<0.05$ & 0.0 & 60.05 & 0.0 \\
\hline Ziriso $(m g / 1)$ & 5 & 0.04 & -99.2 & $<0.02$ & $>-99.6$ \\
\hline
\end{tabular}

* [(P1-FR) $/$ PR $] 100$

\# [(P2-PR $) / F R] .100$ 


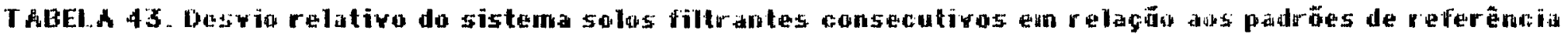
utilizados pela CETESO

Pitriodo de inmostragem : Jane ir o 1 yat

\begin{tabular}{|c|c|c|c|c|c|}
\hline PARAP IETFOOS & $\begin{array}{c}\text { PADPOES } \\
\text { FEFEFEMUIA } \\
\text { FE }\end{array}$ & $\begin{array}{l}\text { Agua de Entra } \\
\text { da (Rio Fira } \\
\text { cicatis) P1 }\end{array}$ & $\begin{array}{l}\text { Re Firatioba } \\
\text { (os) }\end{array}$ & $\begin{array}{l}\text { Saida } \\
\text { Solo filtrarite } \\
\text { P2 }\end{array}$ & $\begin{array}{l}\text { OR \# } \\
\text { Sisturitis } \\
\text { (SE) }\end{array}$ \\
\hline D.B.O. (rog/o & 5 & 3.90 & -220 & 1.30 & -74.0 \\
\hline Coli fecal (nmp) & 1000 & 379650 & 370650 & 115 & -38.5 \\
\hline Coli total (rimp) & 5000 & 1165000 & 2320110 & 11955 & 139.1 \\
\hline Pitrito (mig/l) & 1 & $<0.01$ & 2990 & $: 0.01$ & 9990 \\
\hline Nitrato (mogl) & 10 & 0.47 & -95.3 & 0.11 & -98.9 \\
\hline N-amoriacal (moll & 0.5 & 0.31 & -38.0 & 0.20 & $>-60.0$ \\
\hline Bärio $(m g / 1)$ & 1 & 0.08 & 92.0 & 0.05 & -95.0 \\
\hline Cadrnio (ming/i) & 0.01 & $<0.01$ & 00 & 0.01 & 0.0 \\
\hline Chumbo (mg/1) & 0.1 & $<0.10$ & 0.0 & 80.10 & 0.0 \\
\hline Cobre (migil) & 1 & 0.05 & -97.0 & 00.02 & $3-98.0$ \\
\hline Crarno (ming/i) & 0.05 & $<0.05$ & 0.0 & 0.05 & 0.0 \\
\hline Zinco (mo/i) & 5 & 0.03 & -99.4 & 0.02 & -996 \\
\hline
\end{tabular}

$*[(\mathrm{P} 1-\mathrm{PR}) / \mathrm{PR}] .100$

\# [(PZ-PR)/PR] 100 
TABEL A 44. Desvio relativo do sistema solos filtrantes consecutivos em relaçāo aos padrōes de referềncia utilizados pela CETESB

Periodo de amostragem: Ferereiro/1987.

\begin{tabular}{|c|c|c|c|c|c|}
\hline F'ARAMIETRŨS & $\begin{array}{c}\text { FÁLROES } \\
\text { REFERENCIA } \\
\text { PR } \\
\end{array}$ & $\begin{array}{l}\text { Agua de Entra- } \\
\text { da (Rio Fira- } \\
\text { cicaba) P1 }\end{array}$ & $\begin{array}{c}\text { DR * } \\
\text { Rio Firacicaba } \\
\text { (x) }\end{array}$ & $\begin{array}{c}\text { Salda } \\
\text { Sola filtrarite } \\
\text { F2 } \\
\end{array}$ & $\begin{array}{c}\text { DF } \\
\text { Sistemi } \\
(0) \\
\end{array}$ \\
\hline D.B.O. (nig/1) & 5 & - & - & - & - \\
\hline Coli fecal (nmp) & 1000 & 9300 & 830.0 & 30 & $>-97.0$ \\
\hline Coli total (nmp) & 5000 & 230000 & 4500.0 & 2300 & -54.0 \\
\hline Nitrito $(\mathrm{mg} / \mathrm{l})$ & 1 & $<0.01$ & $2-99.0$ & $<0.01$ & $>-99.0$ \\
\hline Nitrato (mig/) & 10 & 1.35 & -86.5 & 3.40 & -66.0 \\
\hline $\mathrm{N}$-amoriacal (mig/1 & 0.5 & 0.27 & -46.0 & $<0.20$ & $>-60.0$ \\
\hline Búrio (mg/) & 1 & 0.04 & -96.0 & 0.01 & -99.0 \\
\hline Códrnio (mgin) & 0.01 & $<0.01$ & 0.0 & $<0.01$ & 0.0 \\
\hline Chumbo $(\mathrm{mg} / \mathrm{l})$ & 0.1 & $<0.10$ & 0.0 & $<0.10$ & 0.0 \\
\hline Cotire (ning/l) & 1 & $<0.02$ & $>-98.0$ & $<0.02$ & $>-98.0$ \\
\hline Cromo (mg/l) & 0.05 & $<0.05$ & 0.0 & 0.05 & 0.0 \\
\hline Zinoo (mg/1) & 5 & 0.04 & -99.2 & 0.22 & $-95 . E$ \\
\hline
\end{tabular}

* $[(\mathrm{P} 1-\mathrm{PR}) / \mathrm{FR}] .100$

\#[(F2-FR)/FR $] .100$ 
TABEL A 45. Desyio relatiyo do sistema solos filtrantes consecutiyos em relaçáo aos padrōes de referência utilizados pela CETESB

Periodo de amostragem: Marso/1987.

\begin{tabular}{|c|c|c|c|c|c|}
\hline PARAMETROS & $\begin{array}{c}\text { FADROES } \\
\text { REFEREMLIA } \\
\text { PR } \\
\end{array}$ & $\begin{array}{l}\text { Agua de Entra- } \\
\text { da (Rio Pira- } \\
\text { cicaba) P1 }\end{array}$ & $\begin{array}{c}\text { DR* } \\
\text { Rio Pir aoisaba } \\
(\mathscr{G}) \\
\end{array}$ & $\begin{array}{c}\text { Saída } \\
\text { Solo filtrante } \\
\text { P2 } \\
\end{array}$ & $\begin{array}{c}\text { DR \# } \\
\text { Sistema } \\
\text { (\%) }\end{array}$ \\
\hline D.B.0.(mg/1) & 5 & 3.75 & -25.0 & 1.47 & -70.6 \\
\hline Coli fecal (nmp) & 1000 & - & - & - & - \\
\hline Coli total (nimp) & 5000 & 430000 & 8500.0 & 9300 & 86.0 \\
\hline Nitrito (ng/l) & 1 & $<0.01$ & $>-99.0$ & $<0.01$ & $>-99.0$ \\
\hline Nitrato $(\mathrm{mg} / \mathrm{l})$ & 10 & 0.54 & -94.6 & 0.04 & -99.6 \\
\hline N-amoniacal (mg/l & 0.5 & 0.32 & $-3 \in .0$ & $<0.20$ & $>-60.0$ \\
\hline Bório (mg/l) & 1 & 0.05 & -95.0 & 0.02 & -98.0 \\
\hline Cádrrio (mg/l) & 0.01 & $<0.01$ & 0.0 & $<0.01$ & 0.0 \\
\hline Chumito (mg/i) & 0.1 & 0.13 & 30.0 & $<0.10$ & 0.0 \\
\hline Cobre (mg/l) & 1 & $<0.02$ & $>-98.0$ & $<0.02$ & $>-98.0$ \\
\hline Cromo (mg/l) & 0.05 & $<0.05$ & 0.0 & $<0.05$ & 0.0 \\
\hline Zinoo $(\mathrm{mg} / \mathrm{l})$ & 5 & 0.04 & -99.2 & $<0.02$ & $>-99.6$ \\
\hline
\end{tabular}

$*[(P 1-P R) / P R] .100$

\# $[(\mathrm{P} 2-\mathrm{FR}) / \mathrm{FR}] .100$ 
TABEL 4 46. Desvio relativo do sistema solos filtrantes cansecutivos em relaçăo aos padrōes de referência utilizados pela CETESB

Período de amostragem: Abril/1987.

\begin{tabular}{|c|c|c|c|c|c|}
\hline FARAMETRUS & $\begin{array}{c}\text { FACROES } \\
\text { REFERENCIA } \\
\text { PR } \\
\end{array}$ & $\begin{array}{l}\text { Agua de Entra- } \\
\text { da (Rio Pira- } \\
\text { cicaba) P1 }\end{array}$ & $\begin{array}{c}\text { DR * } \\
\text { Rio Pir acicaba } \\
(8)\end{array}$ & $\begin{array}{c}\text { Saída } \\
\text { Solo filtrarite } \\
\text { F2 } \\
\end{array}$ & $\begin{array}{l}\text { DR\# } \\
\text { Sistemis } \\
(\$) \\
\end{array}$ \\
\hline D.B.O. $(\mathrm{mg} / 1)$ & 5 & 3.10 & -38.0 & - & - \\
\hline Coli feoal (nmp) & 1000 & 43000 & 4200.0 & 23000 & 2200.0 \\
\hline Coli total (n,mp) & 5000 & 2300000 & 45900.0 & 23000 & 360.0 \\
\hline Nitrito (mg/l) & 1 & $<0.01$ & $>-99.0$ & $<0.01$ & $>-99.0$ \\
\hline Nitrato (mg/l) & 10 & 0.65 & -93.5 & 0.48 & -95.2 \\
\hline H-amoniacal (mg/1 & 0.5 & 0.42 & -16.0 & $<0.20$ & $>-60.0$ \\
\hline Bário (mg/1) & 1 & 0.05 & -95.0 & 0.03 & -97.0 \\
\hline Códmio (mg/l) & 0.01 & $<0.01$ & 0.0 & $<0.01$ & 0.0 \\
\hline Chumbo (mg/i) & 0.1 & $<0.10$ & 0.0 & $<0.10$ & 0.0 \\
\hline Cobre (mg/l) & 1 & $<0.02$ & $>-98.0$ & $<0.02$ & $3-98.0$ \\
\hline Cromo (mg/l) & 0.05 & 0.05 & 0.0 & 0.05 & 0.0 \\
\hline Zinoo (mg/p) & 5 & $<0.02$ & $>-99.6$ & 0.02 & -99.6 \\
\hline
\end{tabular}

* $[(P 1-P R) / F R] .100$

* [(P2-FR)/FR $] .100$ 
TABEL A 47. Desvio relatiro do sistema solos filtrantes consecutivos em relação aas padrōes de referência utilizados pela CETESB

Periodo de amostragem: Maio/1987.

\begin{tabular}{|c|c|c|c|c|c|}
\hline FARAMETROS & $\begin{array}{l}\text { PADROES } \\
\text { REFERENCIA } \\
\text { FR }\end{array}$ & $\begin{array}{l}\text { Agua de Entra- } \\
\text { da (Rio Pira- } \\
\text { cicaba) P1 }\end{array}$ & $\begin{array}{c}\text { DR * } \\
\text { Rio Pir joicaba } \\
(\%) \\
\end{array}$ & $\begin{array}{c}\text { Saída } \\
\text { Solo filtrante } \\
\text { F2 } \\
\end{array}$ & $\begin{array}{l}\text { OR \# } \\
\text { Sistema } \\
(\%)\end{array}$ \\
\hline D.B.O. $(\mathrm{mg} / \mathrm{l})$ & 5 & 4.90 & -2.0 & 1.66 & -66.8 \\
\hline Coli fecal (nmp) & 1000 & 430000 & 42900.0 & $<30$ & $>-97.0$ \\
\hline Coli total (nmp) & 5000 & 23000000 & 459900.0 & 4300 & -14.0 \\
\hline Nitrito (mg/l) & 1 & $<0.01$ & $>-99.0$ & $<0.01$ & $>-99.0$ \\
\hline Nitrato (mg/1) & 10 & 0.49 & -95.1 & 0.25 & -97.5 \\
\hline N-amoniacal (mgh) & 0.5 & $<0.20$ & $>-601.0$ & $<0.20$ & $>-60.0$ \\
\hline Bário $(\mathrm{mg} / \mathrm{l})$ & 1 & 0.10 & -90.0 & 0.04 & -96.0 \\
\hline Cádmio (mg/p) & 0.01 & $<0.01$ & 0.0 & $<0.01$ & 0.0 \\
\hline Chumbo (mg/i) & 0.1 & 0.23 & 130.0 & $<0.10$ & 0.0 \\
\hline Cotre (mg/i) & 1 & $<0.02$ & $>-98.0$ & $<0.02$ & $>-98.0$ \\
\hline Cramo (mg/i) & 0.05 & 0.06 & 20.0 & $<0.05$ & 0.0 \\
\hline Zinco $(\mathrm{mg} / \mathrm{l})$ & 5 & 0.06 & -98.8 & 0.03 & -99.4 \\
\hline
\end{tabular}

* [(P1-PR)/PR $] .100$

\#[(P2-PR $) / P R] .100$ 
TABEL 48. Desrio relatiro do sistema solos filtrantes consecutivos em irelaçöo aos padrōes de referência utilizados pela CETESB

Periodo de amostragem: Junho/1987.

\begin{tabular}{|c|c|c|c|c|c|}
\hline \multirow{3}{*}{ FARAIMTRUS } & \multirow{3}{*}{$\begin{array}{c}\text { FADRDES } \\
\text { REFERENILIA } \\
\text { PR }\end{array}$} & \multirow{2}{*}{$\begin{array}{l}\text { Agua de Entra- } \\
\text { da (Rio Pira- }\end{array}$} & \multirow{3}{*}{$\begin{array}{c}\text { DR * } \\
\text { Rio Piracioaba } \\
\text { ( } 6)\end{array}$} & \multirow{3}{*}{$\begin{array}{c}\text { Sáida } \\
\text { Solo filtrante } \\
\text { P2 }\end{array}$} & \multirow{3}{*}{$\begin{array}{l}\text { DR } \\
\text { Sistering } \\
\text { (B) }\end{array}$} \\
\hline & & & & & \\
\hline & & Gioabs) P1 & & & \\
\hline D.B.0.(mg/i) & 5 & 5.05 & 1.0 & 2.41 & -51.8 \\
\hline Coli feoal (nmp) & 1000 & 23000 & 2200.0 & $<30$ & $2-970$ \\
\hline Coli total (nmp) & 5000 & 430000 & 8500.0 & 1500 & -70.0 \\
\hline Nitrito (mgig) & 1 & $<0.01$ & $2-99.0$ & 80.01 & $>-99.0$ \\
\hline Nitrato (mgli) & 10 & 0.24 & -97.6 & 0.10 & -99.0 \\
\hline N-amoniacal (rogll & 0.5 & 0.53 & 6.0 & $<0.20$ & $>-60.0$ \\
\hline Bário (mg lí) & 1 & 0.06 & -94.0 & 0.03 & -97.0 \\
\hline Cádritio (migli) & 0.01 & $<0.01$ & 0.0 & $<0.01$ & 0.0 \\
\hline Chumbú (mgli) & 0.1 & 0.10 & 0.0 & $: \quad 0.10$ & 0.0 \\
\hline Cotre (mg/l) & 1 & 0.02 & -98.0 & $<0.02$ & $>-98.0$ \\
\hline Cromo (mg/1) & 0.05 & $<0.05$ & 0.0 & $<0.05$ & 0.0 \\
\hline Zinso (mg/i) & 5 & 0.03 & -99.4 & $<0.02$ & $>-99.6$ \\
\hline
\end{tabular}

$*[(P 1-P R) / F R] .100$

\#[(P2-FR)/FR].100 


\section{CONCLUSÕES}

a) Em geral observou-se uma variaçăo da eficiência dos sistemas durante o ano, para os diversos processos de purificaçüo hidrica.

๖) As análises realizadas demonstraram que as águas do Rio Piracicaba, no periodo de junho/1986 a junho/1987, estavam fora dos porâmetros de classificaçũo do rio como classe 2.

c) As maiores contaminaçôes da aguj sùu decorrentes da existencia de coliformes fecais e totais, do demanda biaqumica de axigènio, do $\mathrm{H}$ - amoniacal, bem como pela presença em ilguns meses de cobre e chumbo.

d) 0 sistema utilizando plantas aquáticas flutuantes e solos filtrantes com numa yazão média de $96 \mathrm{l} / \mathrm{s} / \mathrm{ha}$, foi eficiente durante 0 ano todo para enquadrar as águas do Rio Piracicaba dentro dos padrões exigidos para um rio de classe 2, cujas águas podem ser utilizadas para abastecimento doméstico. A exceção foi observada nos meses de junho/1986 e abril/1987 para coliformes fecais a nos meses de junho, dezembro/1986 e abril/1987, para coliformes totais.

e) D sistema utilizando solos filtrantes consecutivos com 
uma yazẫo média de $49 \mathrm{~V} / \mathrm{s} / \mathrm{ha}$, foi eficiente durante o ano todo para enquadrar as águas do Rio Piracicaba, dentro dos padrōes exigidos para um rio classe 2, cujas águas podem ser utilizadas para abastecimento doméstico.

A exceção foi observada nos meses de junho, agosto/1986 e abril/1987 para coliformes fecais, nos meses de junho, ngosto, novembro, dezembroi 1986 e joneiro, marco, abril/1987 para coliformes totois a no mês de junho/ 1986 para cromo.

f) Na maioria dos meses em estudo, as águas do tratamento global dos dois sistemos atingiu os limites exigidos pelos cnterios de potabilidade, sendo que para seu consumo, bastaria uma simples cloração. 


\section{LITERATURA CITADA}

AMASEK. Cocoa, Fla., Amasek Inc., 1985. 8p.

BATANOUNY, K. H. \& EL FIKY, A. M. The water hyacinth (Eichamio crossines. solms) in the Nilo system Egypt. Aquatic hatony, 1 (3): 243-52, 1975. BLAKE, G. ; KAIGATE, B. ; FOURCY, A. Incorporation of cadmium by water hyacinth. In: SEMINARIO SOBRE D USO DE MACROFITAS NO CONTROLE DA POLUIÇAD DA AGUA. Piracicaba, CENA, 1986. p. 176-81.

BRUNETTI, N. ; SPENCER, N.R. ; BONETTI, M. ; MARZETTI, P. ; PACCIARONI, F. ; FRANCONI, U. Utilization de la jacinthe d'eau (Eichomio crossipes Mort. salms) pour le traitement des eaux usées et résiduaires en italie. Entretiens ecaligues de Dijon, Dijon, 9 : 14-8 p., mar. 1981.

CETESB; NORMALIZAÇAO TECNICA DE SANEAMENTO AMBIENTAL. L5-117. CETESB; MORMALIZAÇAO TECNICA DE SANEAMENTO AMEIENTAL. L5-120. CETESB; NORMALIZAÇAO TECNICA DE SANEAMENTO AMBIENTAL. L5-156. CETESB; NORMALIZACAO TECNICA DE SANEAMENTO AMBIENTAL. L5-202. GSK land treatment facility. White Castle, GSK Land Treatment Inc. , 1988. s.p.

HAYES, T. D. ; ISAACSON, H. R. ; REDDY, K. R. ; CHYNOWETH, D.P. ; BILJETINA, R. ivater hyocinth systems for water treatment. In: Reduly, K. R. \& Smith, w. H. Aquatic plants for water treatment and resource recovery. 
Orlando, Magnolia, 1987. 121-38 p.

JOGLEKAR, Y. R. \& SONAR V. G. Aflicotion of water hyocinths for treatment af domestic wias te weter. generation af biagss and argonic monure in: Reddy, K. R. \& Smith, $W$. H. Aquatic plants for water treatment and resource recovery. Orlando, Magnolia, 1987. 747-53 P.

KAWAI, H. \& GRIECO, Y. M. Utilizaçăo do aguapé para tratamento de esgoto doméstico; Estabelecimento de critérios de dimensionamento de lagoa de aguapé e abordagem de alguns problemas operacionais. Feyssto DAE, Sŏo Paulo, 43 (135) : 79-90, dez. 1983.

LEGISLAÇAO; CONTROLE DA POLUIÇAO AMBIENTAL DO ESTADO DE SAO PAULO. São Paulo, 1986.

MOUSSE, R.A. ; CHAGAS, J.M. ; TERRA, A.R.S. Utilização de lagoas de maturação com aguapé (Eichornia crassipes) na remoção de algas e coliformes em efluentes da alagoa de estabilização. In: CONGRESSO LATINO AMERICANO DE MICROBIOLOGIA, 8, Santiago, 1979. Resumas, Santiago, s. ed., 1979. s.p.

OSTROWSKI, C. ; ROQUETE PINTO, C. L. ; CAÇONA, A. J. ; SILVA, S. M. do. Utilização de plantas aquáticas para controle de poluição $e$ aproveitamento industrial. Informstiva do $/ N T$, Rio de Janeiro, 14(27): 16-20, set./dez. 1981.

PENFOUND, W. \& EARLE, T.T. The biology of the water hyacinth. ECol Mon, $18(4)$ : s.p., 1948.

ROGERS JR., H. H. Nutrient remoyal by water hyacinth, Auburn, 1971. 80p. (Master of Science-AUBURN UNIVERSITY)

a ROQUETE PINTO, C. L. ; CAÇONIA, A. ; SOUZA, M.M. ; SANTOS, A. dos. aguapé 
Como concentradora de prata. Fevisto de quimica industrial, Rio de Janeiro:17-27, ago. 1983 .

SALATI, E. \& RODRIGUES, N. S. De poluente a nutriente, a descoberta do aguapé. Reyisto Brosileiro Tecnalogico. Brosilio. 13(3) : 37-42, jun./jul. 1982.

SALATI, E. Edanhic- phytadepuration : a new annoach ta wastewater trestment. In: Reddy, K. R. \& Smith, W. H. Aquatic plants for water treatment and resource recovery. Orlando, Magnolia, 1987. 199-208p.

- SANTOS, P. V. M. doS \& LEAD, R. R. L. 0 aguapé em sistemas aquáticos de đespoluição de esgotos; suas vantagens e limitações. Săo Paulo, Cio Energëtice de Säa Foula, 1983. 33p. (apostila).

SAITO, S. M. T. Exame bacteriológico em tratamento de recuperação de efluentes da Bacia do Piracicaba. In : REUNIAO ANUAL DA SPBC . 34., Campinas, 1982. fesumas Säo Paulo, SBPC, 1982. p. 589.

SALES, L. A. C. 0 aguapé como fonte de energia. (apresentado no Seminário de Biomassas, Unicamp) , Campinas, 1978.

TCHOBANOGLOUS, G. Aquatio plonts systems for water treotment; Enginering cansiderations In: Reddy, K. R. \& Smith, W. H. Aquatic plants for water treatment and resource and recovery. Orlando, Magnolia, 1987. $27-48 \mathrm{p}$.

THABARAGI, G. J. Aquatio treatment in Flöido. Fraspects ond constaints. In: Reddy, K. R. \& Smith, W. H. Aquatic plants for water and resource and recovery. Orlando, Magnolia, 1987. 987-996 p.

TORNISIELD, V. L.; VICTORIA, R.L.; RODRIGUES, N. S.; FURLAN, G. R. Absorpyion of labelled mercury $\left({ }^{203} \mathrm{Hg}\right)$ by water hyacinth Eichornio 
Crassipes (Mart/SOlms. In: SEMINARIO SOBRE O USO DE MACROFITAS NO CONTROLE DE POLUIÇAO DA AGUA. Piracicaba, CENA, 1986. p. 176-81.

WOLVERTON, B.C. Water hyacinths for removal of cadmiun and nickel from polluted waters. NAS SA technicol memoronown, USA, TM - X72722: 13-5, 1975 a.

- WOLVERTON, B.C. \& Mac Donald, R. C. Water hyacinths and alligator weeds for removal of lead mercury from pollued waters. NASSid tecknical memoranoun, USA, TM-Y -72723: 10-2, 1975 a.

WOLVERTON, B.C. \& Mac Donald, R. C. Water hyacinths and alligator weeds for removal of silver, cobalt, and strontium front pollueted waters. NASA tecknical memaranoun, USA, TM - X - 72727: $9-11,1975 \mathrm{~b}$.

WOLVERTON, B.C. Water hyocinth for removal of phenols from pollueted waters. NASA4 tecknicol memorondun, USA, TM - X - 72722: $12-5$, $1975 b$.

WOLVERTON, B.C. Engineering desing data forsmall vascular aquatic plant waste water treatment systems. NASA4. NSTL Station, Mississipi $39529,1979$. 